\title{
RADAR RETURN FROM A CONTINUOUS VEGETATION CANOPY
}

\author{
Remote Sensing Laboratory \\ RSL Technical Report 177-56
}

Thomas F. Bush

Fawwaz T. Ulaby

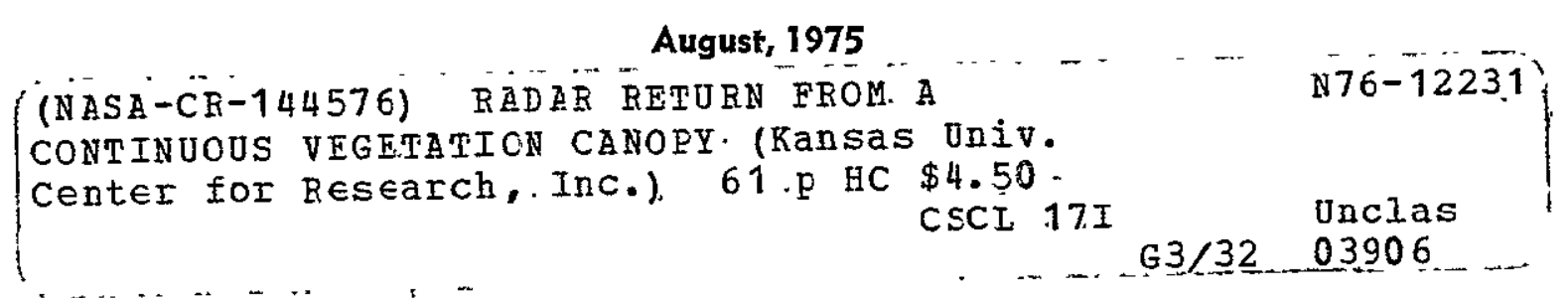

Supported by:

NATIONAL AERONAUTICS AND SPACE ADMINISTRATION Lyndon B. Johnson Space Center

Houston, Texas 77058

CONTRACT NAS 9-10261 


\section{THE UNIVERSITY OF KANSAS SPACE TECHNOLOGY CENTER}

Raymond Nichols Hall

Center for Research, Inc.

2291 Irving Hill Drive-Campus West

Lawrence, Kansas 66045

Telephone: $\quad 913-864-4832$

RADAR RETURN FROM A CONTINUOUS VEGETATION CANOPY

Remote Sensing Laboratory

RSL Technical Report 177-56

Thomas F. Bush

Fawwaz T. Ulaby

August, 1975

Supported by:

NATIONAL AERONAUTICS AND SPACE ADMINISTRATION

Lyndon B. Johnson Space Center

Houston, Texas 77058

CONTRACT NAS 9-1026] 


\section{TABLE OF CONTENTS}

Page

ABSTRACT • • • • • • • • • • • • • • • • • • .

1.0 INTRODUCTION . . . . . . . . . . . . . . . .

2.0 SCATTEROMETER SYSTEM • . . . . . . . . . . . 1

3.0 GROUND DATA ACQUISITION . . . . . . . . . . 3

3.1 Soil Moisture . . . . . . . . . . . 3

3.2 Plant Moisture - . . . . . . . . . 66

3.3 Plant Height . . . . . . . . . . 6

4.0 CANOPY MODEL • . . . . . . . . . . . . . . 8

5.0 DATA PRESENTATION AND DISCUSSION . . . . 11

5.1 Temporal Variations of $\sigma^{\circ}$. . . . . . . . . 11

5.2 Implementation of the Canopy Model . . . . . . 20

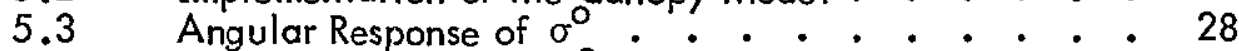

5.4 Spectral Response of $\sigma^{\circ}$. . . . . . . . . 39

6.0 CONCLUDING REMÁRKS . . . . . . . . . . . . 39

REFERENCES . • • • . • • • • • • • • • • • • • 45

APPENDIX A: Ground Truth Summary for 1974 Alfalfa . . . . . 46

Scattering Experiment

APPENDIX B: Alfalfa Scattering Coefficients, 1974 . • • • . 47 


\section{LIST OF FIGURES}

Page

Figure 1. Summarized ground truth data record for alfalfa, 1974. 5

Figure 2. Diagram.showing field locations of soil samples. $\quad 7$

Figure 3. Temporal variations of $\sigma^{\circ}$ measured at $8.6 \mathrm{GHz}$ for angles of incidence of a) $0^{\circ}$, b) $10^{\circ}$, c) $40^{\circ}$, and d) $70^{\circ}$.

Figure 4. Temporal variations of $\sigma^{\circ}$ measured at $13.0 \mathrm{GHz}$ for angles of incidence of a) $0^{\circ}$, b) $10^{\circ}$, c) $40^{\circ}$, and d) $70^{\circ}$.

Figure 5. Temporal variations of $\sigma^{\circ}$ measured at $17.0 \mathrm{GHz}$ for angles of incidence of a) $0^{\circ}$, b) $10^{\circ}$, c) $40^{\circ}$, and d) $70^{\circ}$.

Figure 6. Temporal variations of $\bar{\sigma}^{\circ}$ (the average value of $\sigma_{\bar{H}}{ }^{\circ}$. and $\sigma_{\bar{V}}{ }^{\circ}$ ) as measured at nadir with $\hat{\sigma}^{\circ}$, the values predicted by the canopy model presented in section 4.0. Data are presented at a) $8.6 \mathrm{GHz}$, b) $13.0 \mathrm{GHz}$, and c) $17.0 \mathrm{GHz}$.

Figure 7. Response of $\hat{\bar{\sigma}}^{0}$, the value of $\vec{\sigma}^{\circ}$ predicted by the canopy model, as a function of canopy height and soil moisture, $m_{5}$. Curves are presented at a) $8.6 \mathrm{GHz}$, b) $13.0 \mathrm{GHz}$, and c) $17.0 \mathrm{GHz}$.

Figure 8. Angular response of $\sigma^{\circ}$ of harvested alfalfa at $8.6 \mathrm{GHz}$ $\left(\sigma_{H}{ }^{\circ}\right.$ and $\sigma_{V}{ }^{\prime}, 8 a$ and $\left.8 b\right), 13.0 \mathrm{GHz}\left(\sigma_{H}^{\circ}\right.$ and $\sigma^{\circ}$, $8 \mathrm{c}$ and $8 \mathrm{~d})$ and $17.0 \mathrm{GHz}$ ( $\sigma_{\mathrm{H}}^{\circ}$ and $\sigma_{\mathrm{V}} \mathrm{O}, 8 \mathrm{e}$ and $\left.8 \mathrm{f}\right)$. 'Note that both curves represent $\sigma$ of harvested alfalfa $(11 \mathrm{~cm}$ and $17 \mathrm{~cm}$ ) and that the values of the soil moistures were comparable but not identical.

Figure 9. Angular response of $\sigma^{\circ}$ of two nearly mature stands of alfalfa at $8.6 \mathrm{GHz}$ ( $\sigma_{\mathrm{H}}^{\circ}$ and $\sigma_{\bar{V}}^{\circ} 9 \mathrm{a}$ and $9 \mathrm{~b}$ ), $13.0 \mathrm{GHz}$ $\left(\sigma_{H}^{\circ}\right.$ and $\sigma_{V}, 9 \mathrm{c}$ and $\left.9 \mathrm{~d}\right)$, and ${ }^{\prime}{ }^{\prime} 7.0 \mathrm{GHz}\left(\sigma_{\mathrm{H}}{ }^{\circ}\right.$ and $\sigma_{\mathrm{V}}^{\circ}$, $9 e$ and $9 f)$. Although the crops heights are practically identical, the measured values of soil moisture are quite different. 


\section{LIST OF FIGURES}

Page

Figure 10. Angular response of $\sigma^{\circ}$ of harvested and mature alfalfa at $8.6 \mathrm{GHz}\left(\sigma_{\mathrm{H}}^{\circ}\right.$ and ${ }^{\circ}{ }^{\circ}, 10 \mathrm{a}$ and $\left.10 \mathrm{~b}\right), 13.0 \mathrm{GHz}$ ( $\sigma_{H}^{\circ}$ and $\sigma_{\mathrm{Y}}, \mathrm{H}_{10 \mathrm{c} \text { and }} \mathrm{YOd}^{\circ}$, and $17.0 \mathrm{GHz}\left(\sigma_{\mathrm{H}}^{\circ}\right.$ and $\sigma 0,10 \mathrm{e}$ and $10 \mathrm{f})$. Note the soil moistures which are nearly equal.

Figure 11. Spectral response of $\sigma_{H}^{\circ}$ and $\sigma_{\bar{V}}^{\circ}$ for two stands of alfalfa at different growth stages at $0^{\circ}$ ( $a$ and $b$ ), $30^{\circ}(c$ and $d), 50^{\circ}\left(e\right.$ and $f$ ), and $70^{\circ}$ (g and $\left.h\right)$.

\section{LIST OF TABLES}

Table 1. MAS 8-18 system specifications.

Table 2. Number of sparially independent measurements with $90 \%$ confidence intervals of $\sigma^{\circ}(\mathrm{dB})$ of alfalfa.

Table 3. Estimated values of the regression constants as a function of frequency for the proposed canopy model of $\hat{\sigma}^{\circ}$. 


\section{ABSTRACT}

The radar backscatter coefficient, $\sigma^{\circ}$, of al falfa was investigated as a function of both radar parameters and the physical characteristics of the alfalfa canopy. Measurements were acquired with an 8-18 GHz FM-CW mobile radar over an angular range of $0^{\circ}-70^{\circ}$ as measured from nadir. The experimental data indicates that the excursions of $\sigma^{\circ}$ at nadir cover a range of nearly $18 \mathrm{~dB}$ during one complete growing cycle. An empirical model for $\sigma^{\circ}$ was developed which accounts for its variability in terms of soil moisture, plant moisture and plant height. 


\subsection{INTRODUCTION}

Critical to the successful application of radar remote sensing techniques to agricultural land use mapping is the understanding of the dependence of the backscattering coefficient $\sigma^{\circ}$ of a vegetated scene on the geometrical and electrical properties of the remotely sensed scene. Establishing these relationships requires a) the acquisition of backscatter data over a wide range of the measurable target parameters and b) the construction of theoretical and/or empirical models (based on the measured data) from which in-depth inferences can be made on the targetsignal interaction process. Moreover, since the desired relationships are often a function of the signal parameters (frequency, polarization and incidence angle), it is important that the data collection and modeling be made over as wide a range of the signal parameters as is practically feasible with present day sensors.

This study presents the results of an investigation conducted to determine the microwave backscattering properties of a continuous vegetation canopy over the 8-18 GHz frequency region $(3.75-1.67 \mathrm{~cm}$ in wavelength). Using a truck-mounted radar spectrometer, measurements were acquired from an alfalfa field at angles of incidence ranging from nadir $\left(0^{\circ}\right)$ to $70^{\circ}$ for horizontal transmit-horizontal receive $(\mathrm{HH})$ and vertical transmit-vertical receive (VV) polarization configurations. As a perennial crop, alfalfa is usually harvested three or often four times per year; upon reaching a height of $50-70 \mathrm{~cm}$, it is cut, dried and baled, and then allowed to grow again. During the 1974 summer season radar observations were made over two complete growing cycles of alfalfa.

\subsection{SCATTEROMETER SYSTEM}

The scatterometer employed in collecting the data used in this study is the 8-18 GHz Microwave Active Spectrometer (MAS 8-18) [1]. This is a mobile, truck-mounted system capable of making scattering measurements at 11 frequencies in its 8-18 GHz range. It employs a dual antenna system configured to allow both horizontal-transmit horizontal-receive $(\mathrm{HH})$ and vertical-transmit vertical-receive (W) modes of operation. Measurements can be made at angles of incidence between $0^{\circ}$ (nadir) and $70^{\circ}$. Table 1 presents the system specifications pertinent to the discussion of this experiment. 
TABLE 1 .

MAS 8-18 System Specifications

Type

Modulating Waveform

Frequency Range

FM sweep: $\Delta f$

Transmitter Power

Intermediate Frequency

IF Bandwidth

Antennas

Height above ground

Reflector diameter

Feeds

Polarization

Incidence Angle Range

Calibration:

Internal

External
FM-CW

Triangular

8-18 GHz

$800 \mathrm{MHz}$

$10 \mathrm{dBm}(10 \mathrm{~mW})$

$50 \mathrm{kHz}$

$10.0 \mathrm{kHz}$

$26 \mathrm{~m}$

$61 \mathrm{~cm}$

Cavity backed, log-periodic

Horizontal transmit-Horizontal receive $(\mathrm{HH})$

Vertical transmit-Vertical receive (VV)

$0^{\circ}$ (nadir) $-80^{\circ}$

Delay Line

Luneberg Lens 
Being a wide band radar the MAS 8-18 provided fading reduction by averaging samples of the return signal energy over its $800 \mathrm{MHz}$ bandwidth. Due to the limited extent of the resolution cell ared, frequency averaging would not provide the fading reduction necessary for the data precision and accuracy desired. Thus spatial averaging was also employed.

The number of independent samples of return power averaged in the frequency domain can be determined through the knowledge of the target extent measured radially from the radar antenna [2]. For this experiment however, the target height, and thus the radial target extent changed as the vegetation canopy matured. For this reason a worst case approach was taken by assuming that no penetration of the radar signal into the vegetation canopy occurred. This assumption and a knowledge of the number of spatially independent measurements collected allow the estimation of confidence intervals for $\sigma^{\circ}$. Ninety per cent confidence intervals for $\sigma^{\circ}$ of alfalfa are presented in Table 2. Since these confidence intervals are based on a zero penetration assumption, under most conditions the confidence intervals associated with the measured data will most likely be narrower than those shown in Table 2 .

\subsection{GROUND DATA ACQUISITION}

Because the methods of collecting and processing the ground "truth" data acquired in support of the scattering measurements have been previously discussed by Cihlar [3], only a short description of the processing methods used and a summary of the results obtained will be presented. Figure 1 provides, in a summarized fashion, a time history of the pertinent target characteristics with a more complete ground data record being available in Appendix $A$.

\subsection{Soil Moisture}

A recent report by $C$ ihlar and Ulaby [4] reviews the dielectric properties of various soil types as a function of their physical properties. Of the conclusions reached it was noted that soil moisture played the overwhelming role in determining the complex 
Table 2. Number of Spatially Independent Measurements with $90 \%$ Confidence Intervals of $\sigma^{\circ}(\mathrm{dB})$ of Alfalfa

$\begin{array}{ccc}\begin{array}{c}\text { Incidence } \\ \text { Angle }\end{array} & \begin{array}{c}\text { Number of Spatially } \\ \text { Independent Measurements }\end{array} & \begin{array}{c}90 \% \text { Confidence } \\ \text { Intervals (dB) }\end{array} \\ 0^{\circ} & 18 & +1.8 \\ 10^{\circ} & 17 & \frac{-2.0}{+1.8} \\ 20^{\circ} & 16 & \frac{-2.0}{+1.0} \\ 30^{\circ} & 15 & \frac{-1.3}{+0.9} \\ 40^{\circ} & 14 & -1.0 \\ 50^{\circ} & 13 & \frac{-0.8}{+0.8} \\ 60^{\circ} & 13 & \frac{-0.7}{+0.7} \\ 70^{\circ} & 13 & \frac{-0.7}{+0.4} \\ & & \frac{-0.4}{+0.3}\end{array}$


G

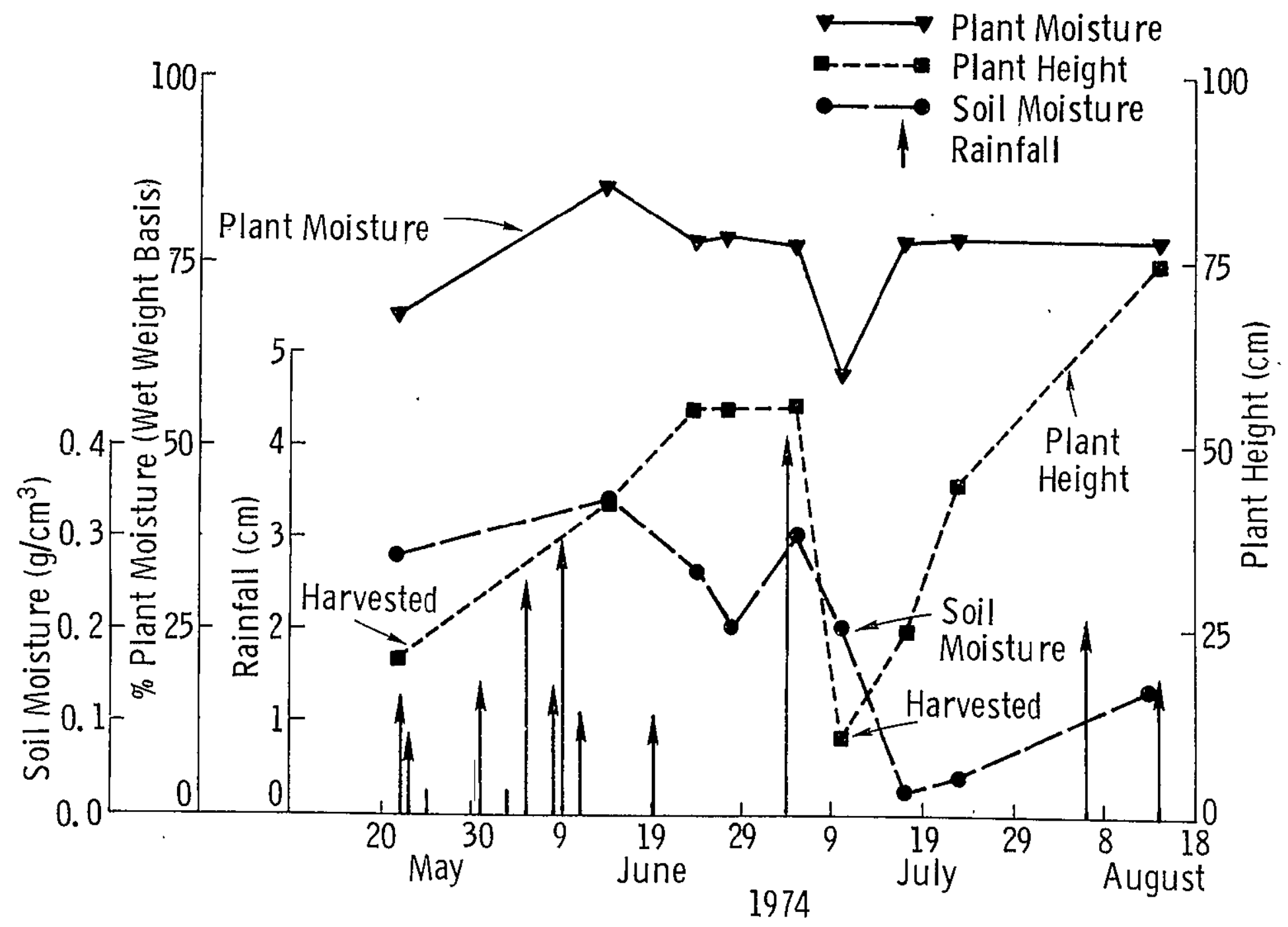

Figure 1. Summarized ground truth data record for alfalfa, 1974. 
dielectric constant of the soil. In turn the dielectric properties of the soil are reflected in $\sigma^{\circ}$. To aid in determining the relationship between $\sigma^{\circ}$ and soil moisture content, soil samples were collected at the time of each scattering measurement. Figure 2 indicates the locations within the test field where soil samples were collected. The location of each pair of sampling points was chosen so that locations \#1, \#2 and \#3 approximately corresponded to scattering measurements made within the angular ranges of $0^{\circ}-20^{\circ}, 30^{\circ}-50^{\circ}$ and $60^{\circ}-70^{\circ}$ respectively. After recording the sample weight, they were dried in an oven and again weighed so that the gravimetric soil moisture content could be determined. The measured values of the soil moisture content were then averaged in a pair-wise manner and converted to volumetric soil moisture content using the soil bulk density as the conversion factor. Thus all soil moisture contents reported herein, designated as $m_{s}$, are expressed in units of $\mathrm{g} / \mathrm{cm}^{3}$. Due to skin depth considerations [4] only the top $2 \mathrm{~cm}$ samples were used in the analyses. Subsequent analyses involving $m_{s}$ will make use of the soil sample location and incidence angle correspondence. For example to determine the effects of $m_{s}$ on $\sigma^{\circ}$ as measured at a $40^{\circ}$ angle of incidence, $m_{s}$ as measured at location \#2 would be used as the independent variable in the analysis. Figure 1 shows the variations of $m_{s}$ at location ${ }^{\#} 2$ as a function of time.

\subsection{Plant Moisture}

As with soil moisture, plant moisture has been shown to significantly influence the dielectric properties of vegetation [5]. Thus, as part of the scattering experiment, a number of alfalfa plant samples were collected at the time a scattering measurement was made. These samples were processed so that the plant moisture content, $m_{p}$, as measured on a wet weight basis was obtained. Figure 1 presents the results of this analysis. It should be noted that the variations of $m_{p}$ as a function of time were somewhat small except for the July 10 value of 0.6 which was measured shortly after the alfalfa was harvested.

\subsection{Plant Height}

In addition to the above parameters, the time history of the average height of the vegetation canopy was also recorded (Figure 1). It should be noted that the alfalfa completed two growth cycles during the observation period. The reader should bear in mind that while plant height is certainly one indicator of plant maturity there are a variety of physiological phenomena occurring during the maturation process. 


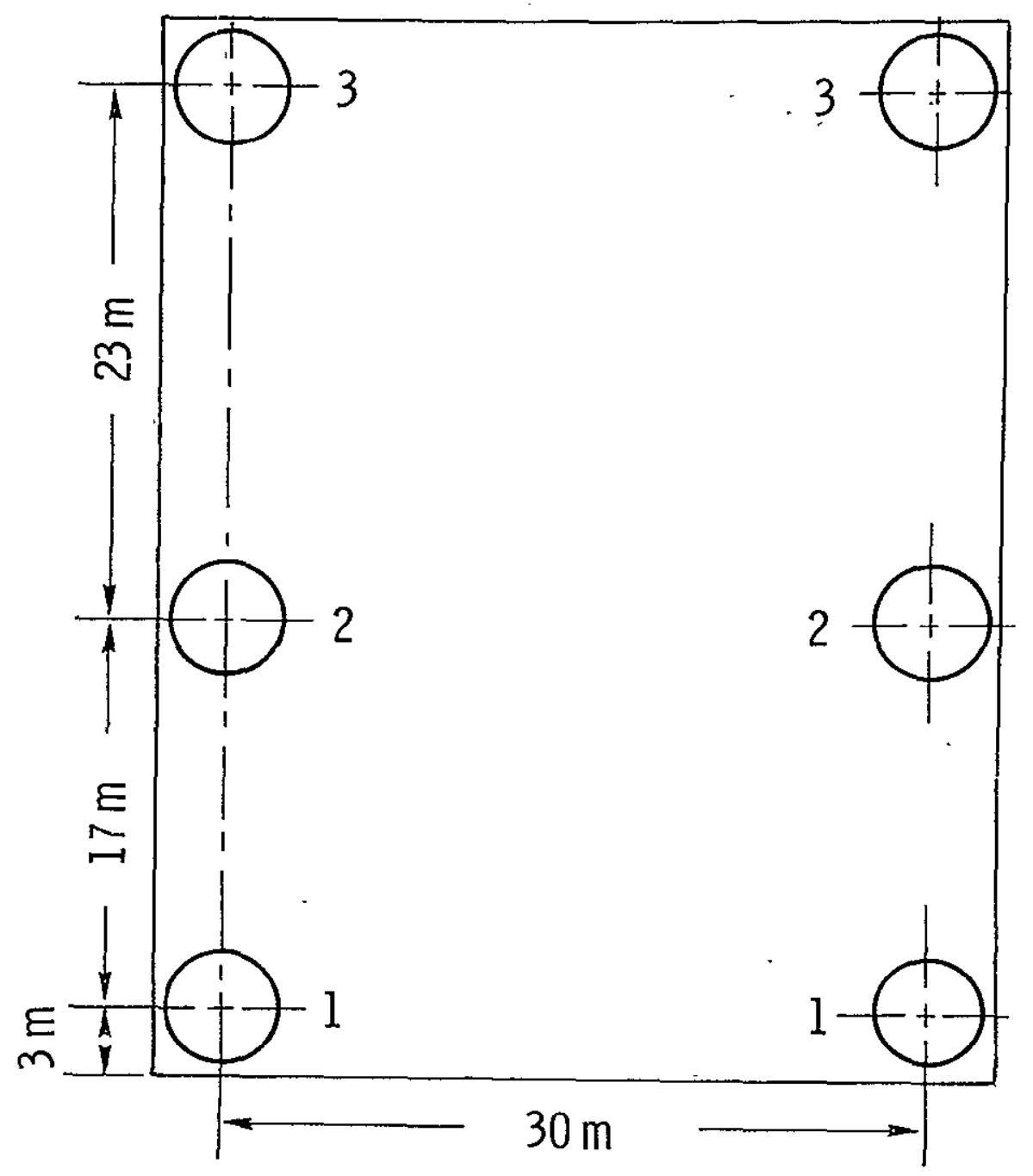

Figure 2. Diagram showing field locations of soil samples. 


\subsection{CANOPY MODEL}

If we consider the alfalfa canopy as a lossy dielectric layer between the air and soil media, then in general, the backscattered return would be composed of contributions by the canopy itself and contributions by the underlying soil. In the absence of vegetation cover, the bare soil backscattering coefficient $\sigma_{\mathrm{bs}}^{\circ}$ expressed in $\mathrm{dB}$ was found to vary linearly with soil moisture content $m_{s}[6]$ which suggests an exponential variation if $\sigma_{\mathrm{bs}}^{\circ}$ is expressed in real units:

$$
\sigma_{b s}^{\circ}=A \exp \left(B \cdot m_{s}\right)
$$

where $A$ and $B$ are constants for a given set of the sensor parameters and the soil surface roughness.

Vegetation is a dynamic target; over a growing cycle several plant parameters of interest can vary. Aside from "shape" variations, these parameters include plant height $h$, the bulk density of the vegetation canopy $\rho$, and plant moisture content $m_{p}$. Measurements of the dielectric constant of plant leaves by Carlson [5] at $8.5 \mathrm{GHz}$ indicate a strong dependence on moisture content. Based on data from com, grass and taxus samples, he proposed the following approximate formula:

$$
\epsilon_{p}=\epsilon_{p}^{\prime}-j \epsilon_{p}^{\prime \prime}=1.5+\left(\frac{\epsilon_{w}^{\prime}}{2}-j \frac{\epsilon_{w}^{\prime \prime}}{3}\right) m_{p}
$$

where $\epsilon^{\prime}$ and $\epsilon^{\prime \prime}$ are the real and imaginary parts of the relative dielectric constant, $m_{p}$ is the fractional amount of moisture present in the vegetation (on a wet weight basis) and the subscripts $p$ and $w$ refer to plant and water respectively. From (2) the loss tangent is given by:

$$
\tan \delta_{p}=\frac{\epsilon_{p}^{\prime \prime}}{\epsilon_{p}^{T}}=\frac{\epsilon^{\prime \prime}{ }_{w} m_{p}}{4.5+1.5 \epsilon_{w}^{\prime} m_{p}}
$$


At an air temperature of $30^{\circ} \mathrm{C}$, typical of the environmental conditions under which the data reported in this paper were acquired, $\left(\epsilon^{\prime}{ }_{w^{\prime}}, \epsilon^{\prime \prime}{ }_{w}\right)$ vary between $(68.0$, 23.8 ) at $8 \mathrm{GHz}$ and $(46.8,35.6)$ at $18 \mathrm{GHz}[7]$. Over two growth cycles of alfalfa, the smallest measured value of $m_{p}$ was 0.6 corresponding to the cut alfalfa and the largest value was 0.85 (Figure 1). In view of the values of $\epsilon^{\prime}{ }_{w}$ and $m_{p^{\prime}}$, neglecting the constant term of 4.5 in the denominator of (3) amounts to less than $10 \%$ error in the worst case. Hence,

$$
\tan \delta_{p} \simeq 2 / 3 \frac{\epsilon^{\prime \prime}}{\epsilon_{w}^{\prime}}
$$

which is independent of $m_{p}$. Moreover, at a given frequency and in the absence of wide variations in the physical temperature of the plant, tan $\delta_{p}$ is approximately a constant.

The attenuation suffered by a wave propagating through a vegetated medium is in general caused by scattering and by absorption losses. In view of the difficulty encountered in accounting for the loss term due to scattering, it will be assumed herein that as a first order approximation, the absorption loss is the dominant term. The justification for making this assumption is borne out by the close fit between the expression derived on this bas is and the experimental results of $\sigma^{\circ}$ at nadir (section 5.2). Neglecting the scattering-loss term is, in effect, equivalent to assuming that the vegetation medium is homogeneous.

The attenuation coefficient of a homogeneous medium of dielectric constant $\epsilon_{p}$ is given by:

$$
\alpha_{p}=\frac{2 \pi}{\lambda}\left[\frac{\epsilon_{p}^{\prime}}{2}\left[\left(1+\tan ^{2} \delta_{p}\right)^{1 / 2}-1\right]\right]^{i / 2}
$$

nepers/ $m$, with the wavelength $\lambda$ expressed in meters. Applying the same approximatic for $\epsilon_{p}^{\prime}$ used in deriving (4), the attenuation coefficient dependence on $m_{p}$ becomes:

$$
\alpha_{p}=k_{1} m_{p}^{1 / 2}
$$

where

$$
k_{1}=\frac{\pi}{\lambda}\left[\epsilon^{\prime}{ }_{w}\left[\left(1+\tan ^{2} \delta_{p}\right)^{1 / 2}-1\right]\right]
$$


which is only frequency and temperature dependent. To account for the fact that the canopy is not a homogeneous layer consisting entirely of plants, but instead is mostly air, the effective canopy attenuation coefficient is defined by:

$$
\alpha_{c}=\rho k_{1} m_{p}^{1 / 2}
$$

where $\rho$ is the bulk density of the vegetation. For most crops $\rho$ is a function of height $h$; with alfalfa, as the plants grow taller they also get denser, thereby suggesting that $\rho$ is an increasing function of $h$. In the absence of experimental values for $\rho$, the following dependence is suggested:

$$
\rho(h)=k_{2} h^{x}
$$

where $k_{2}$ is a constant and $x$ is a positive exponent to be determined empirically (section 5. 2). Assuming that for a given tieight $h$, the canopy is approximately homogeneous, the total roundtrip power attenuation at nadir is then given by:

$$
\begin{aligned}
\Gamma\left(h, m_{p}\right) & =4 \alpha_{c} h \\
& =4 k_{1} k_{2} m_{p}^{1 / 2} h^{x+1} \\
& =C m_{p}^{1 / 2} i^{y}
\end{aligned}
$$

where $C=4 k_{1} k_{2}$ and $y=x+1$. At angles other than nadir, (11) should be modified to account for path length. Neglecting reflection at the canopy-air interface, the soil contribution to the measured backscattering coefficient by the vegetation-covered soil is from (I) and (11):

$$
\begin{aligned}
\sigma_{\mathrm{cs}}^{0} & =A \exp \left(B m_{s}-\Gamma\right) \\
& =A \exp \left(B m_{s}-C m_{p}^{1 / 2} h^{y}\right)
\end{aligned}
$$

In addition to attenuating the soil component, the canopy contributes a backscattering coefficient of its own, $\sigma_{c}{ }^{\circ}$. Since the backscatter from a target is influenced by its dielectric properties and geometry, and due to the lack of an appropriate theory capable of incorporating these parameters, it is suggested here that $\sigma_{c}{ }^{\circ}$ take a form similar to that of $\Gamma$ :

$$
\sigma_{c}^{0}=D m_{p}^{1 / 2} h^{z}
$$


where $D$ and $z$ are constants. The rationale behind the above formulation is that the total attenuation of a lossy medium is closely related to the medium emissivity which in turn is related to its scattering properties [8]. Combining (12) and (13), the total scattering coefficient of the canopy (above the soil) is:

$$
\begin{aligned}
\sigma^{0} & =\sigma_{c s}^{0}+\sigma_{c}^{0} \\
& =A \exp \left(B m_{s}-C m_{p}^{1 / 2} h^{y}\right)+D m_{p}^{1 / 2} h^{z}
\end{aligned}
$$

The application of the above model to the measured data (section 5.2) provides the best agreement between theory and experiment at nadir. The empirically determined values of $y$ and $z$ are 2.6 and 1.0 , respectively.

\subsection{DATA PRESENTATION AND DISCUSSION}

\subsection{Temporal Variations of $\sigma^{\circ}$}

Figures $3 a-d$ present temporal variations of the measured value of $\sigma^{\circ}$, the backscattering coefficient, at $8.6 \mathrm{GHz}$. Both $\sigma_{H}^{\circ}$ and $\sigma_{\mathrm{V}}^{\circ}$ are shown at four angles of incidence, $0^{\circ}(3 \mathrm{a}), 10^{\circ}(3 \mathrm{~b}), 40^{\circ}(3 \mathrm{c})$ and $70^{\circ}(3 \mathrm{~d})$. (Complete data are presented in Appendix $B)$. An initial inspection of Figure $3 a$ indicates that the dynamic range of $\sigma^{\circ}$ (at $8.6 \mathrm{GHz}, 0^{\circ}$ ) during the observation period was nearly $18 \mathrm{~dB}$, implying that indeed the radar responded to the physical variations of the alfalfa as it completed two growth cycles. Two distinct maxima and minima are also noted. The maxima occur on May 22 and July 10 and the minima, while not quite as pronounced, occur near June 28 and August 1. From Figure 1 it is found that the maxima coincide exactly with the days on which the harvested alfalfa was observed. Furthermore the minima correspond to those time periods during which the alfalfa reached maximum height. In fact it is noted that throughout the observation period $\sigma_{H}^{0}$ and $\sigma_{V}^{0}$ are roughly inversely related to plant height (Figure I). 
Frequency $(\mathrm{GHz}): 8.6$

Polarization:

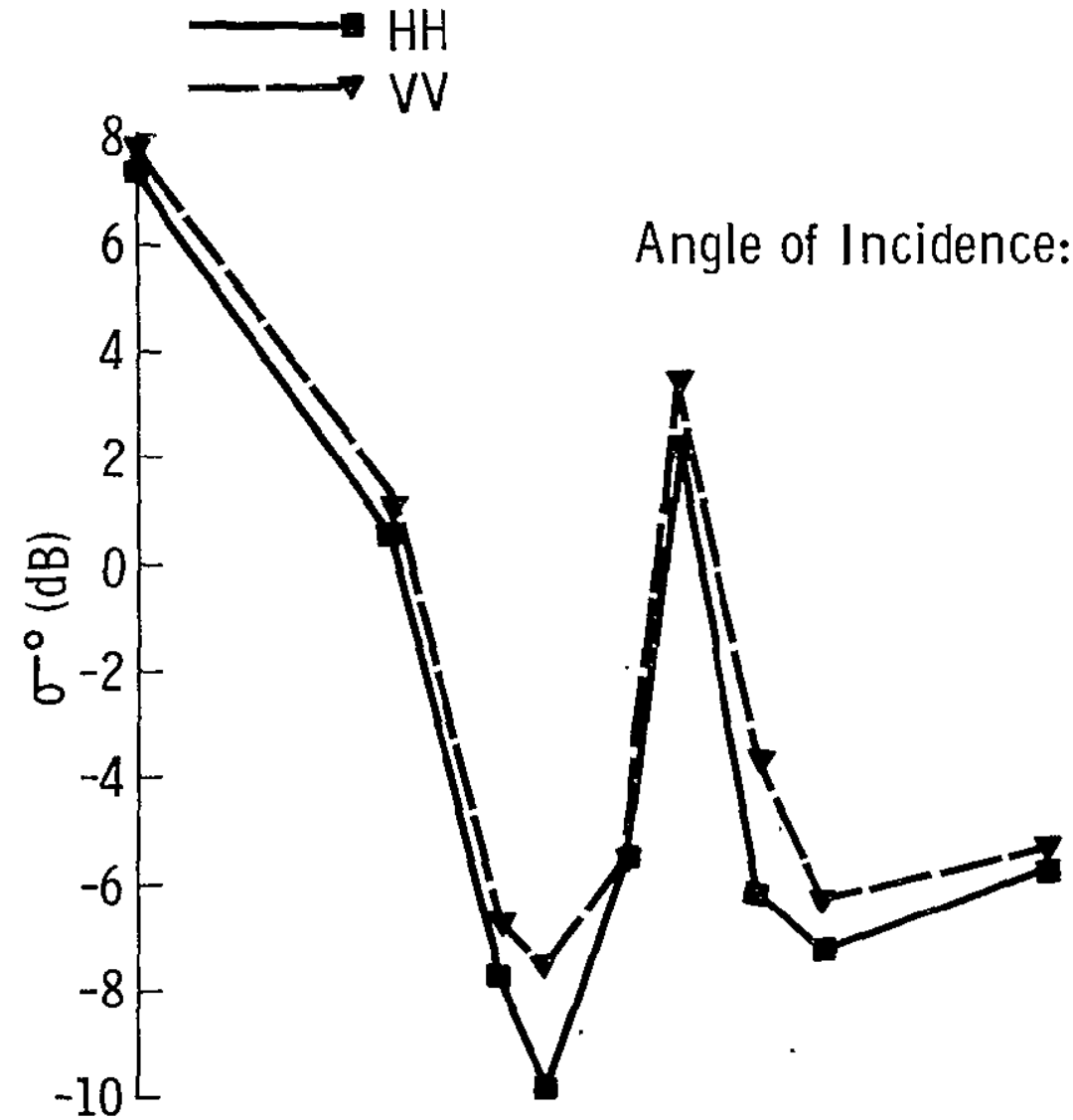

(a)

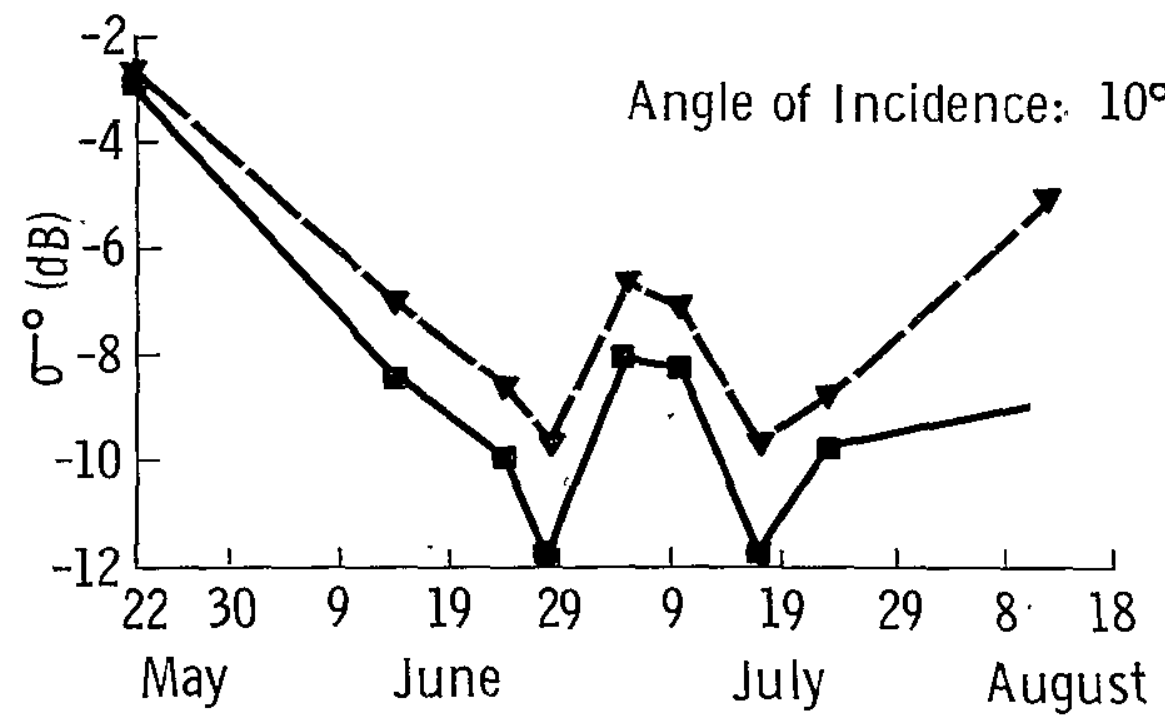

(b)

Figure 3. Temporal variations of $\sigma^{\circ}$ measured at $8.6 \mathrm{GHz}$ for angles of incidence of a) $0^{\circ}$, b) $10^{\circ}$, c) $40^{\circ}$, and d) $70^{\circ}$. 
Frequency $(\mathrm{GHz}): 8.6$

Polarization:
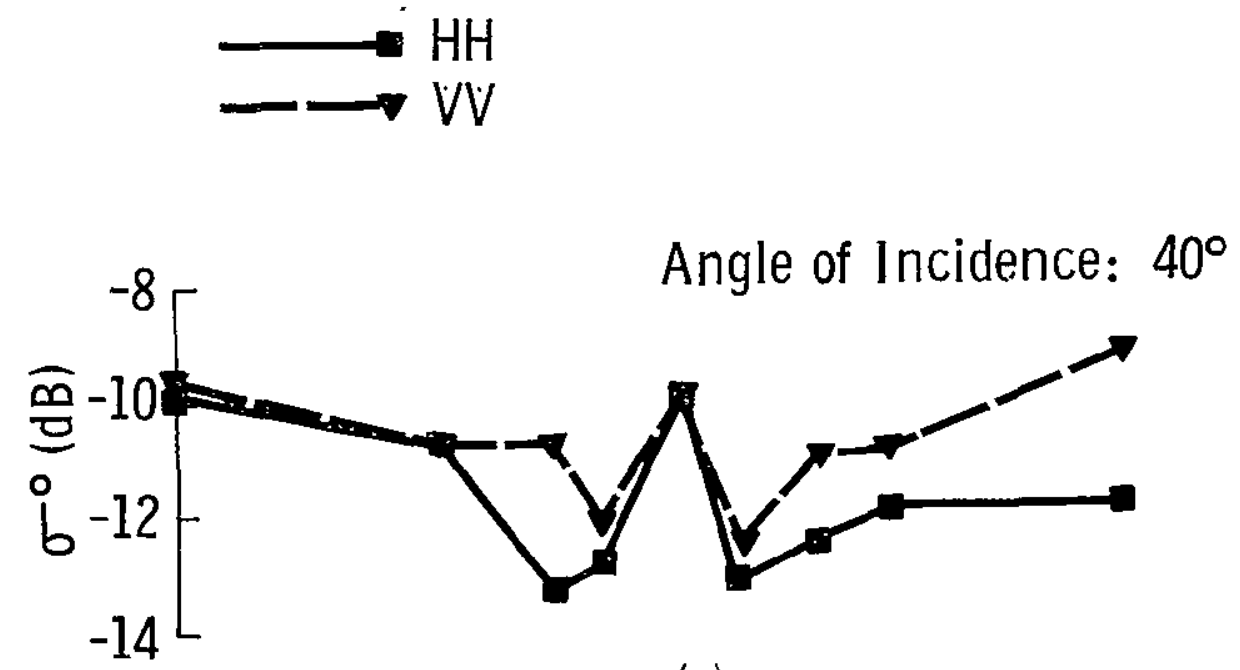

(c)

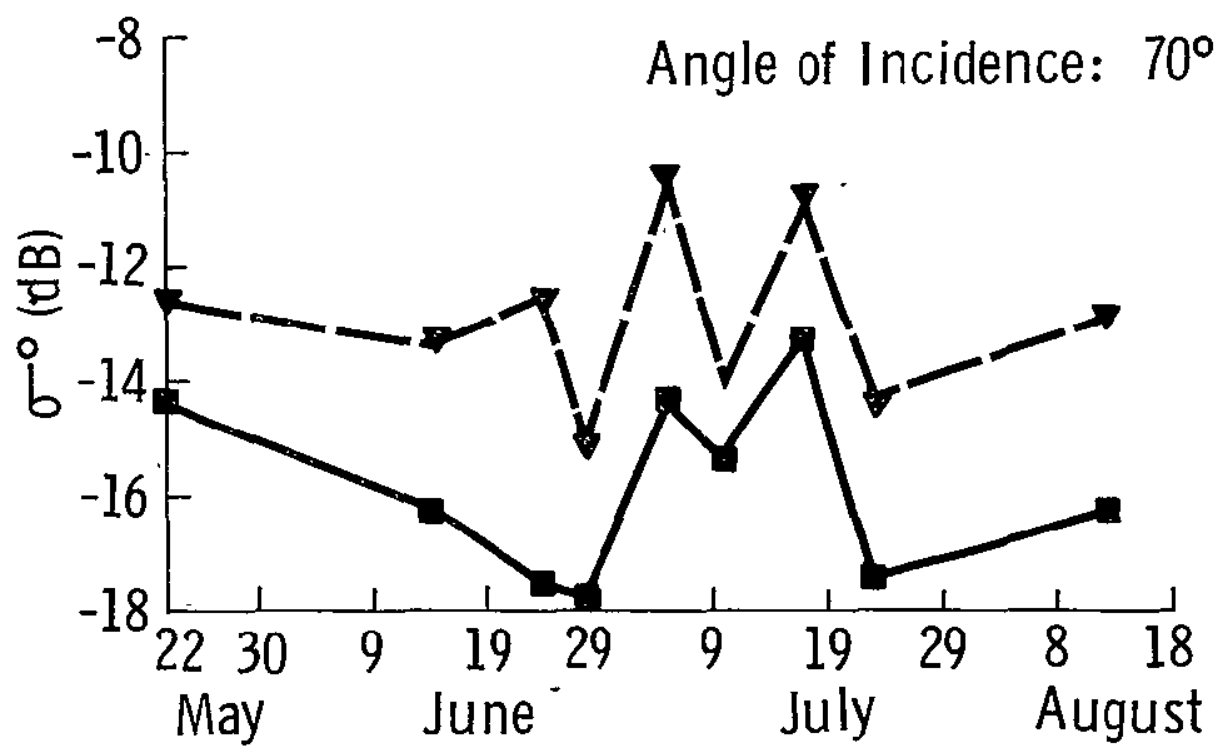

(d) 
In an earlier report [9] discussing 4-8 GHz backscatter data from alfalfa it was suggested that of the total radar return from mature alfalfa, backscatter from the alfalfa alone dominated the return with a relatively small contribution from the underlying soil. Again this seems to be a partial explanation for the behavior of the $\sigma^{\circ}$ versus time curve presented in Figure 3a. Consider the target as two media; the first being the vegetation canopy while the second being the underlying soil. Because alfalfa is a perennial crop the underlying soil is left uncultivated for four or perhaps more years. Due to the action of natural erosive elements (rain, wind, etc.) the soil assumes a quite smooth character. Such was the character of the soil during the observation period under discussion. Thus when a backscatter measurement is made of a short stand of alfalfa at nadir the radar will "see" the smooth soil surface causing a relatively large amount of the incident energy to be reflected back to the radar. As the alfalfa matures however, both the plant height and density increase causing the loss within the canopy to increase. This attenuation will result in a masking of the contributions by the underlying soil. Certainly the return from the vegetation canopy will increase as the canopy height and density increase but it is felt that this effect will not be large enough to balance the reduction in the return from the soil. Perhaps this can be more easily seen by an observation of $\sigma^{\circ}$ as measured on June 14 and July 23. From Figure 1 we note that while the crop heights were nearly equal, (about $44 \mathrm{~cm}$ ) the earlier value of $\sigma^{\circ}$ was measured when $\mathrm{m}_{\mathrm{s}}$, the soil moisture, was about $0.34 \mathrm{~g} / \mathrm{cm}^{3}$ in contrast to $0.04 \mathrm{~g} / \mathrm{cm}^{3}$ as recorded on July 23 . From Figure $3 a$ we note that $\sigma_{H}{ }^{\circ}$ as measured on June 14 was about $7.5 \mathrm{~dB}$ higher than $\sigma_{H}{ }^{\circ}$ on July 23, indicating that soil moisture can have an effect on $\sigma^{\circ}$ of alfalfa at nadir.

Next consider data collected on May 22 and June 24. In this case the soil moisture contents were very similar $\left(0.28 \mathrm{~g} / \mathrm{cm}^{3}\right.$ on $5 / 22$ and $0.26 \mathrm{~g} / \mathrm{cm}^{3}$ on $\left.6 / 24\right)$ while the alfalfa on May 22 was only $17 \mathrm{~cm}$ tall as contrasted with the $55 \mathrm{~cm}$ tall alfalfa measured on June 24. Again from Figure $3 a$ we can note the effect of this change in crop height and density to be that of decreasing $\sigma_{\bar{H}}^{\circ}$ from about $7 \mathrm{~dB}$ on May 22 to a value of about $-8 \mathrm{~dB}$ on June 24 . Thus it appears that at nadir the radar backscatter from mature alfalf̣a is generally dominated by scatter from the plant canopy while the return from short and/or immature alfalfa is strongly dependent on soil moisture. 
Figure $3 b$ presents $\sigma^{\circ}$ as a function of time for an angle of incidence of $10^{\circ}$. An immediate and dramatic change in the trends of $\sigma^{\circ}$ is noted. Perhaps most notable is the lack of a maximum on July 10. Moreover the dynamic range of $\sigma^{\circ}$ has also been reduced to $9 \mathrm{~dB}$, which (in real units) is about $12 \%$ of the observed dynamic range at $0^{\circ}$. Furthermore there does not appear to be as strong a dependence of $\sigma^{\circ}$ on height as was noted earlier for the nadir data. Figures $3 \mathrm{c}$ and $3 \mathrm{~d}$ present data collected at $8.6 \mathrm{GHz}$ at $40^{\circ}$ and $70^{\circ}$ respectively. Again no strong dependence of $\sigma^{\circ}$ on the measured target variables is noted although the $10^{\circ}$ and $40^{\circ}$ data bear certain similarities.

Figures $4 a-d$ present the temporal variations of $\sigma^{\circ}$ as measured at $13.0 \mathrm{GHz}$. It is immediately apparent that the trends observed at $8.6 \mathrm{GHz}$ at a $0^{\circ}$ angle of incidence are present at $13.0 \mathrm{GHz}$. While there are certain shifts in the absolute levels of $\sigma^{\circ}$ as measured at 8.6 and $13.0 \mathrm{GHz}$, the maxima and minima still persist at identical points in time. At $10^{\circ}, 13.0 \mathrm{GHz}$ (Figure $4 \mathrm{~b}$ ) the contrast with the $0^{\circ}$ data is again noted. Furthermore there are no definite consistencies between the $10^{\circ}$ data as measured at $8.6 \mathrm{GHz}$ (Figure $3 \mathrm{~b}$ ) and $13.0 \mathrm{GHz}$ (Figure $4 \mathrm{~b}$ ) or between the response of $\sigma_{H}^{\circ}$ and $\sigma_{\mathrm{V}}{ }^{\circ}$ as measured at $13.0 \mathrm{GHz}$. At $40^{\circ}$ and $70^{\circ}$, Figures $4 \mathrm{c}$ and $4 \mathrm{~d}$, the response of $\sigma^{\circ}$ to the passage of lime is very similar to $\sigma^{\circ}$ as measured at $8.6 \mathrm{GHz}$ at corresponding angles of incidence. It is interesting to note that the dynamic range of $\sigma^{\circ}{ }^{\circ}$ at $13.0 \mathrm{GHz}, 40^{\circ}$ is only $2.8 \mathrm{~dB}$ indicaring very little dependence of $\sigma^{\circ}$ on the various crop characteristics under consideration.

Finally, $17.0 \mathrm{GHz}$ data are presented in Figures $5 \mathrm{a}-\mathrm{d}$. The trends at $0^{\circ}$, Figure $5 \mathrm{a}$, are certainly consisient with the previous observations at 8.6 and $13.0 \mathrm{GHz}$. Again the $10^{\circ}$ data, Figure $5 \mathrm{~b}$, show no consistent variation when compared to the 8.6 or $13.0 \mathrm{GHz} 10^{\circ}$ data. The $40^{\circ}$ and $70^{\circ}$ data (Figures $5 \mathrm{c}$ and $5 \mathrm{~d}$ ) however show responses very similar to those observed at the lower frequencies at corresponding angles of incidence. Although differences between $\sigma_{H}{ }^{\circ}$ and $\sigma_{V}{ }^{\circ}$ will be discussed in section 5.3, if should be noted that all the data discussed so far have displayed a consistent rendency for $\sigma_{\mathrm{V}}{ }^{\circ}$ to be higher than $\sigma_{\mathrm{H}}{ }^{\circ}$ at angles other than $0^{\circ}$. Furthermore it is noted that at all angles other than $10^{\circ}, \sigma_{\mathrm{H}}^{\circ}$ and $\sigma_{\mathrm{V}} \mathrm{O}$ have displayed trends very similar, if not nearly identical, to one another. 


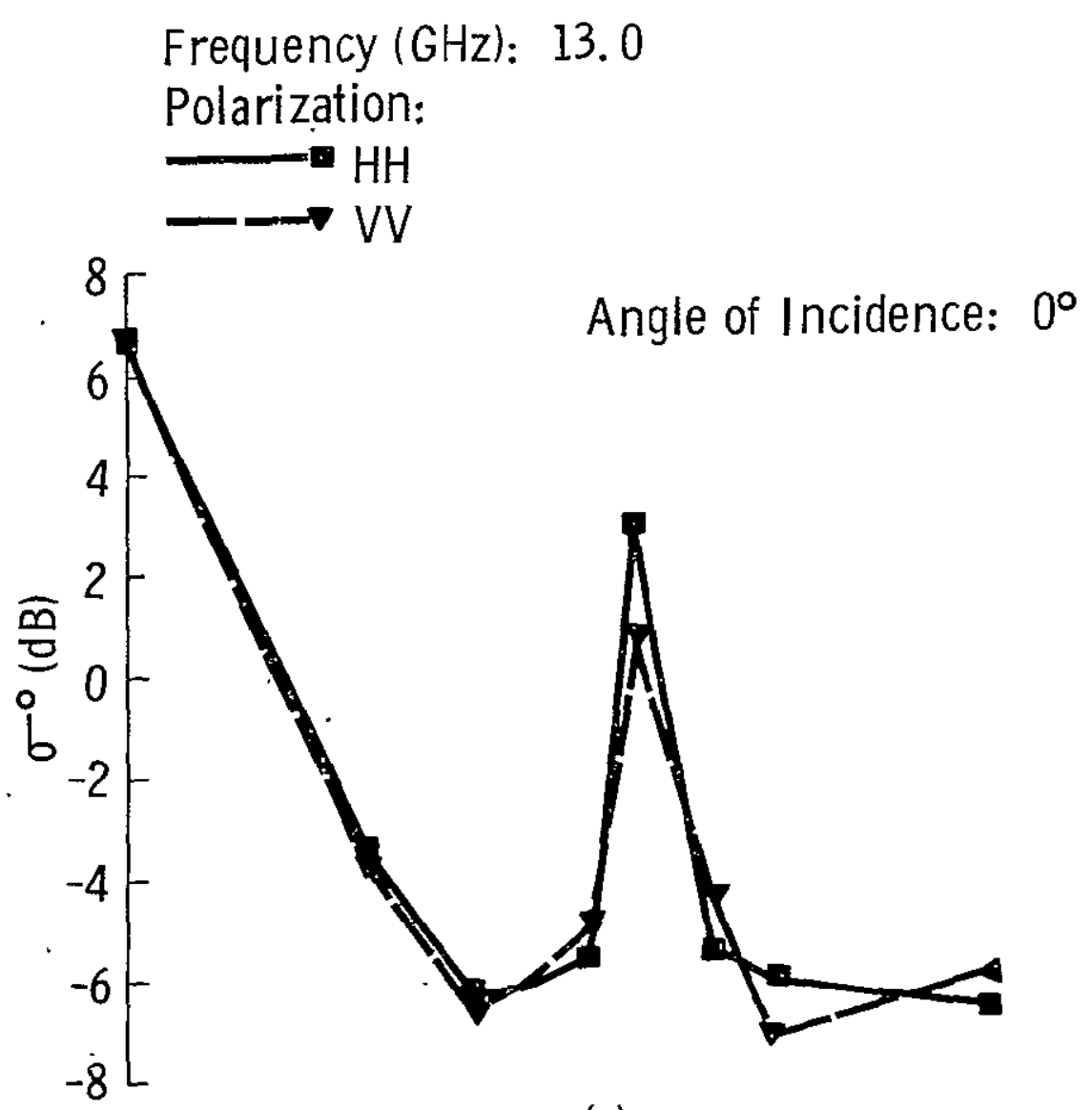

(a)

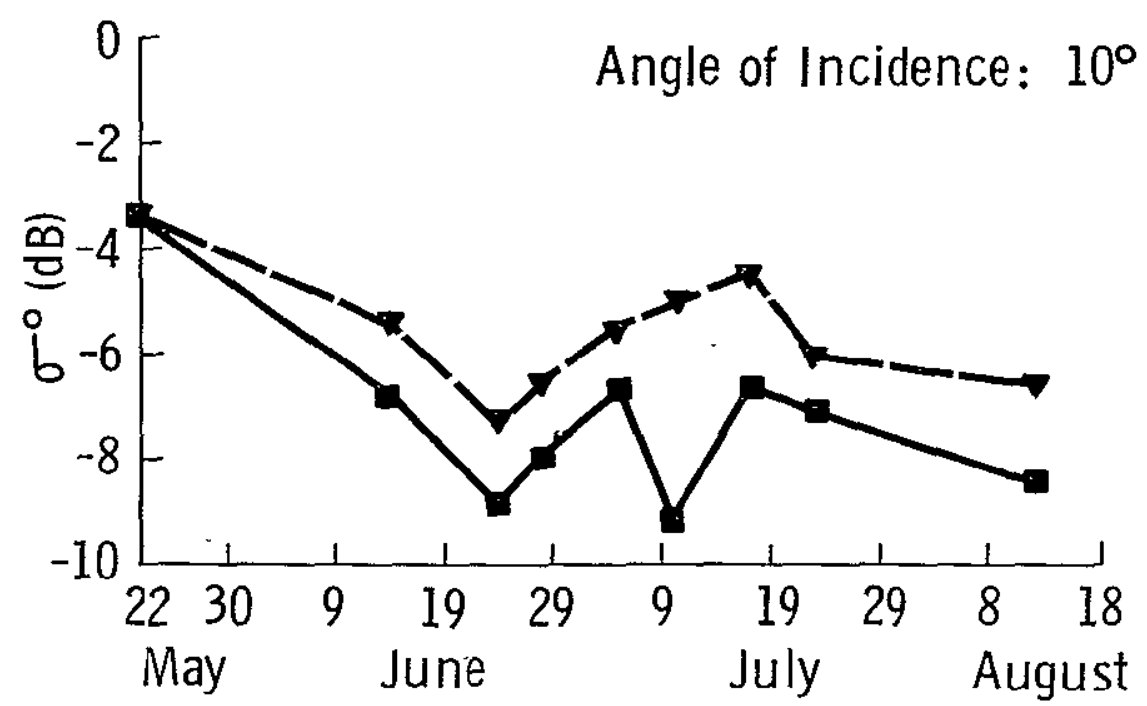

(b)

Figure 4. Temporal variations of $\sigma^{\circ}$ measured at $13.0 \mathrm{GHz}$ for angles of incidence of a) $0^{\circ}$, b) $10^{\circ}$, c) $40^{\circ}$, and d) $70^{\circ}$. 
Frequency (GHz) 13.0

Polarization:
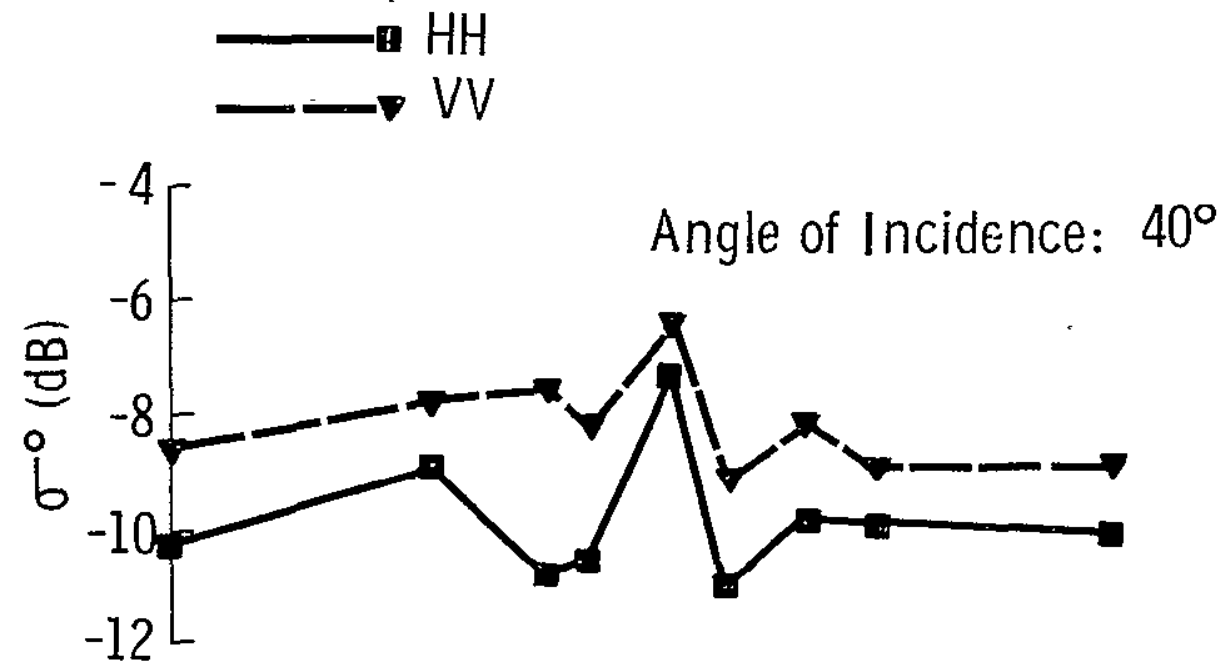

(c)

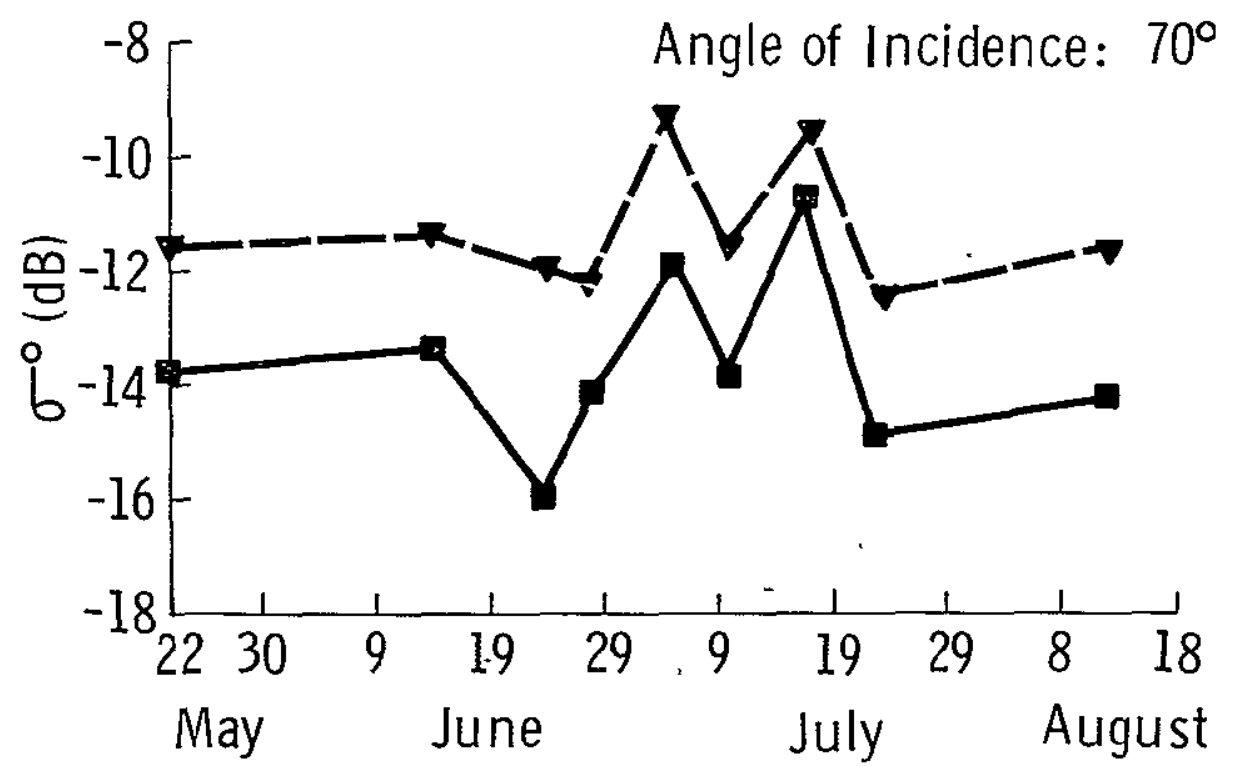

(d) 
Frequency $(\mathrm{GHz}): 17.0$

Polarization:

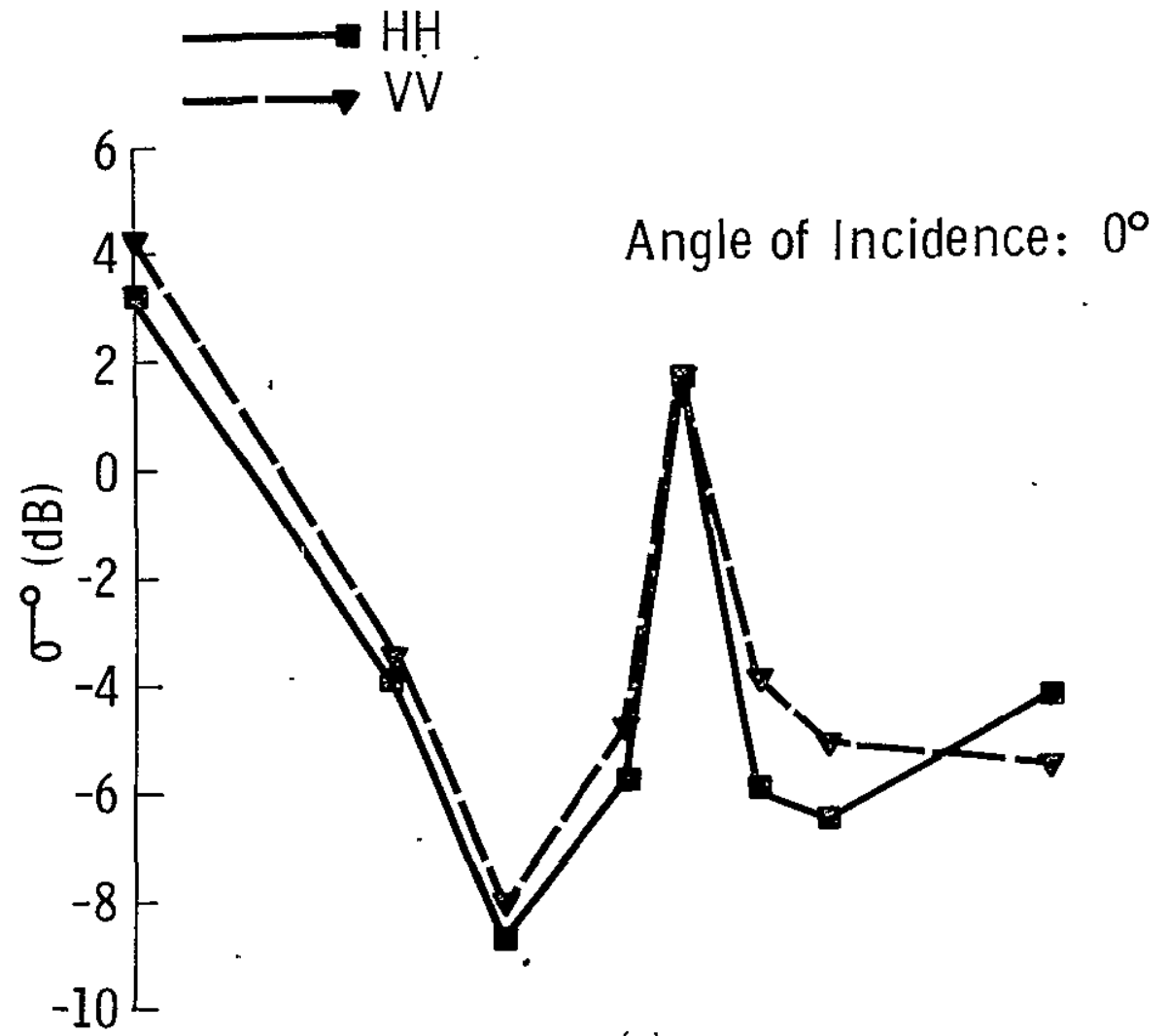

(a)

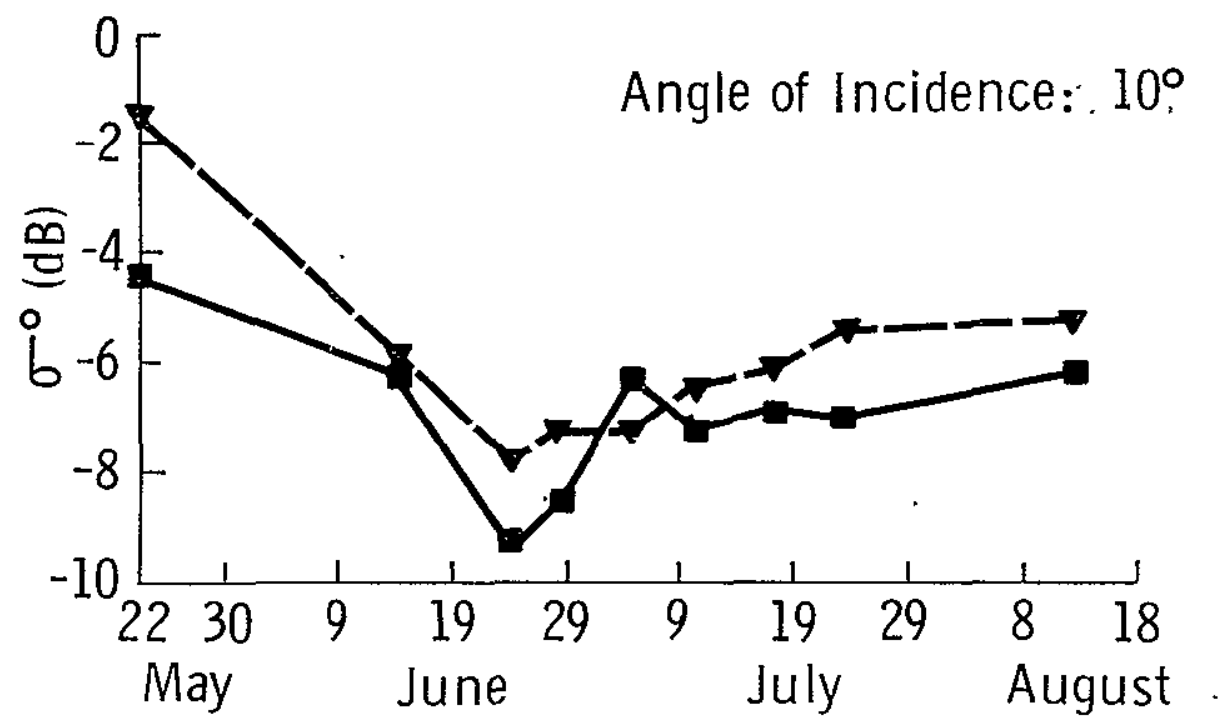

(b)

Figure 5. Temporal variations of $\sigma^{\circ}$ measured at $17.0 \mathrm{GHz}$ for angles of incidence of a) $0^{\circ}$, b) $10^{\circ}$, c) $40^{\circ}$, and d) $70^{\circ}$. 
Frequency $(\mathrm{GHz}): \quad 17.0$

Polarization:

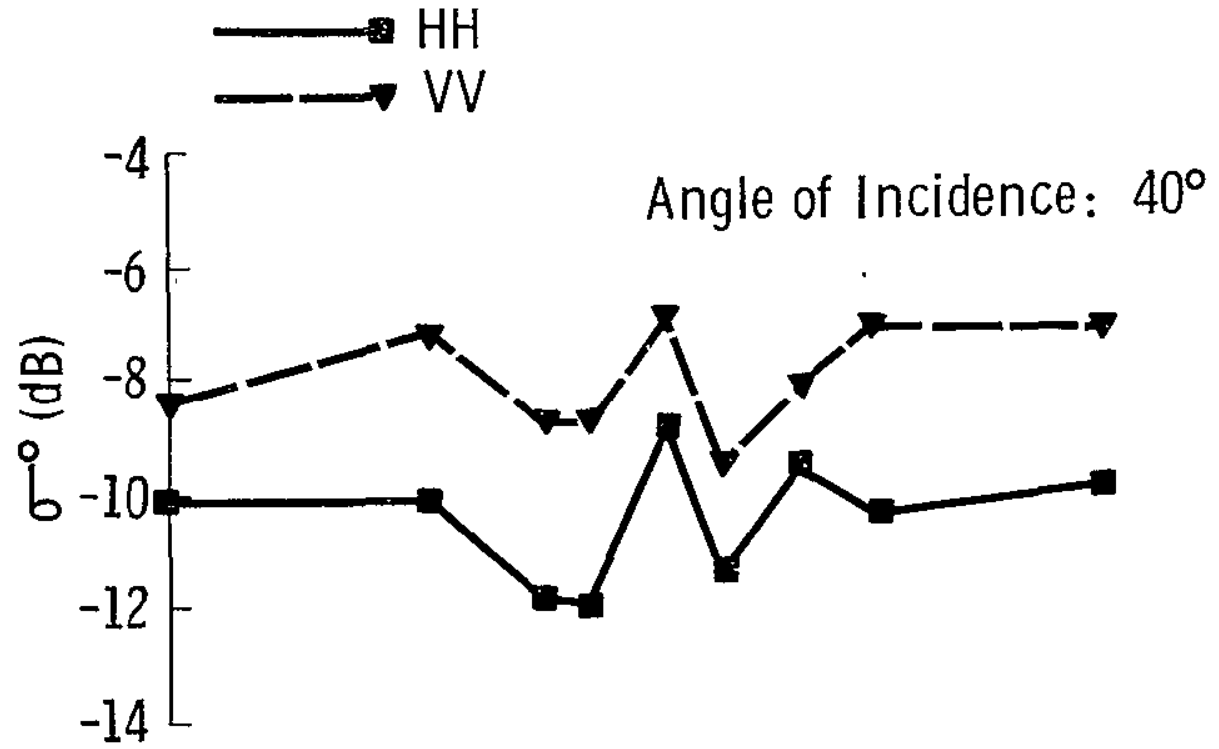

(c)

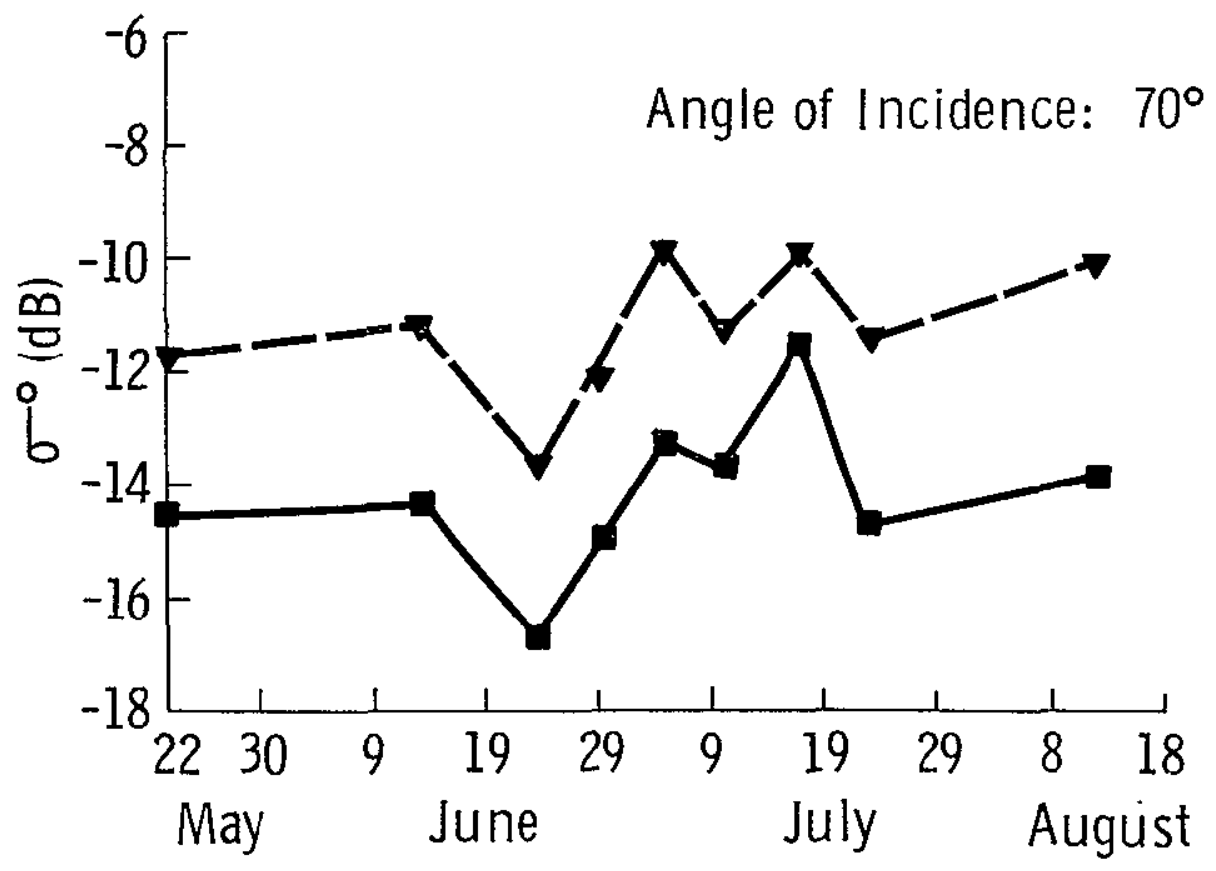

(d) 


\subsection{Implementation of the Canopy Model}

Having discussed the temporal variations of $\sigma^{\circ}$, this section of the report will discuss the estimation of the regression constants $A, B, C$ and $D$ as defined in the canopy model proposed in section 4.0 and the resul ts of the model predictions. To estimate the values of the above regression constants the nonlinear regression program BMDP3R* which obtains a minimum mean squared error fit to a given sef of data, was employed. To reduce the effects of fading in the measured values of $\sigma^{\circ}$ at nadir, ${ }^{\circ}{ }_{\mathrm{H}}{ }^{\circ}$ and $\sigma_{\mathrm{V}}{ }^{\circ}$ were averaged. Because alfalfa is a continous canopy target it is felt that there should be no significant polarization effects in $\sigma^{\circ}$ at nadir. This average value of $\sigma^{\circ}$ will be denoted as $\bar{\sigma}^{\circ}$. At each frequency, the values of $A$, $B, C$ and $D$ were estimated as described above, with the results of these regression analyses presented in Table 3. Making use of these results, Figures ba-c present $\bar{\sigma}^{\circ}$, the average value of ${ }^{\sigma}{ }^{\circ}{ }^{\circ}$ and ${ }^{\sigma}{ }^{\circ}$, and $\hat{\vec{\sigma}}^{\circ}$, the value predicted by the appropriate regression equation. Only the results of the analyses at $8.6,13.0$ and $17.0 \mathrm{GHz}$ are presented in these figures. Note that $\hat{\bar{\sigma}}^{\circ}$ predicts $\bar{\sigma}^{\circ}$ reasonably well, particularly for the higher values of $\bar{\sigma}^{\circ}$.

Making use of the canopy model it is possible to estimate the behavior of $\tilde{\sigma}^{\circ}$ as a function of the various target characteristics. Figures $7 a-c$ present curves of $\hat{\bar{\sigma}}^{\circ}$ as a function of crop height for various values of $m_{s}$, the soil moisture content. Figure $7 a$, representing $\hat{\sigma}^{\circ}$ at $8.6 \mathrm{GHz}$, clearly indicates the dependence of $\sigma^{\circ}$ on soil moisture and crop height. If an average height of 0.35 meters is chosen, for example, it is noted that $\hat{\bar{\sigma}}^{\circ}$ can range between $-7.0 \mathrm{~dB}$ and $+3.0 \mathrm{~dB}$ for a range of $m_{s}$ between 0.0 and $0.30 \mathrm{~g} / \mathrm{cm}^{3}$, respectively. If we chose a value of $h$ of 0.60 meters however, the range over which $\hat{\sigma}^{\circ}$ varies for the same $0.30 \mathrm{~g} / \mathrm{cm}^{3}$ range of $\mathrm{m}_{\mathrm{s}}$ is only about $1.0 \mathrm{~dB}$. Choosing a value of $m_{\mathrm{s}}$ of 0.0 it is seen that the effect of a 0.70 meter increase in height causes $\hat{\bar{\sigma}}^{\circ}$ to vary within a $4.6 \mathrm{~dB}$ range with a minimum occurring around a value of $h=0.5$ meters. For $h<0.5 \mathrm{~m}$, the exponentially decaying shape of the $\quad \hat{\sigma}^{\circ}$ curve indicates that the canopy is acting primarily as an attenuator of the

*BMDP3R was developed at the Heal th Sciences Computing Facility, UCLA, sponsored by NIH Special Research Resources Grant RR-3. BMDP3R was revised February 16, 1973. 
Table 3. Estimated values of the regression constants as a function of trequency for the proposed canopy model of $\hat{\bar{\sigma}}^{\circ}$ where

$$
\begin{aligned}
\hat{\sigma}^{\circ}= & A \cdot \exp \left(B \cdot m_{s}-C \cdot m_{p} l / 2 \cdot h^{2.6}\right) \\
& +D \cdot m_{p}^{1 / 2} \cdot h
\end{aligned}
$$

Frequency

A

B

C

D

$(\mathrm{GHz})$

$\begin{array}{lllll}8.6 & 0.469 & 9.941 & -8.54 & 0.035 \\ 9.4 & 0.252 & 11.324 & -10.12 & 0.033 \\ 10.2 & 0.235 & 14.008 & -13.60 & 0.043 \\ 11.0 & 0.204 & 14.254 & -14.86 & 0.043 \\ 11.8 & 0.375 & 13.005 & -16.76 & 0.048 \\ 13.0 & 0.269 & 12.827 & -14.55 & 0.046 \\ 13.8 & 0.201 & 13.115 & -14.23 & 0.048 \\ 14.6 & 0.579 & 8.370 & -12.01 & 0.049 \\ 15.4 & 0.915 & 6.479 & -10.12 & 0.052 \\ 16.2 & 0.615 & 5.930 & -10.12 & 0.041 \\ 17.0 & 0.556 & 6.585 & -11.07 & 0.047\end{array}$


Frequency (GHz): 8.6

Angle of Incidence (Degrees): $0^{\circ}$

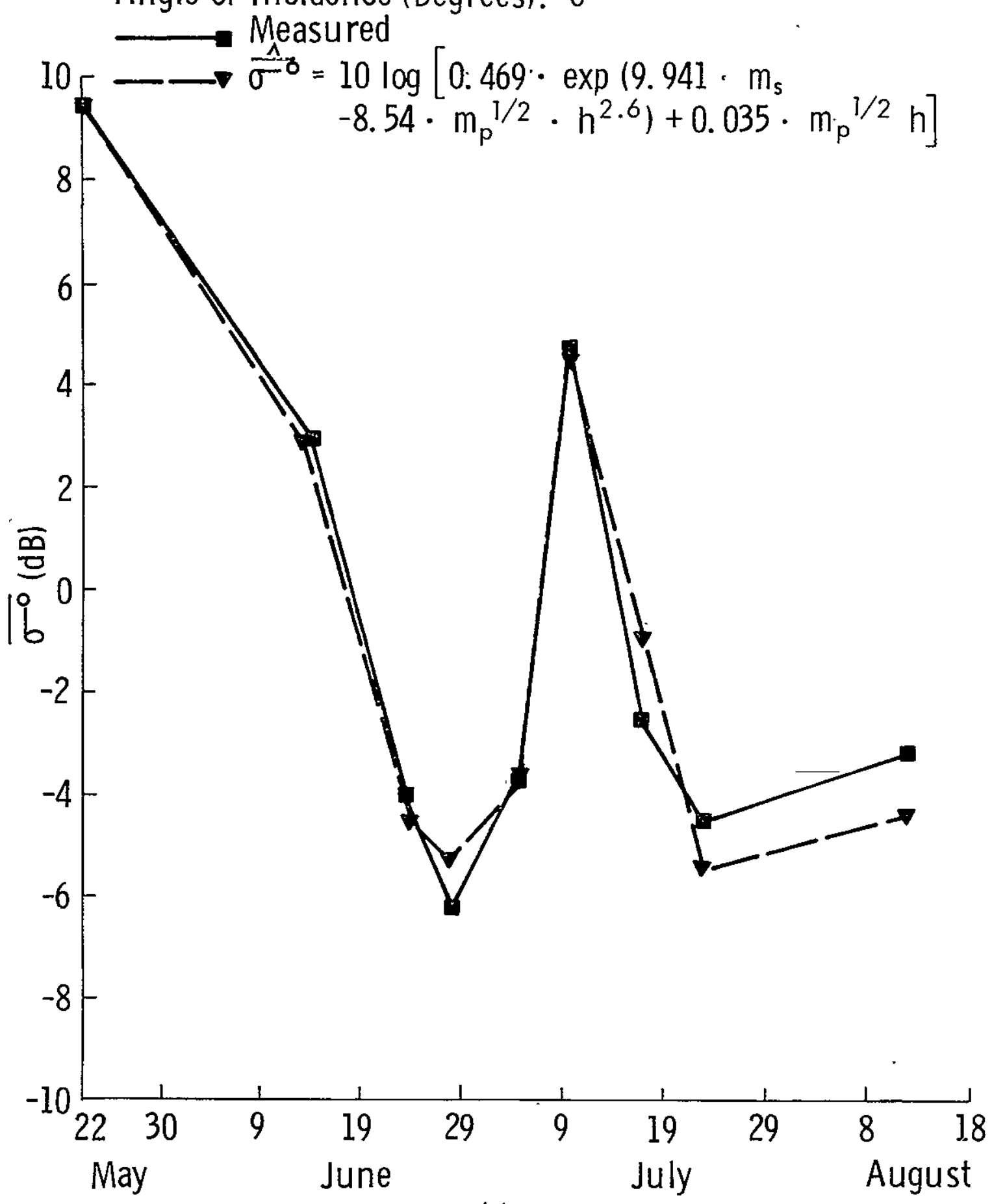

(a)

Figure 6. Temporal variations of $\bar{\sigma}^{0}$ (the average value of $\sigma_{H}{ }^{\circ}$ and $\sigma_{V}{ }^{\circ}$ ) as measured at nadir with $\frac{\hat{\sigma}}{\sigma^{\circ}}$, the values predicted by the canopy model presented in section 4.0. Data are presented at a) 8.6 $\mathrm{GHz}, b) 13.0 \mathrm{GHz}$, and c) $17: 0 \mathrm{GHz}$. 


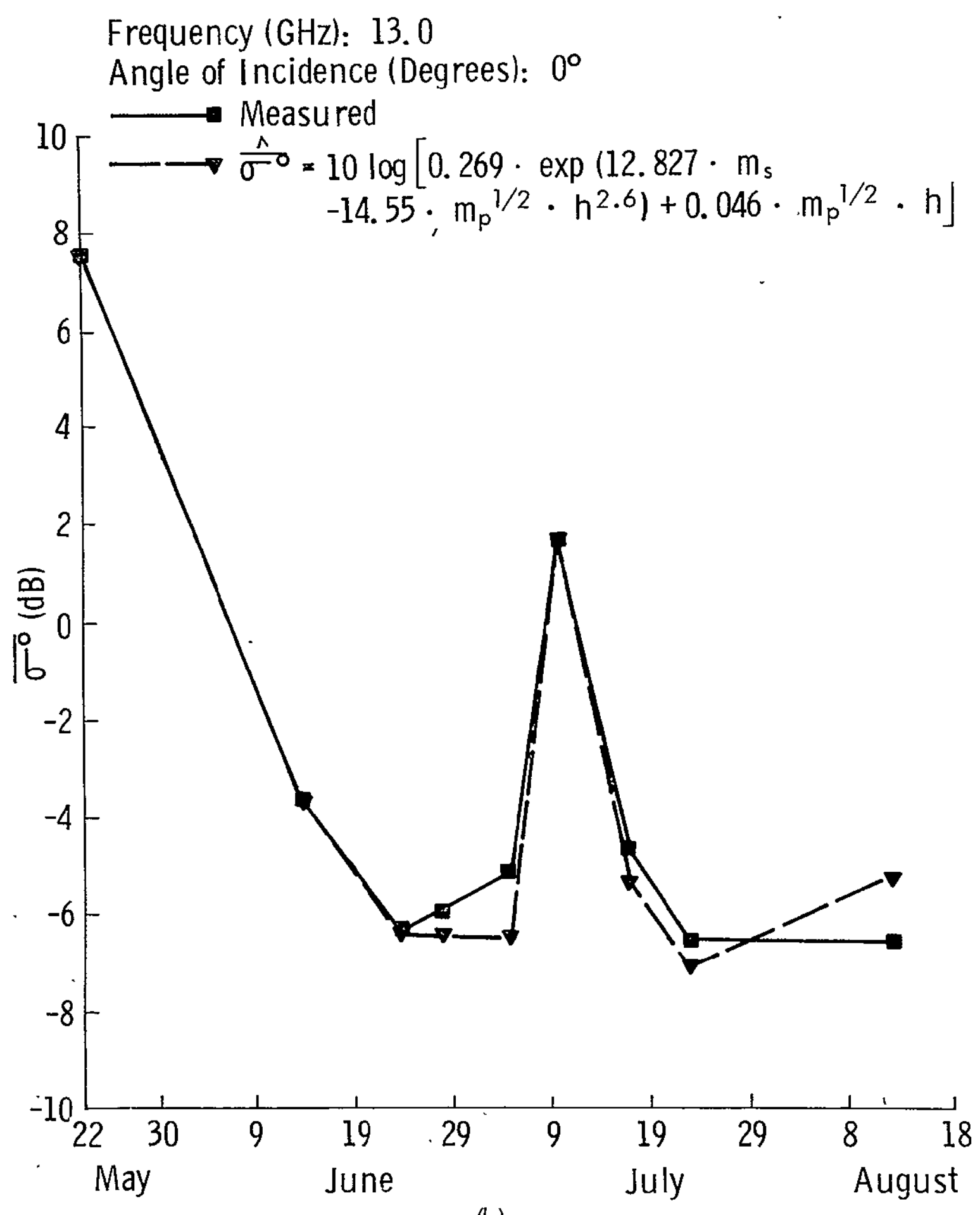

(b) 


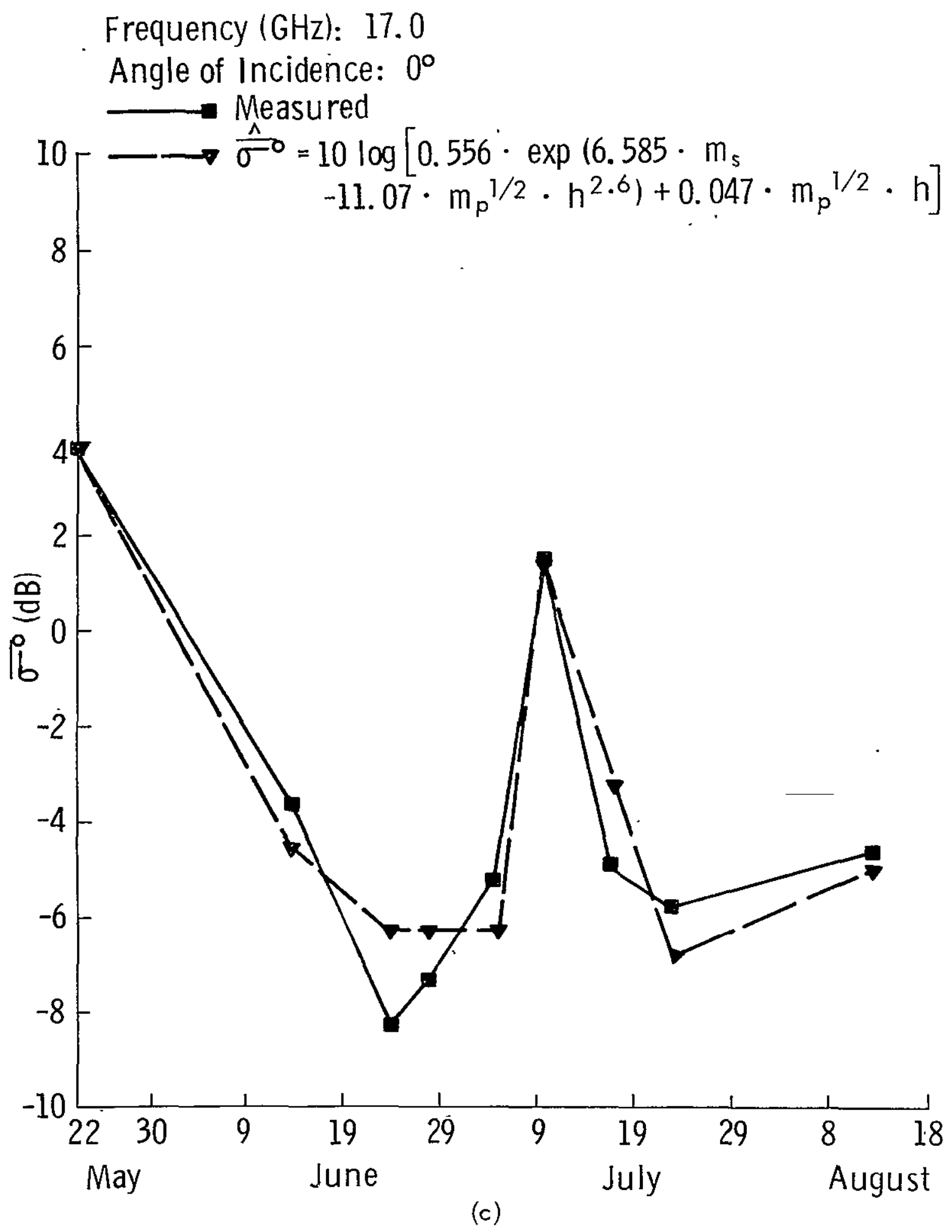




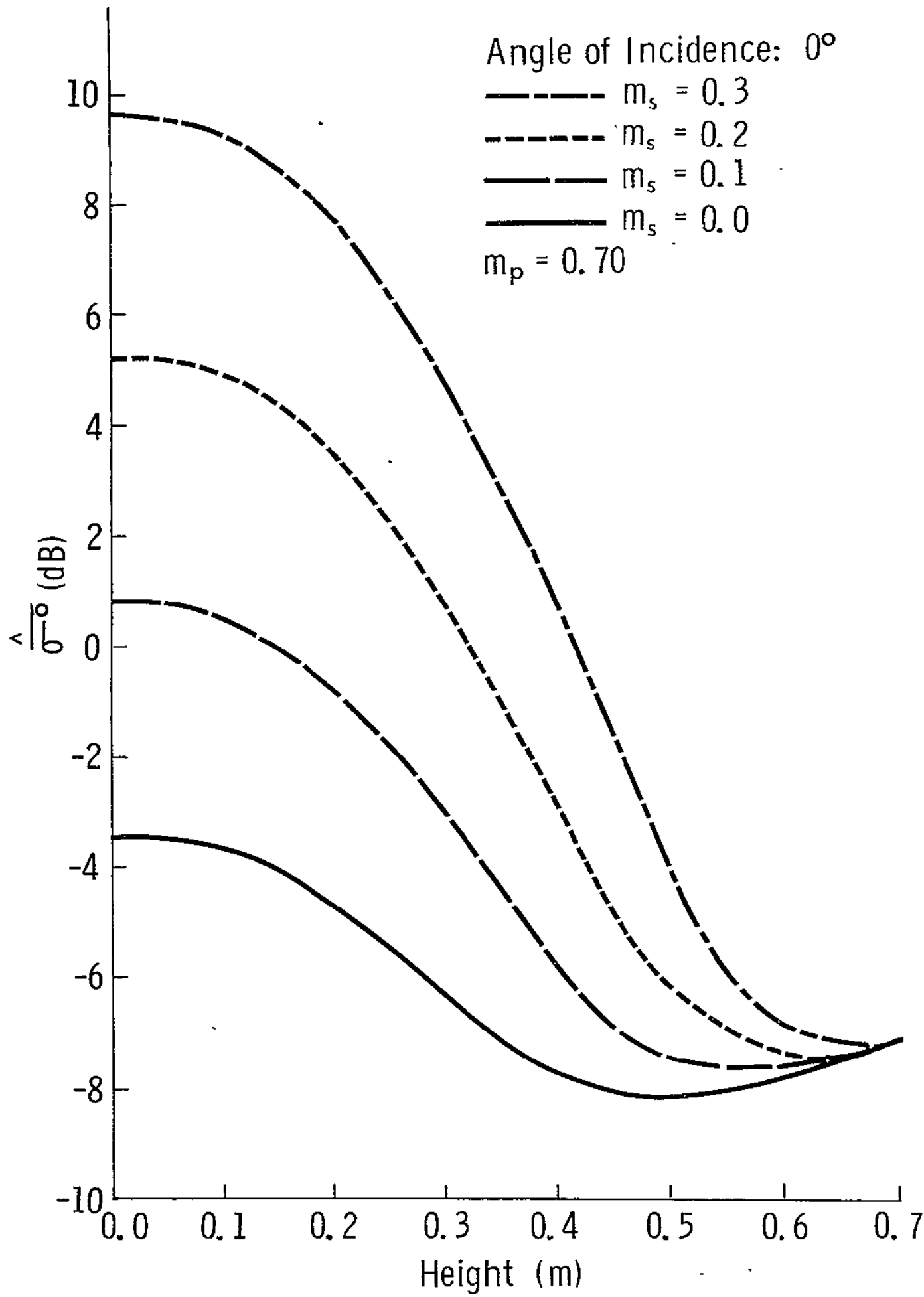

Figure 7. Response of $\hat{\bar{\sigma}}^{0}$, the value of $\bar{\sigma}^{\circ}$ predicted by the canopy model, as a function of canopy height and soil moisture, $m_{s}$. Curves are presented at a) $8.6 \mathrm{GHz}$, b) $13.0 \mathrm{GHz}$, and c) $17.0 \mathrm{GHz}$. 


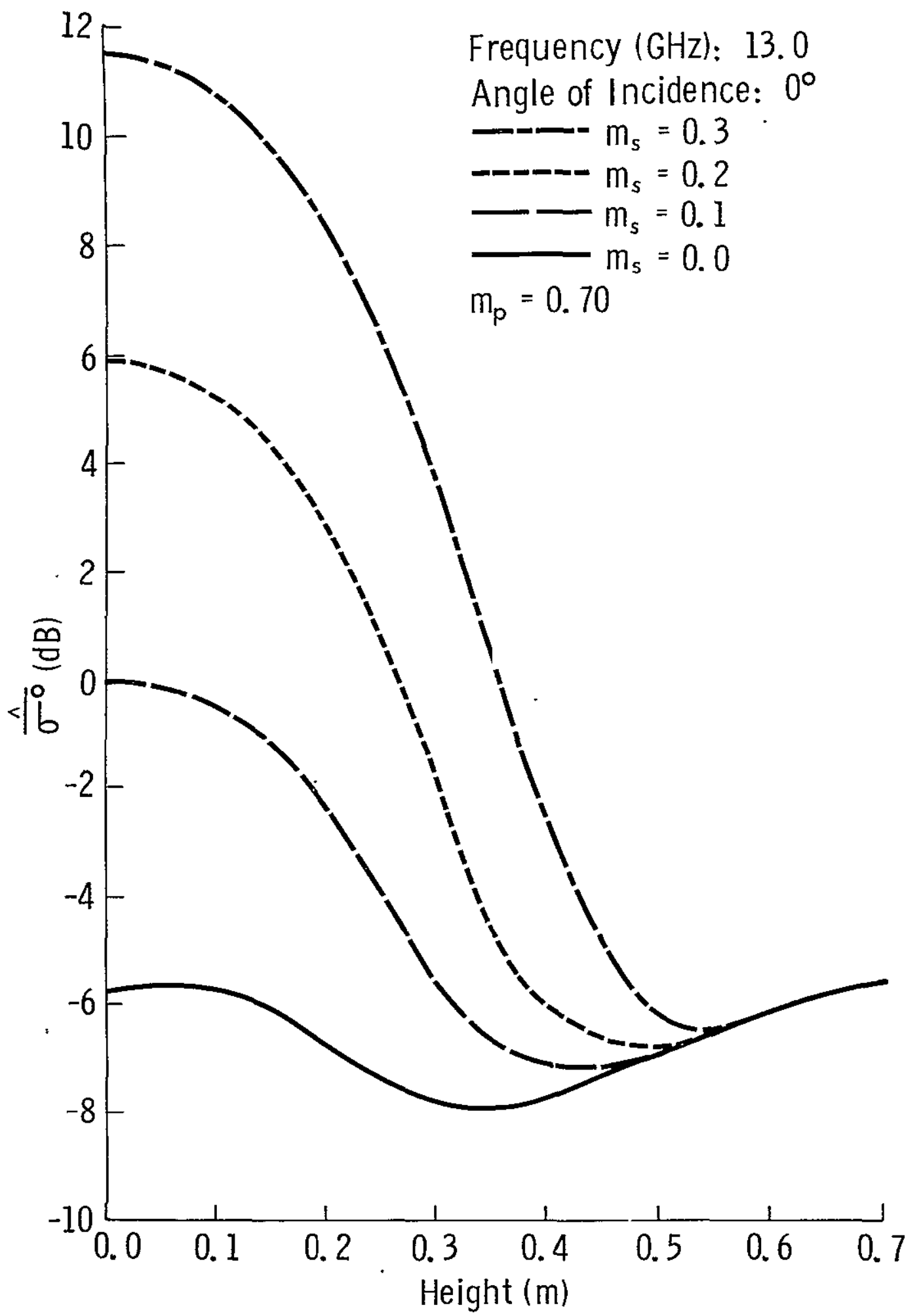

(b) 


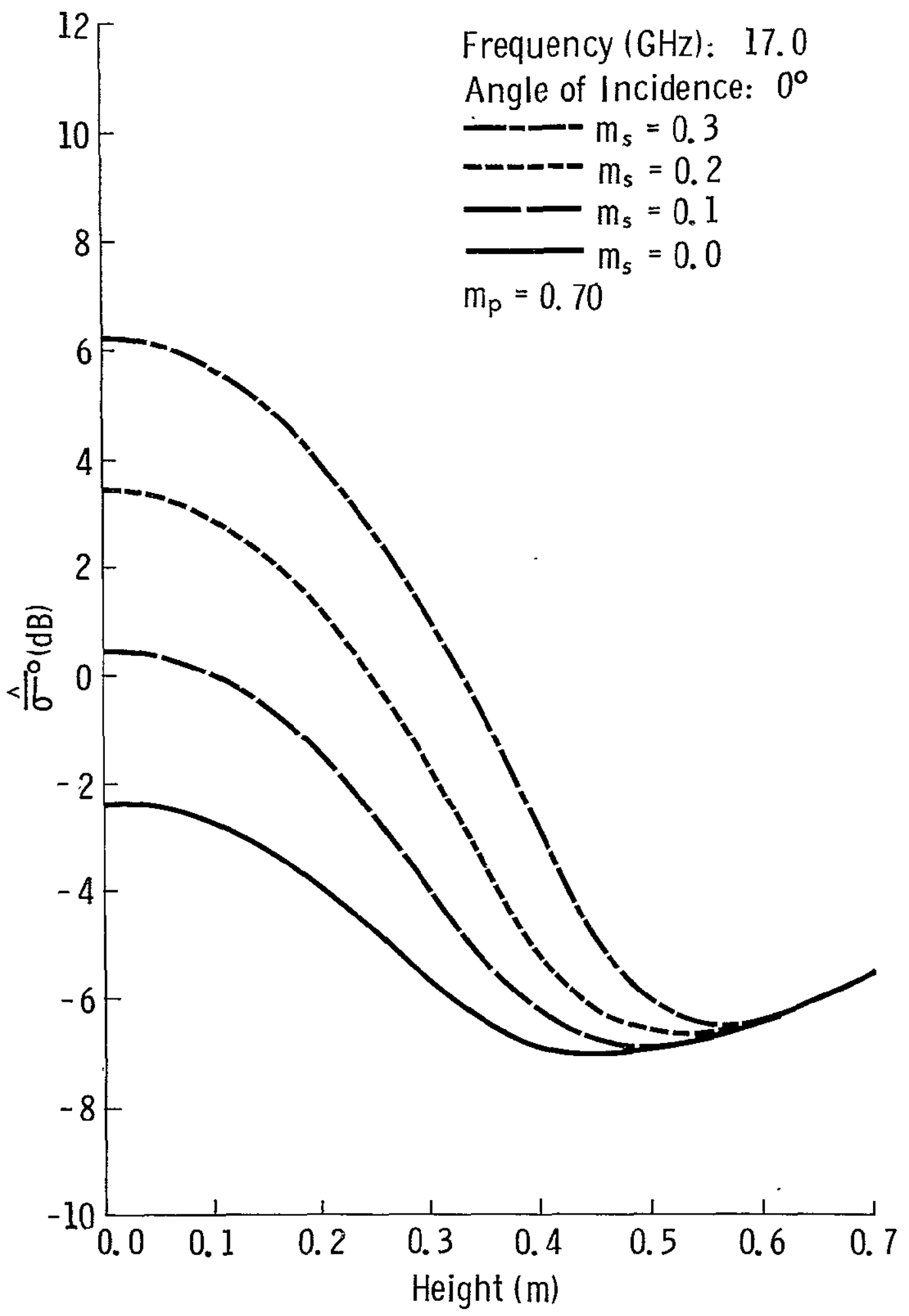

(c) 
soil backscatter component; in other words, the canopy backscatter contribution to the total return is negligible $\left(\sigma_{c}^{0} \ll \sigma_{e s}{ }^{\circ}\right.$ in Equation 14). For $h>$ $0.5 \mathrm{~m}$, on the other hand, the canopy backscatter contribution " ${ }^{\circ}$ becomes dominant over $\sigma_{\mathrm{cs}}^{0}$. At higher values of $m_{\mathrm{s}}$, the position of the minimum in the $\sigma^{0}$ versus $h$ curve increases towards higher values of $h$. At $m_{s}=0.3 \mathrm{~g} / \mathrm{cm}^{3}$, for example, the minimum is barely discernible at $h=0.67 \mathrm{~m}$.

Figures $7 \mathrm{~b}$ and $7 \mathrm{c}$ present the response of $\hat{\sigma}^{\circ}$ to height and soil moisture variations at 13.0 and $17.0 \mathrm{GHz}$. The effects of the frequency increase are clearly identifiable in these figures. Note that whereas $\hat{\sigma}_{0}^{\circ}$ showed a dependence on $\mathrm{m}_{\mathrm{s}}$ at a height of 0.5 meters at $8.6 \mathrm{GHz}$, very little dependence is noted at $13.0 \mathrm{GHz}$ (Figure $7 \mathrm{~b}$ ) or $17.0 \mathrm{GHz}$ (Figure $7 \mathrm{c}$ ). In fact it appears that $\frac{\hat{\sigma}^{\circ}}{\mathrm{\sigma}}$ is totally independent of $m_{s}$ for canopy heights greater than 0.55 meters. Attempts to functionally characterize $\sigma_{H}{ }^{\circ}$ and $\sigma_{V}{ }^{\circ}$ at angles other than nadir met with little success. While certain temporal trends can be recognized in the data, there does not appear to be any consistent dependence of $\sigma^{\circ}$ upon the measured target characteristics.

\subsection{Angular Response of $\sigma^{\circ}$}

Curves depicting $\sigma^{\circ}(\mathrm{dB})$ as a function of angle of incidence offen yielded useful information on the "character" of the scattering surface or volume. For this reason a number of examples of the angular response of $\sigma^{\circ}$ of alfalfa under various conditions are now presented. Figures $8 a-f$ present the angular response of $\sigma_{\bar{H}}{ }^{\circ}$ and $\sigma^{\circ}{ }^{\circ}$ of alfalfa at three frequencies. Two curves representing $\sigma^{\circ}$ for $17 \mathrm{~cm}$ alfalfa and $11 \mathrm{~cm}$ alfalfa are shown for each frequency-polarization combination. Consider the $8.6 \mathrm{GHz}$ data, Figures $8 \mathrm{a}$ and $8 \mathrm{~b}$. From these curves we can immediarely make two observations. First, assuming the rather short alfalfa had negligible effect on the total backscatter from the target, we note that the soil underlying the alfalfa appears "relatively smooth". This can be inferred from the $10 \mathrm{~dB}$ decrease in $\sigma^{\circ}$ as the incidence angle changes from $0^{\circ}$ to $10^{\circ}$. Second we note that with the very low vegetation canopy even a small change in $m_{s}$ has a marked influence on $\sigma^{\circ}$. At $0^{\circ}$ a change in $m_{s}$ from $0.20 \mathrm{~g} / \mathrm{cm}^{3}$ to $0.28 \mathrm{~g} / \mathrm{cm}^{3}$ causes $\sigma^{\circ}$ to increase by about $5 \mathrm{~dB}$. At $13.0 \mathrm{GHz}$, Figures $8 \mathrm{c}$ and $8 \mathrm{~d}$, the curves still suggest that a "relatively smooth" description of the soil surface is in order. Also the effect of soil moisture is still apparent. We can note, however, a slight change in the behavior of the curves depicting $\sigma_{\bar{V}}^{\circ}$, particularly in the $20^{\circ}-70^{\circ}$ region where the curves show a tendency to converge, which was not observed at $8.6 \mathrm{GHz}$. At $17.0 \mathrm{GHz}$ (Figures $8 \mathrm{e}$ and $8 \mathrm{f}$ ) the shape 


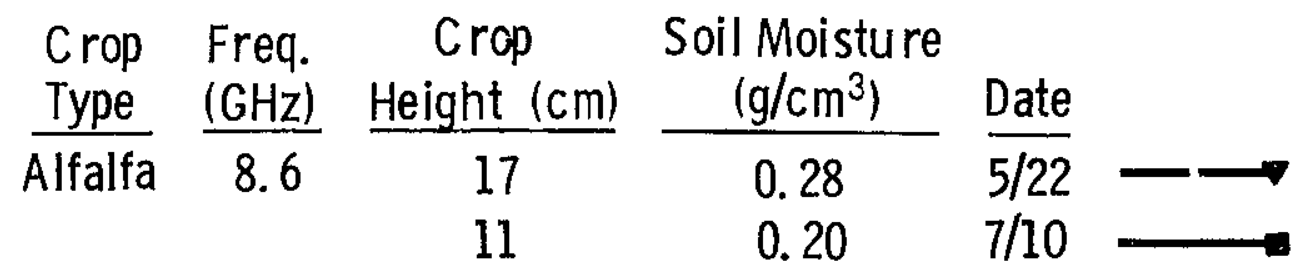

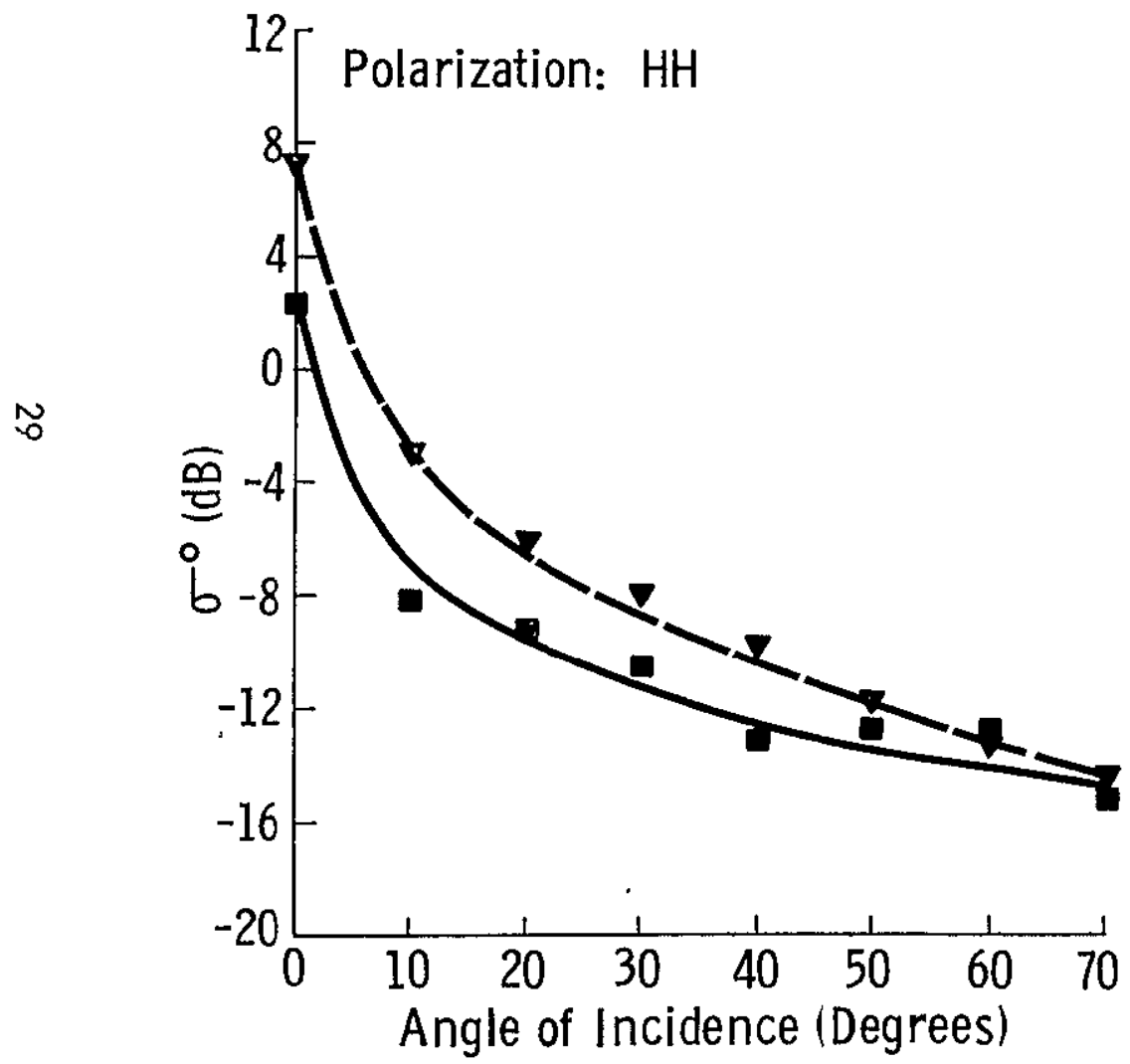

(a)

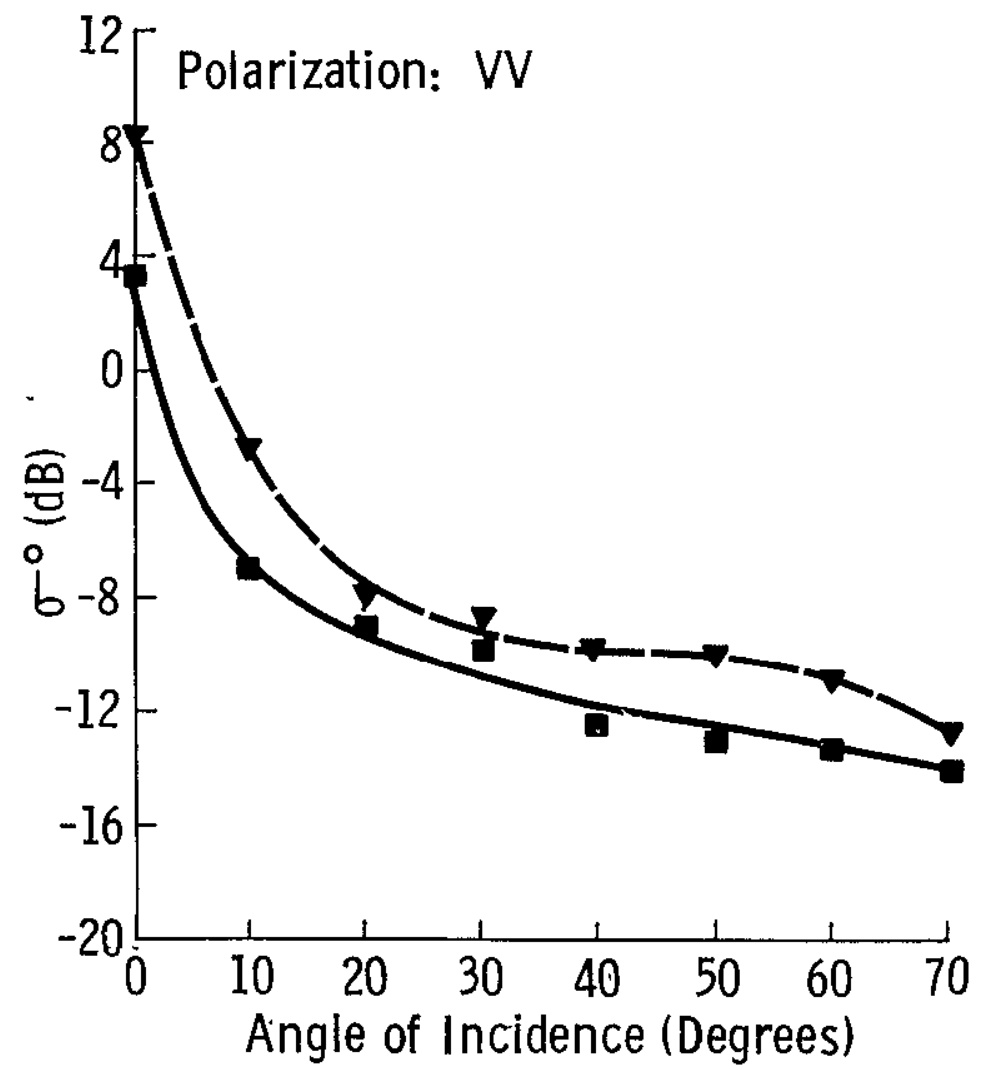

(b)

Figure 8. Angular response of $\sigma^{\circ}$ of harvested alfalfa at $8.6 \mathrm{GHz}^{\circ}\left(\sigma_{\mathrm{H}}^{\circ}\right.$ and $\sigma_{\mathrm{v}}^{\circ}, 8 \mathrm{a}$ and $\left.8 \mathrm{~b}\right), 13.0 \mathrm{GHz}^{\circ}\left(\sigma_{\mathrm{H}}^{\circ}\right.$ and $\sigma_{\mathrm{V}}{ }^{\circ}$, $8 \mathrm{c}$ and $8 \mathrm{~d})$ and $17.0 \mathrm{GHz}\left(\sigma_{\mathrm{H}}{ }^{\circ}\right.$ and $\sigma_{\mathrm{V}}^{\circ}, 8 \mathrm{e}$ and $\left.8 \mathrm{f}\right)$. Note that both curves represent $\sigma^{\circ}$ of harvested alfalfa (11 $\mathrm{cm}$ and $17 \mathrm{~cm}$ ) and that the values of the soil moistures were comparable but not identical. 


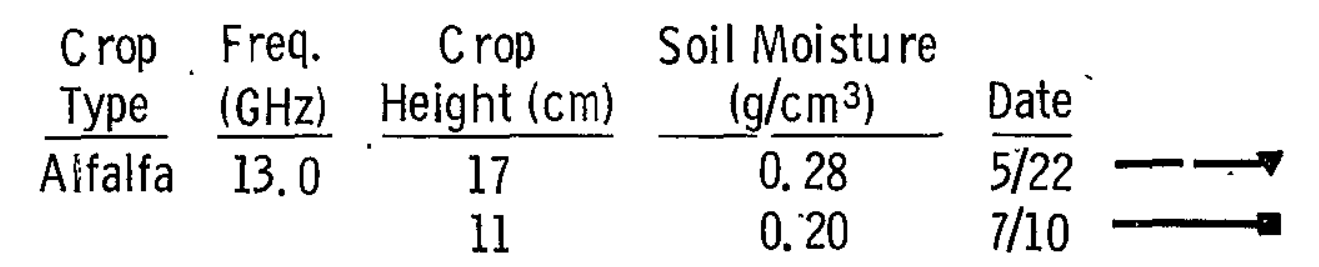

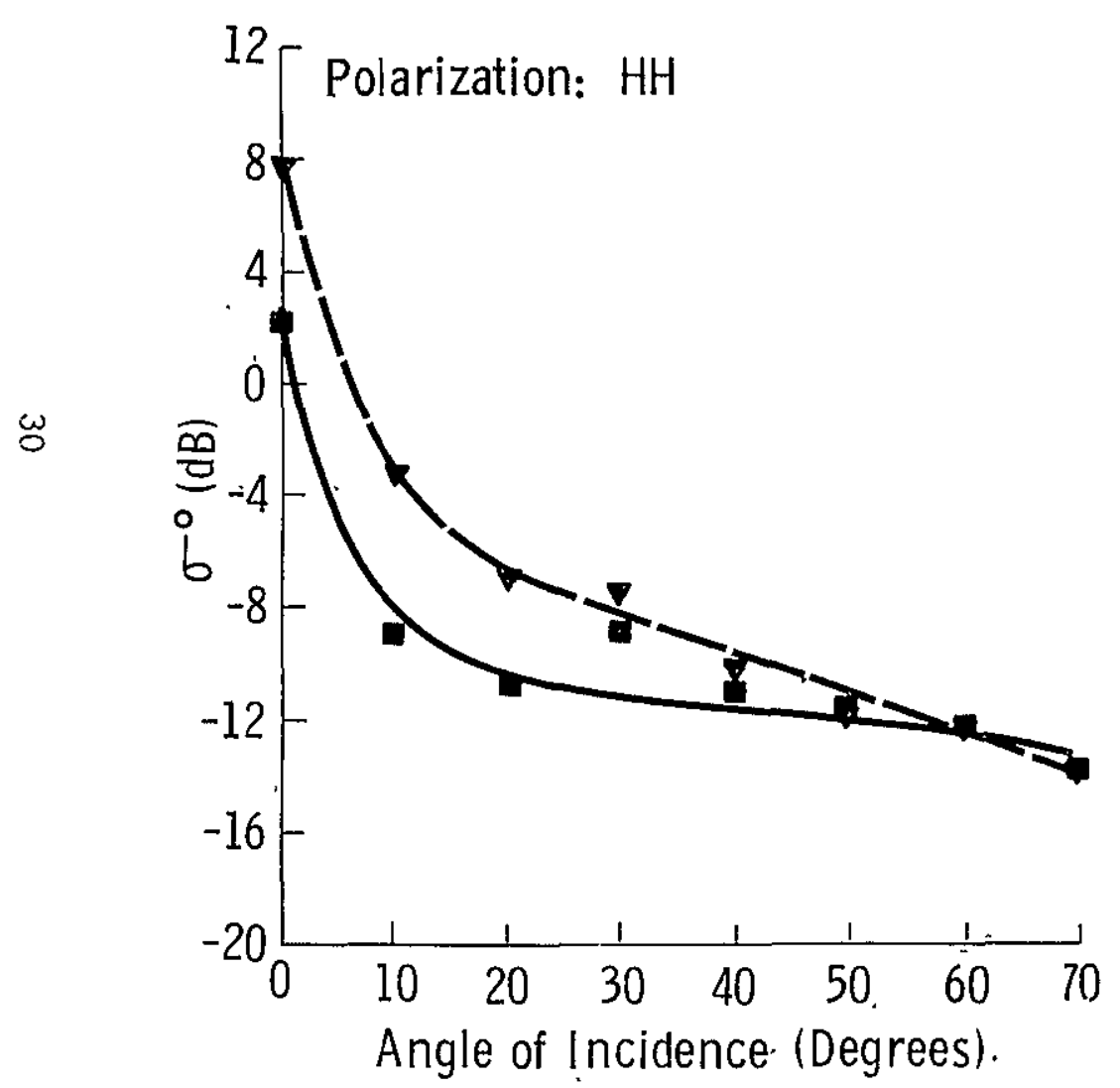

(c)

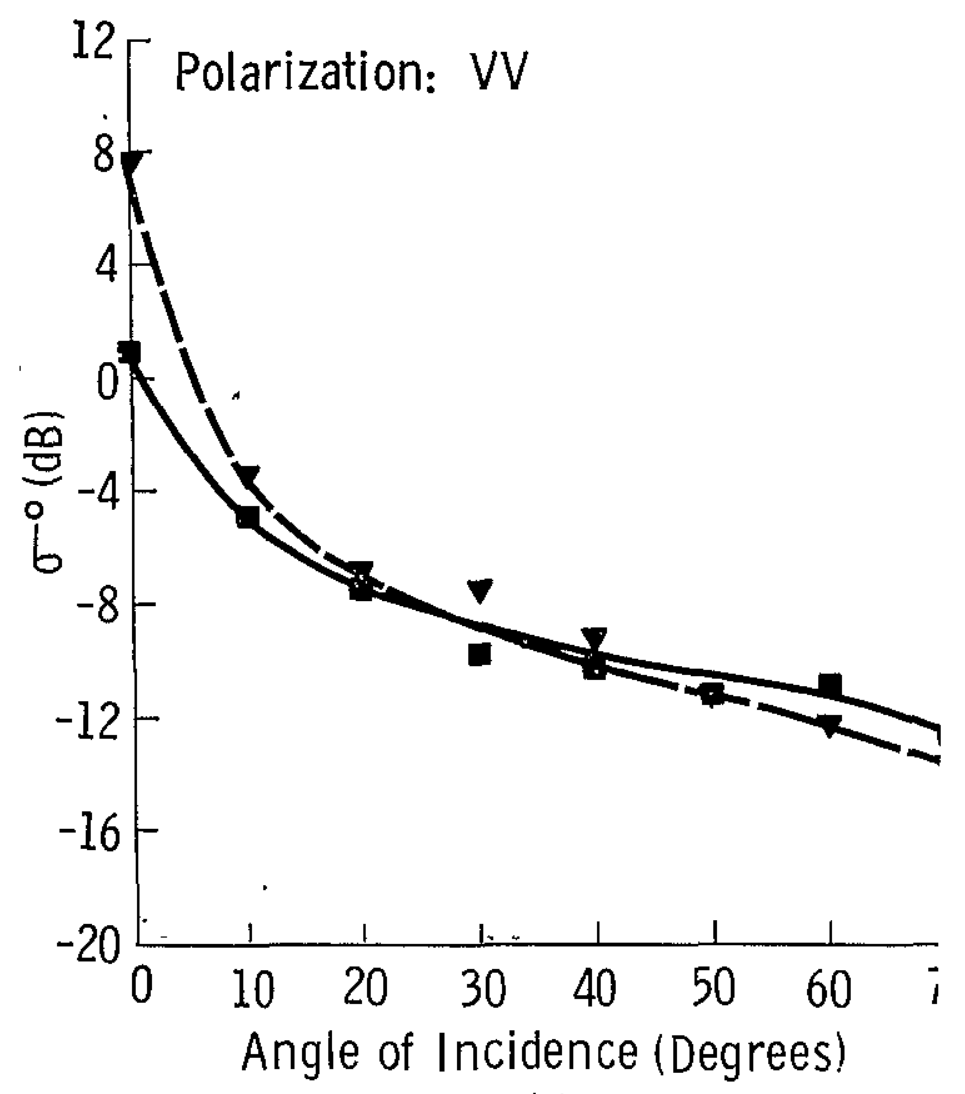

(d) 


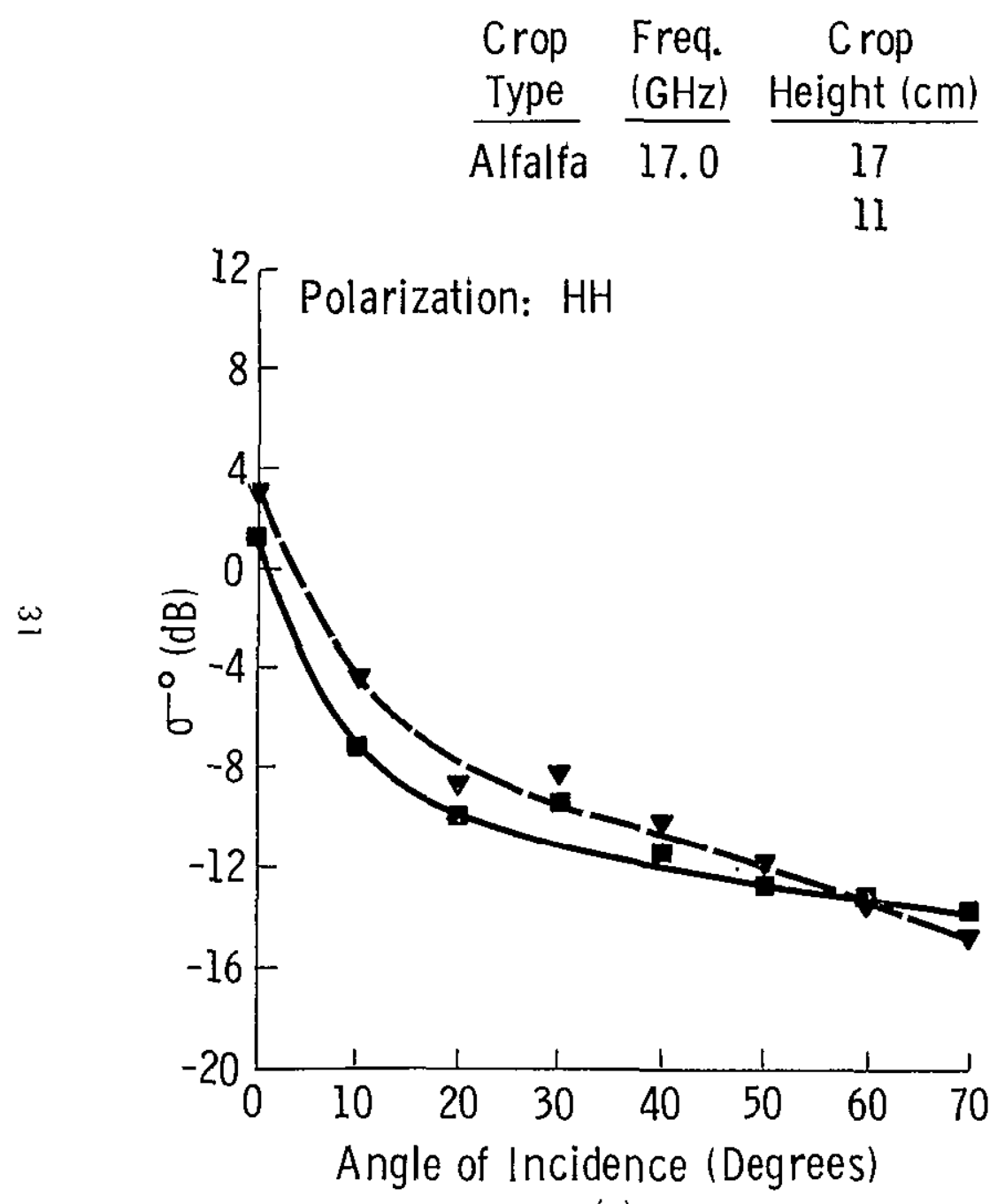

(e)
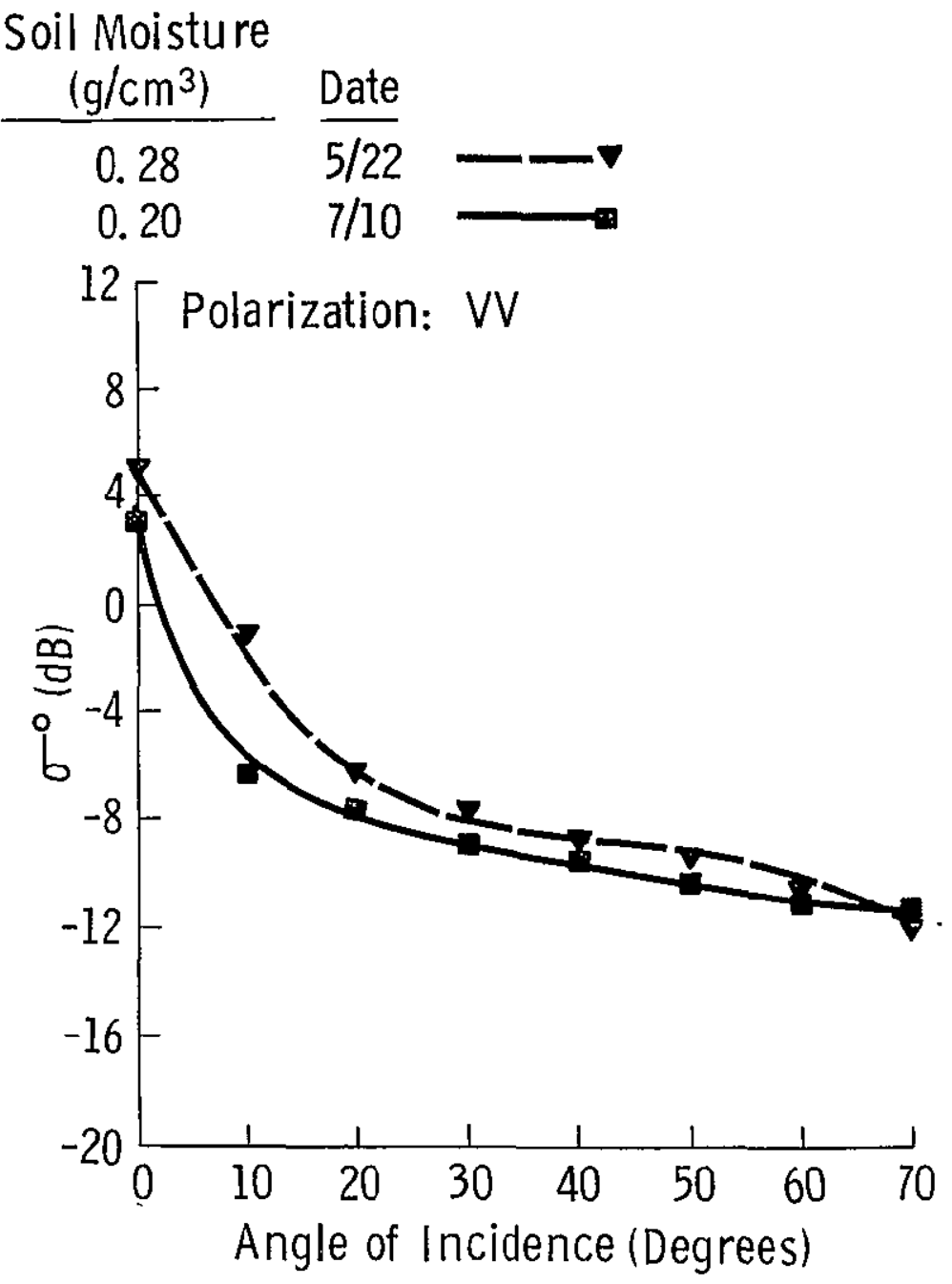

(f) 
of the curves in the $0^{\circ}-10^{\circ}$ region begin to imply a slightly rougher surface than noted at the lower frequencies. Now, at $17.0 \mathrm{GHz}$, we note about an $8 \mathrm{~dB}$ or less decrease in $\sigma^{\circ}$ from $0^{\circ}$ to $10^{\circ}$ as contrasted with a $10 \mathrm{~dB}$ decrease at 8.6 and 13.0 GHz. Also, it appears that the sensitivity of $\sigma^{\circ}$ to variations in soil moisture has been reduced, particularly at nadir.

In Figures 9a-f the angular responses of $\sigma^{\circ}$ for two taller stands of alfalfa have been plotted. Note that while the canopies are comparable in height, the soil moistures are markedly different. In Figures $9 a$ and $9 b, \sigma^{\circ}$ at $8.6 \mathrm{GHz}$ is presented. While both data sets exhibit nearly identical behavior in the $10^{\circ}-70^{\circ}$ region, the effect of soil moisture is still observed at nadir. An interesting aspect of these curves appears in the $40^{\circ}-70^{\circ}$ region; while $\sigma_{\mathrm{H}}{ }^{\circ}$ decreases by about $5 \mathrm{~dB}$ from $40^{\circ}$ to $70^{\circ}$ (Figure $9 a$ ), $\sigma_{V}^{0}$ decreases by only about $3 \mathrm{~dB}$. Next, consider $\cdot \sigma^{\circ}$ at $13.0 \mathrm{GHz}$, Figures $9 c$ and $9 d$. The effect of soil moisture at nadir is smaller than the effect observed at $8.6 \mathrm{GHz}$. This is probably the result of added attenuation resulting from the frequency increase. Between $10^{\circ}$ and $70^{\circ}$, however, the effect of the frequency increase is merely to increase $\sigma^{\circ}$ at all angles without changing the shape of the angular response. At $17.0 \mathrm{GHz}$, Figures $9 e$ and $9 f$, this effect of the frequency increase is apparent, particularly for the horizontally polarized data. Also, whereas at 8.6 and 13.0 $\mathrm{GHz}$ the curves depicting the two different data sets were usually distinguishable at the higher angles, at $17.0 \mathrm{GHz}$ the curves are very nearly coincident with one another for angles higher than $20^{\circ}$.

Finally consider Figures $10 \mathrm{a}-\mathrm{f}$ where $17 \mathrm{~cm}$ alfalfa is compared to a $55 \mathrm{~cm}$ stand of alfalfa. Note that the soil moisture content in both cases are nearly identical. At 8.6 GHz the effect of harvest is again noted to be quite dramatic at nadir. At the higher angles the effect is still apparent although certainly to a much lesser extent. It is inferesting to compare the shapes of these two curves as frequency is increased; between $8.6 \mathrm{GHz}$ and $13.0 \mathrm{GHz}$, for example, a marked change in the shape of the $\sigma^{\circ}$ response of the $55 \mathrm{~cm}$ canopy is observed, particularly for $\sigma_{\mathrm{V}}^{\circ}$. The shape of this curve indicates that the target assumed a rather rough electromagnetic character while the effect on $\sigma_{V}{ }^{\circ}$ for the $17 \mathrm{~cm}$ canopy was relatively minimal. At $17.0 \mathrm{GHz}$ however, both targets assume a rough appearance. While the taller farget continued to appear rough the shorter canopy changed remarkably, in terms of roughness, between 13.0 and $17.0 \mathrm{GHz}$ causing the curves to be quite similar in the $30^{\circ}-70^{\circ}$ region. Similar effects are noted for ${ }^{\circ}{ }_{\mathrm{H}}$ although the response to frequency is not nearly so marked as for $\sigma_{\bar{V}}^{\circ}$. 


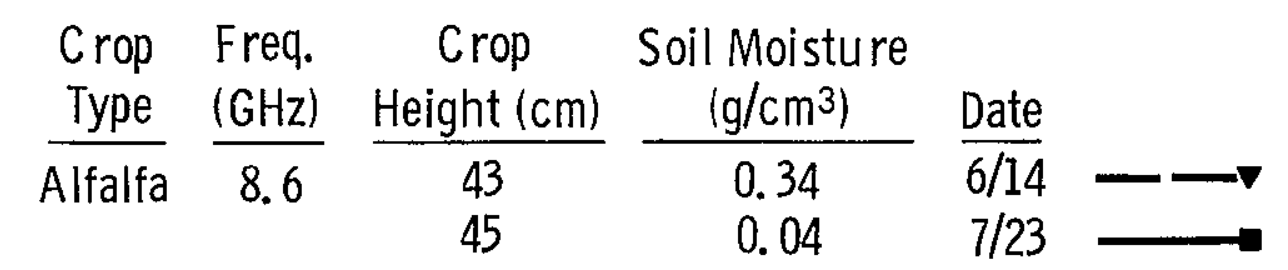

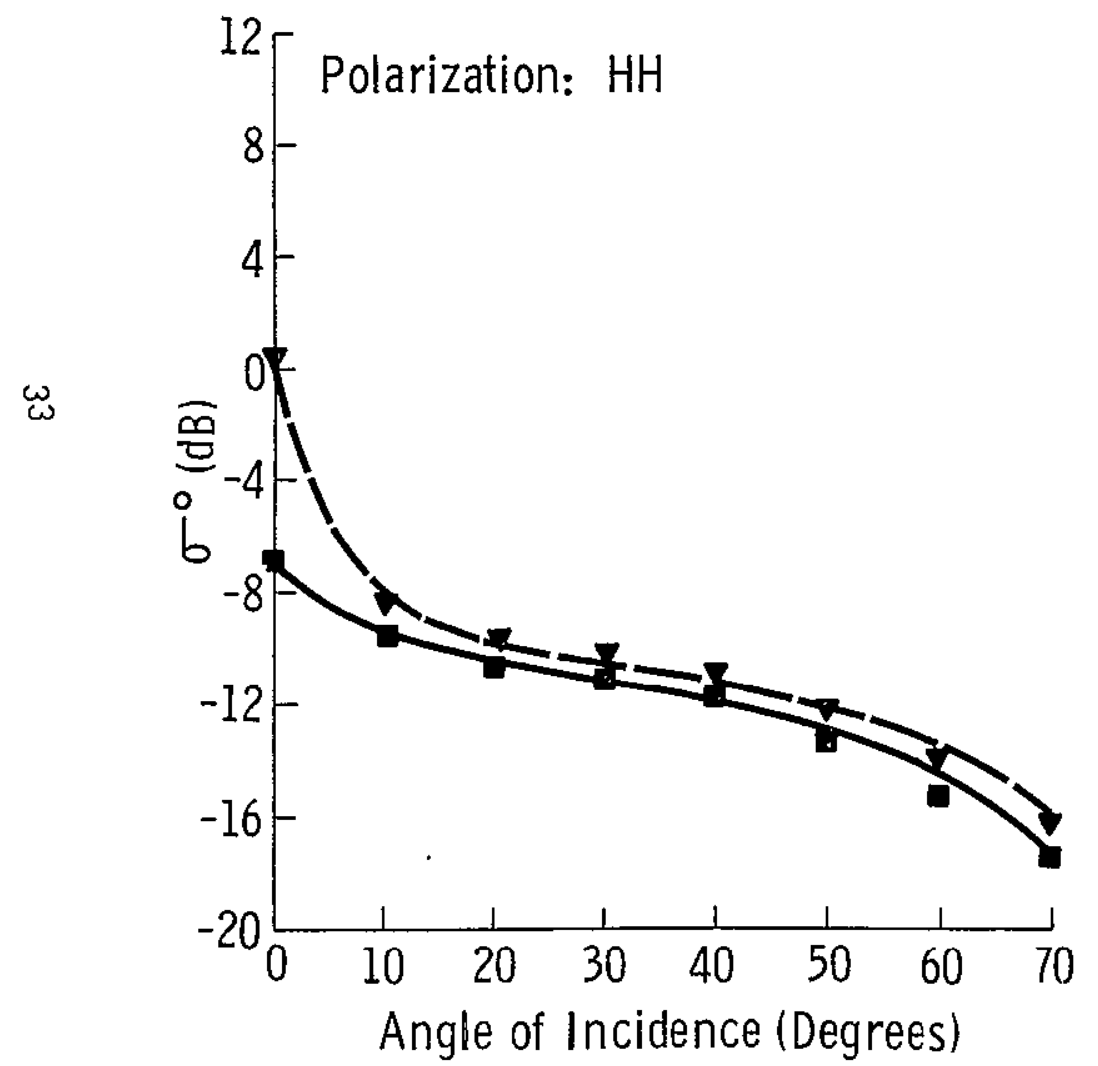

(a)

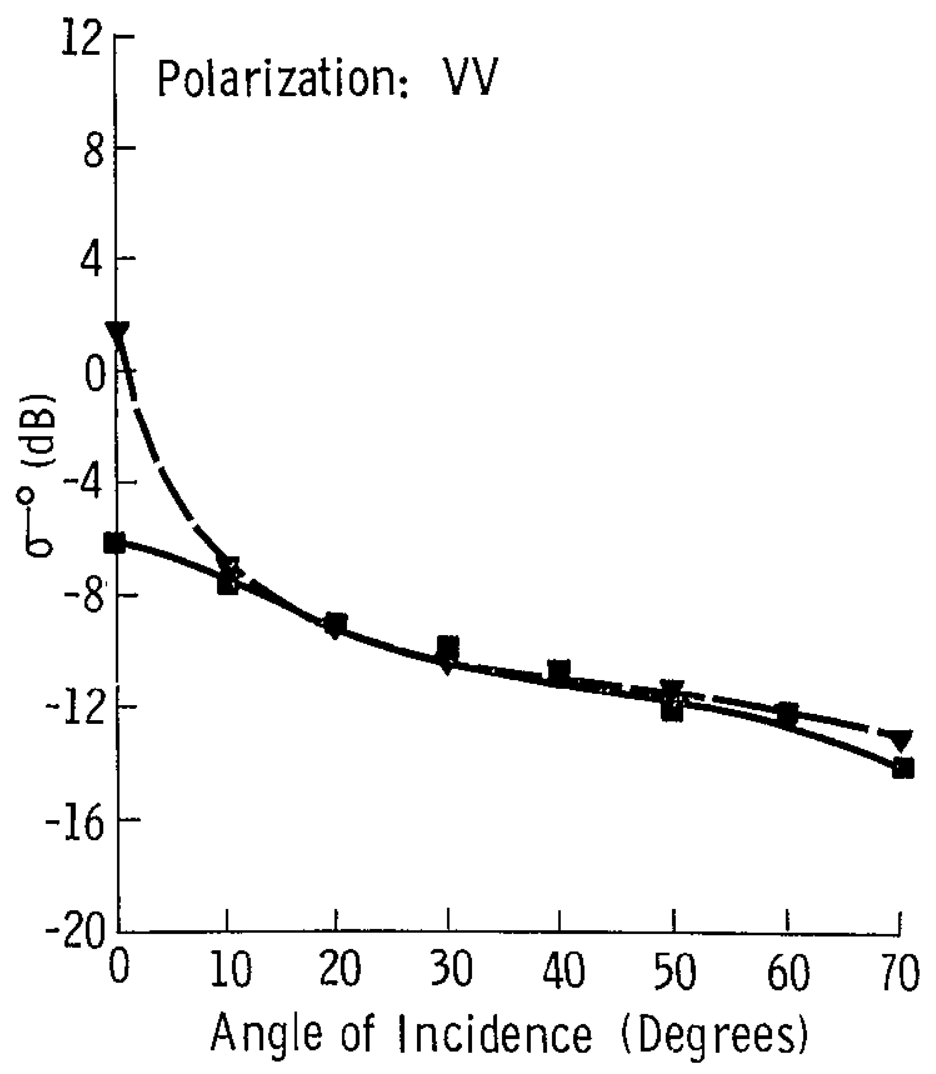

(b)

Figure 9. Angular response of $\sigma^{\circ}$ of two nearly mature stands of alfalfa at $8.6 \mathrm{GHz}\left(\sigma_{H^{\circ}}\right.$ and $\sigma_{\mathrm{v}}^{\circ} ; 9 \mathrm{a}$ and $\left.9 \mathrm{~b}\right), 13.0 \mathrm{GHz}$ $\left(\sigma^{\circ}\right.$ and $\sigma_{v}^{\circ}, 9 \mathrm{c}$ and $\left.9 \mathrm{~d}\right)$, and $17.0 \mathrm{GHz}^{\circ}\left(\sigma_{\mathrm{H}}{ }^{\circ}\right.$ and $\sigma_{\mathrm{v}}^{\circ}, 9 \mathrm{e}$ and $\left.9 \mathrm{f}\right)$. Although the crop heights are practically identical, the measured values of soil moisture are quite different. 


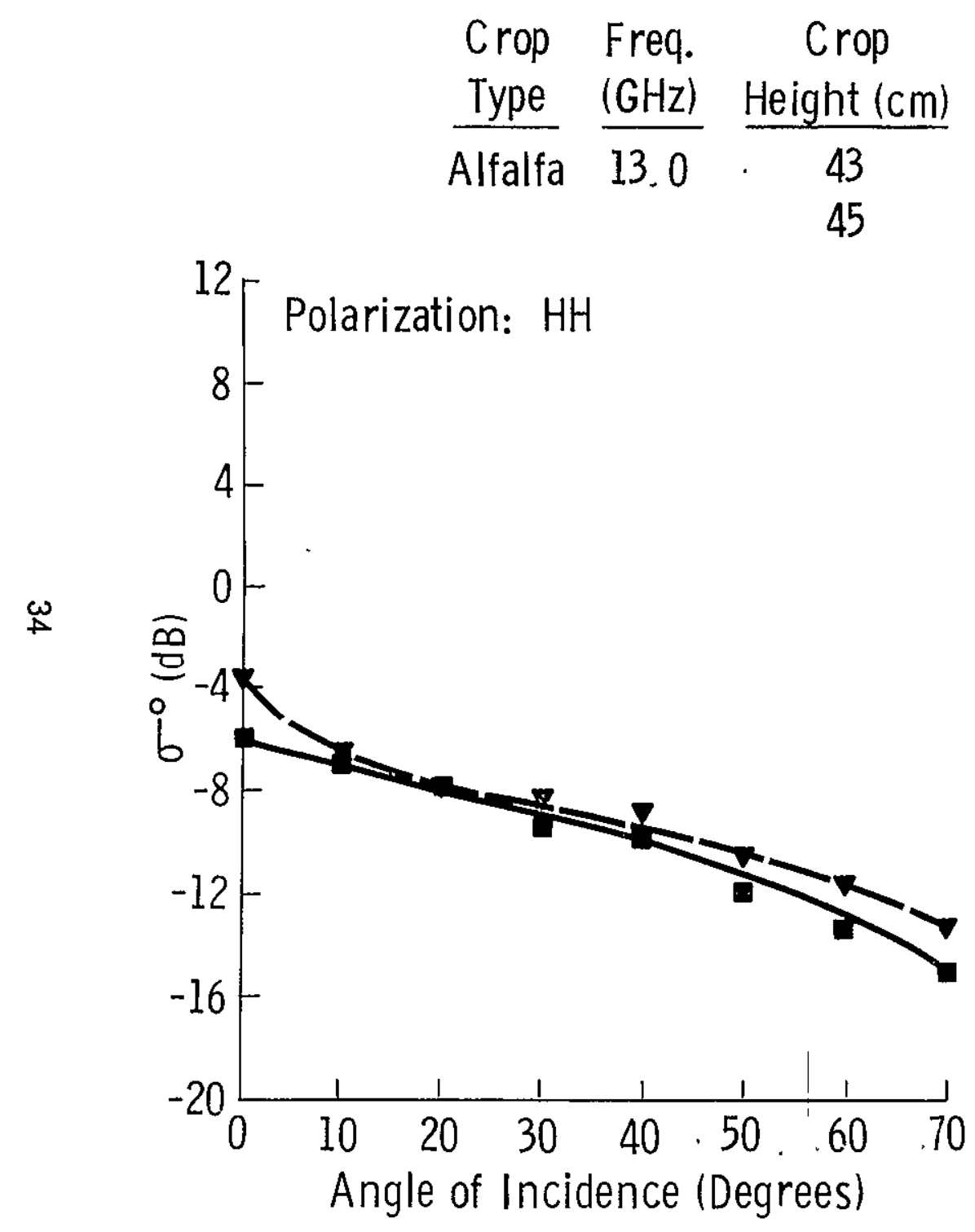

(c)
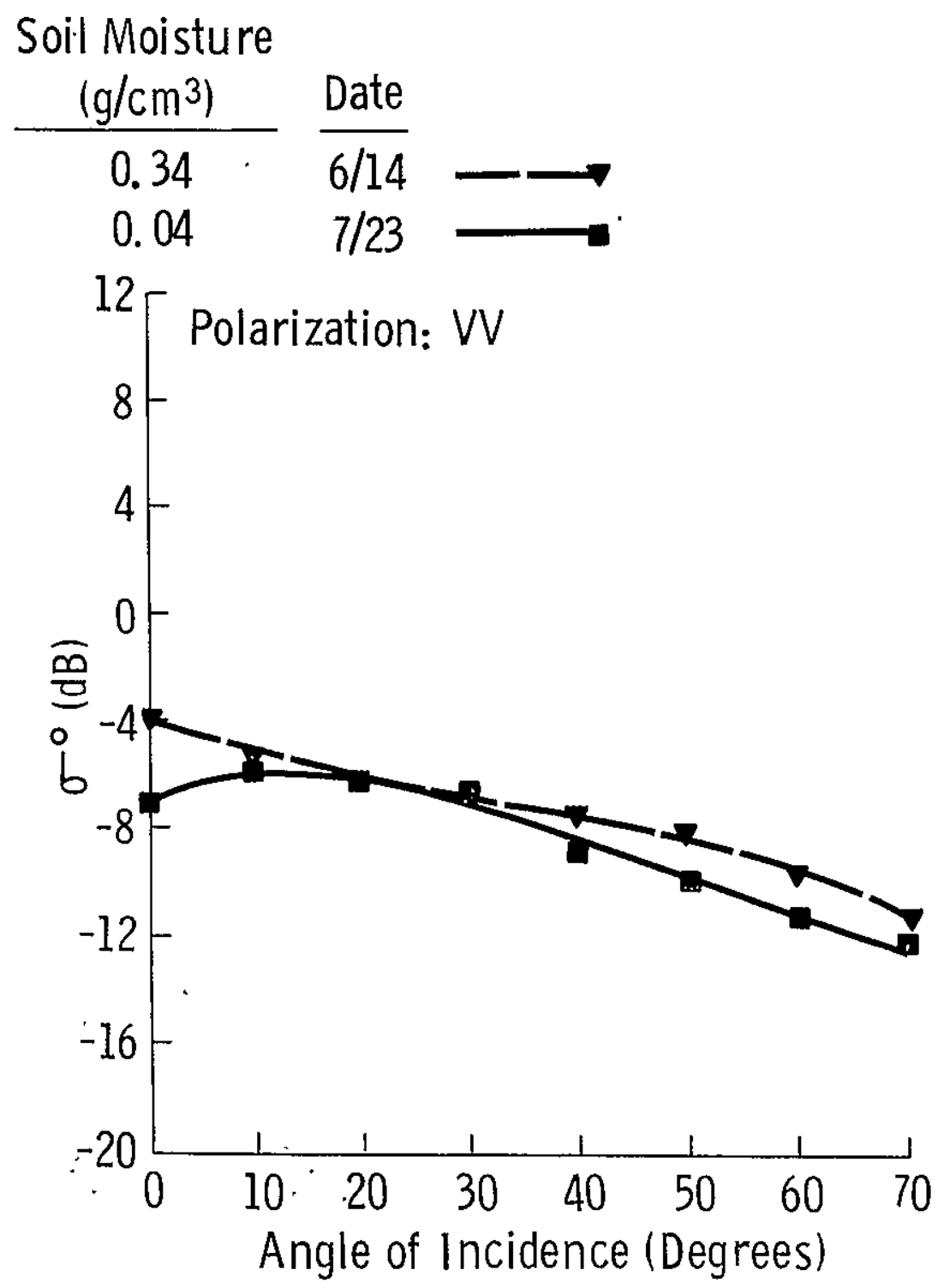

(d) 


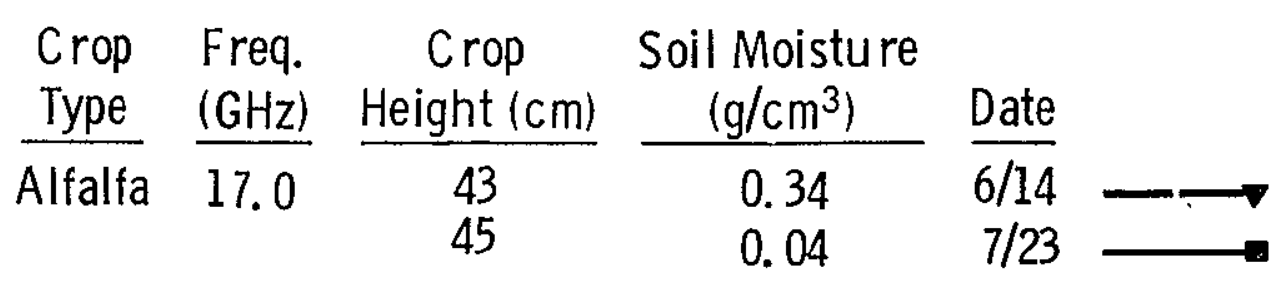

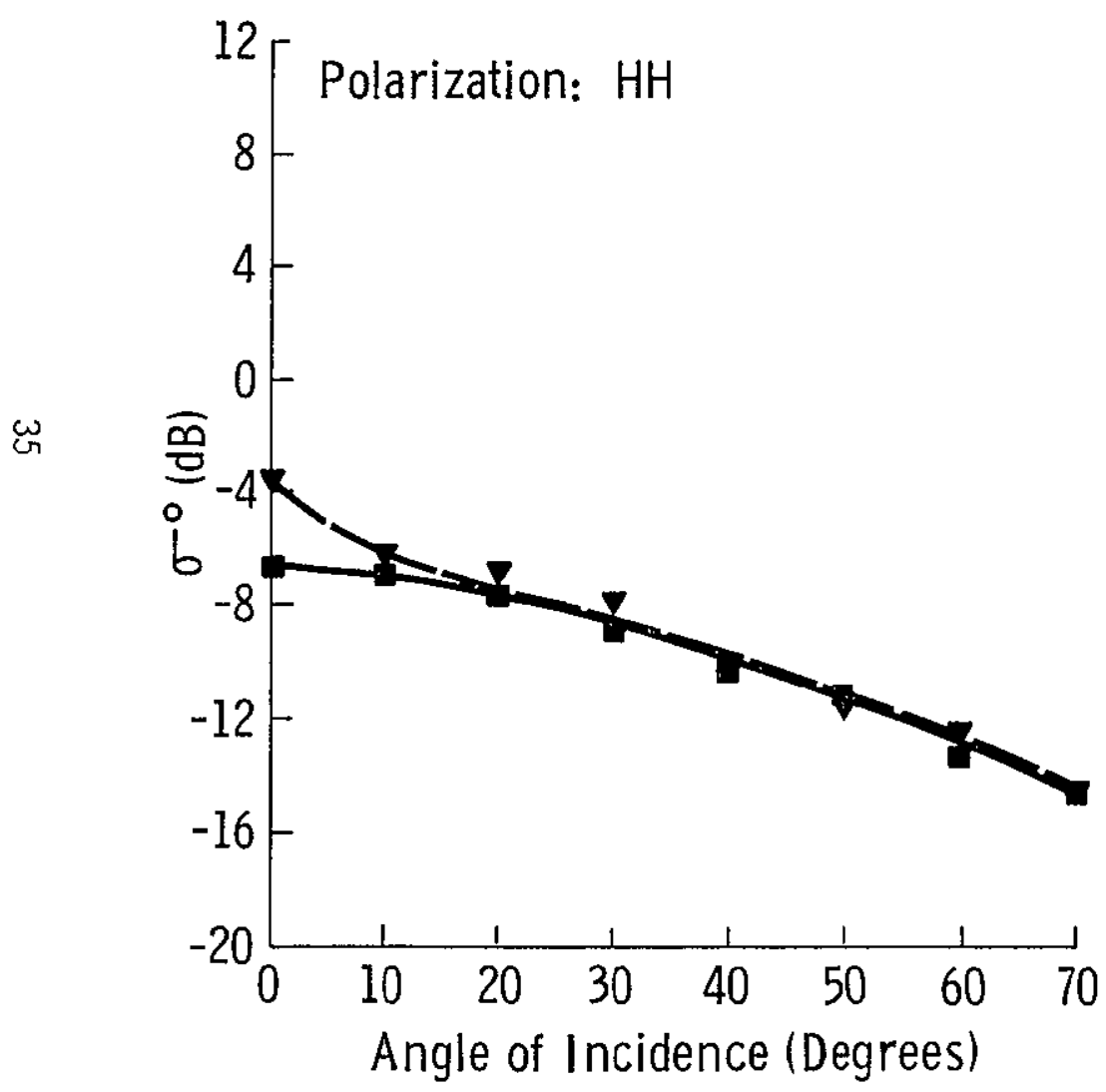

(e)

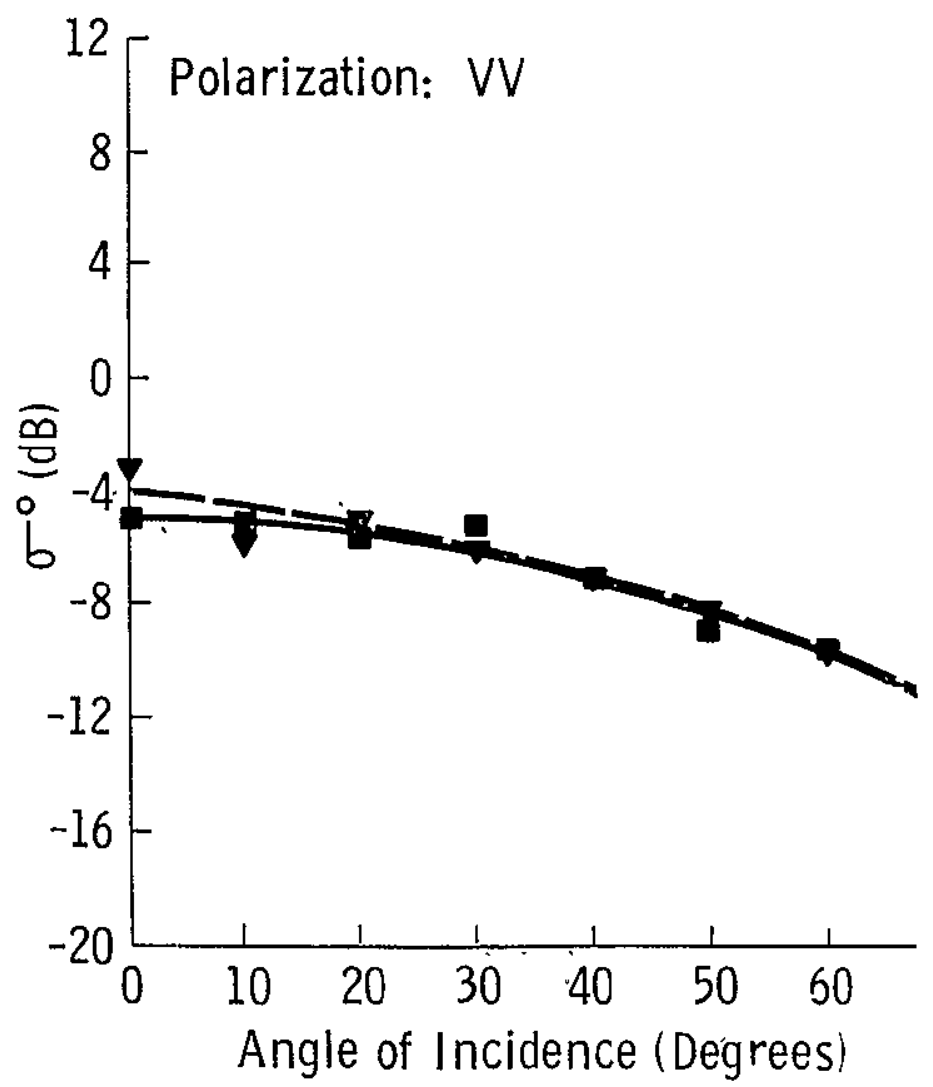

(f) 


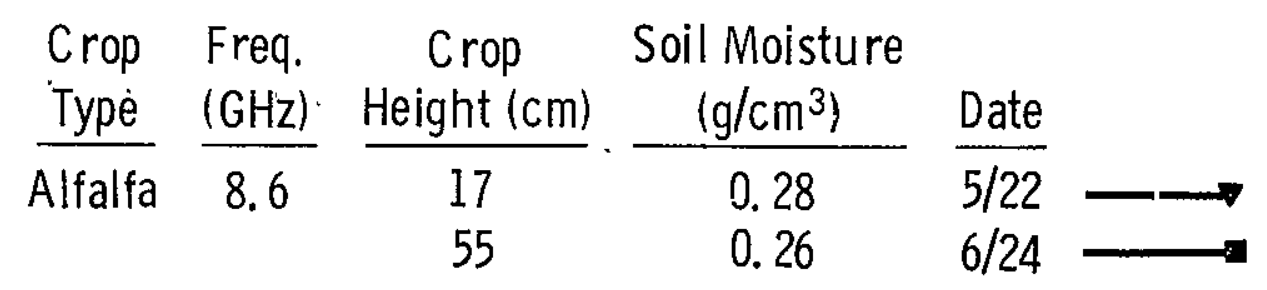

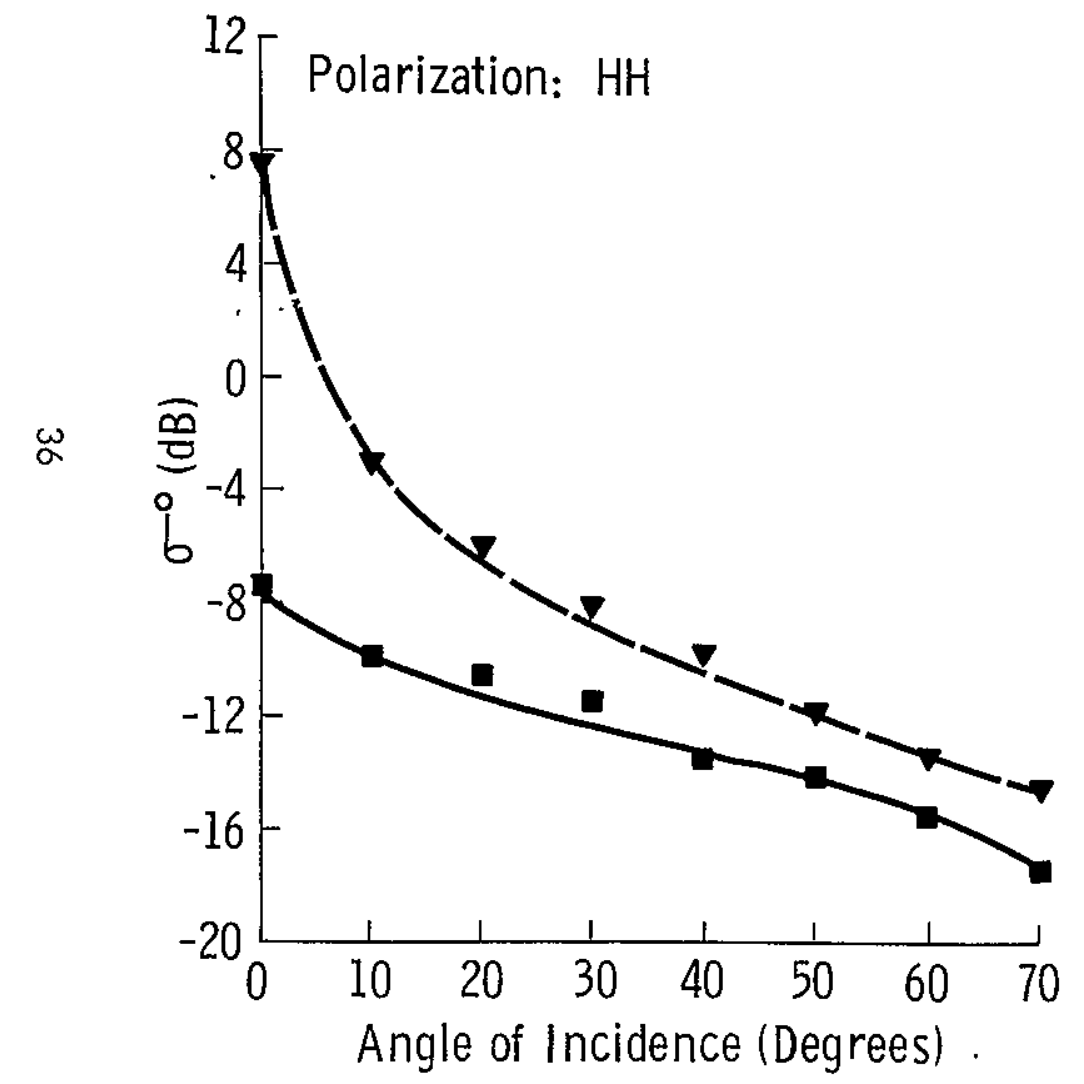

(a)

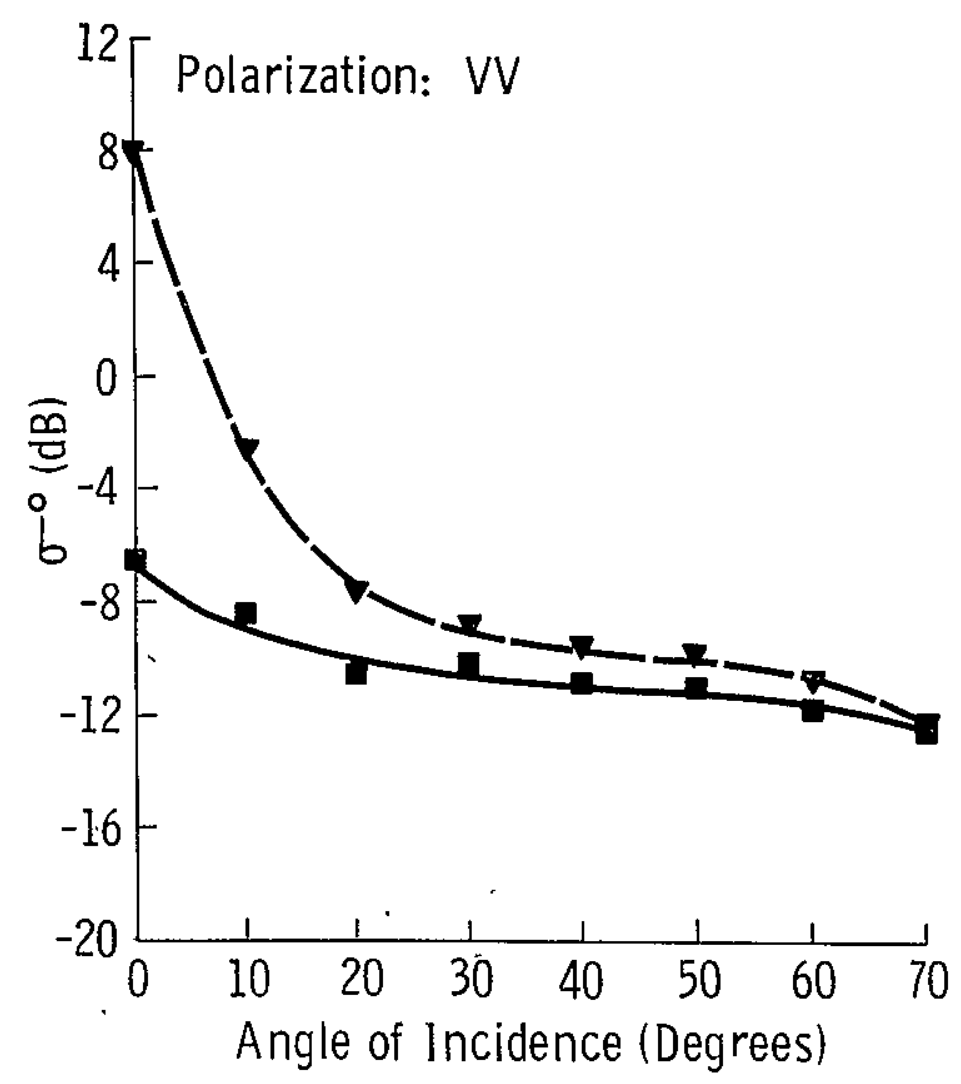

(b)

Figure 10. Angular response of $\sigma^{\circ}$ of harvested and mature alfalfa at $8.6 \mathrm{GHz}\left(\sigma_{H}^{\circ}\right.$ and $\sigma_{\mathrm{V}}^{\circ}, 10 \mathrm{a}$ and $\left.10 \mathrm{~b}\right), 13.0 \mathrm{GHz}$ $\left(\sigma_{\mathrm{H}}^{\circ}\right.$ and $\sigma_{\mathrm{v}}^{\circ}, 10 \mathrm{c}$ and $\left.10 \mathrm{~d}\right)$, and $17.0 \mathrm{GHz}\left(\sigma_{\mathrm{H}}^{\circ}\right.$ and $\sigma_{\mathrm{v}}^{\circ}, 10 \mathrm{e}$ and $\left.10 \mathrm{f}\right)$. Note the soil moistures which are nearly equal. 


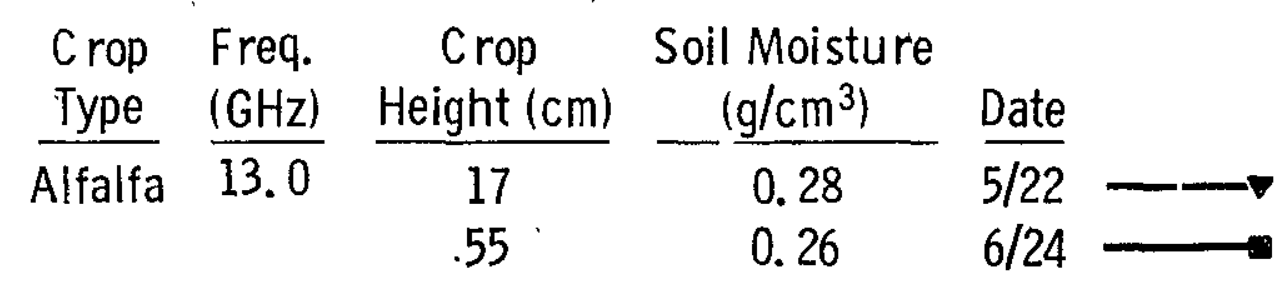

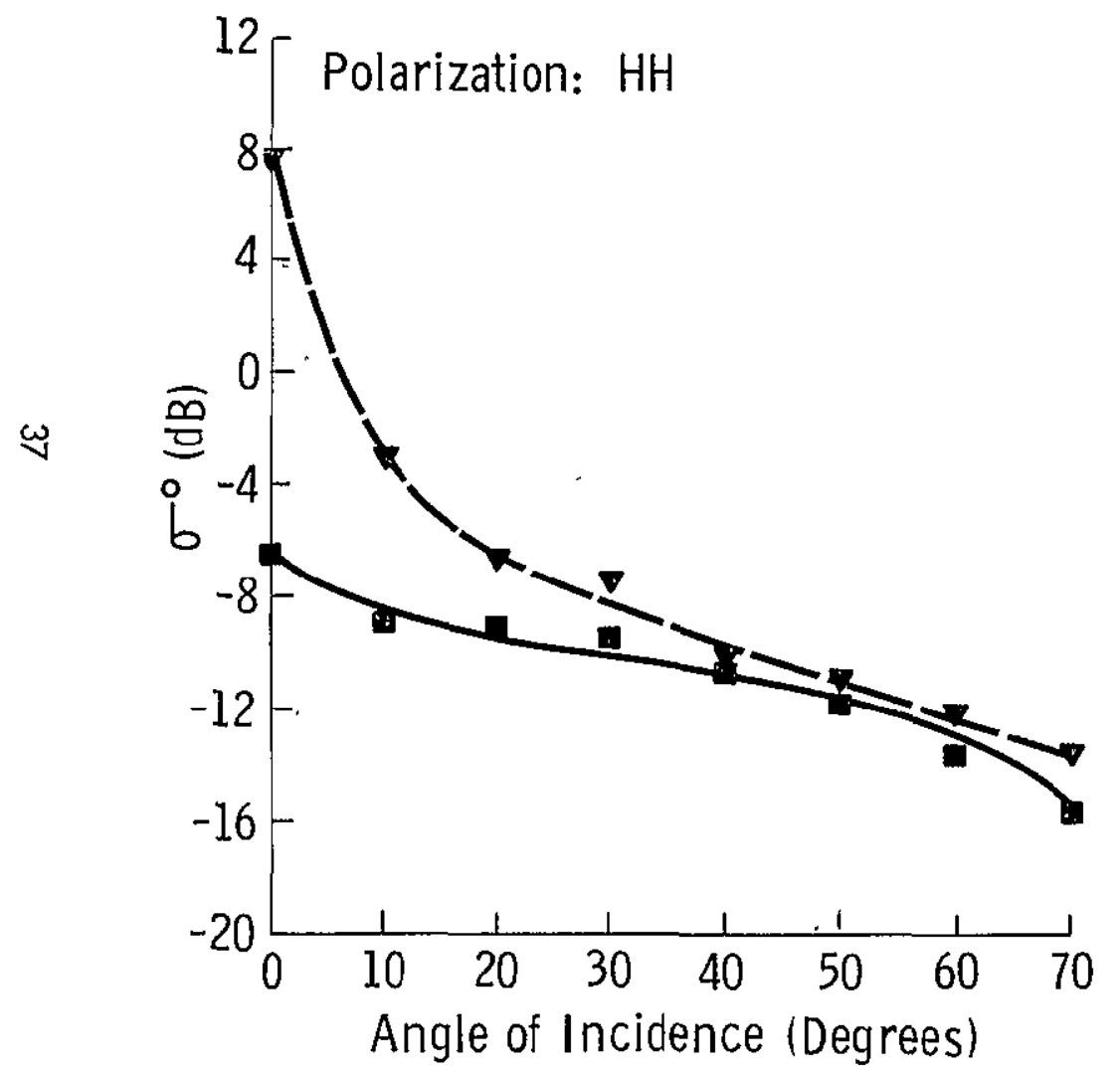

(c)

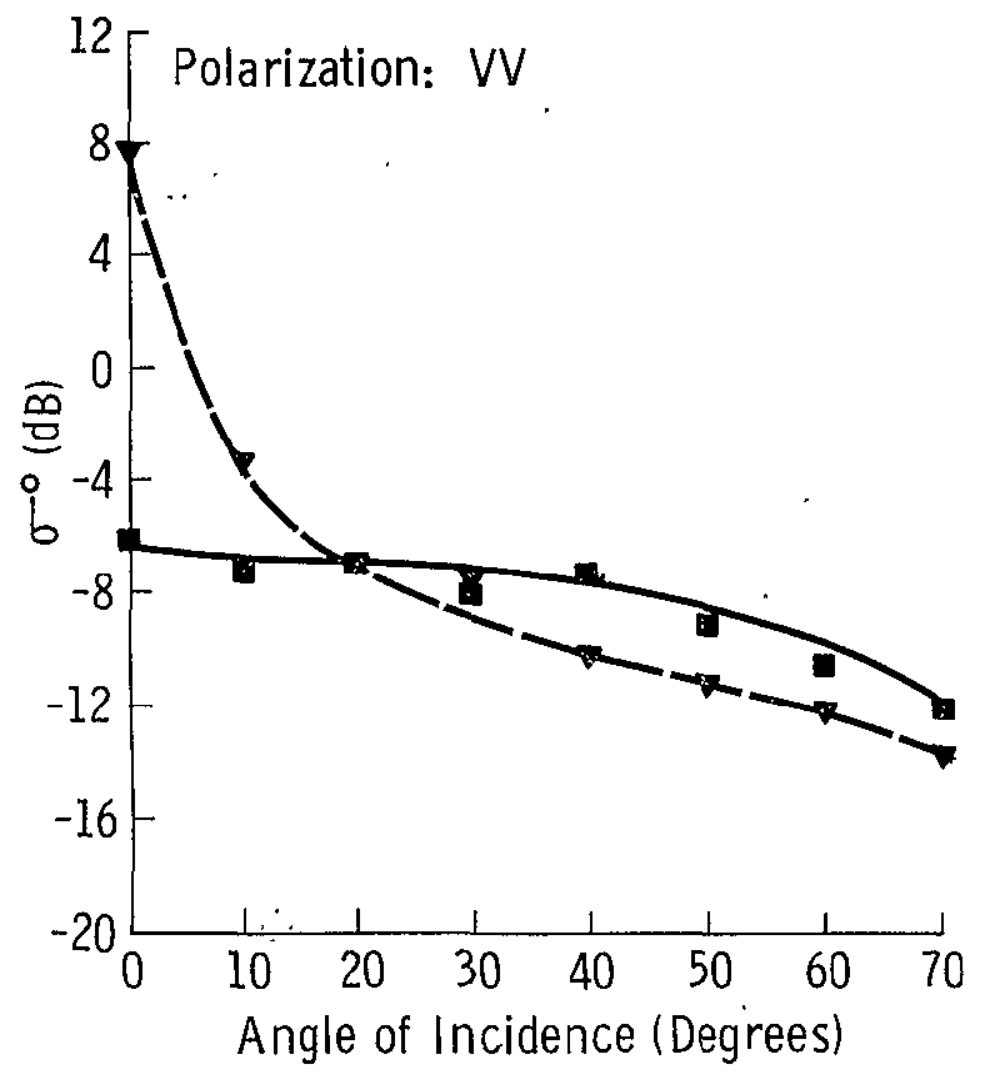

(d) 


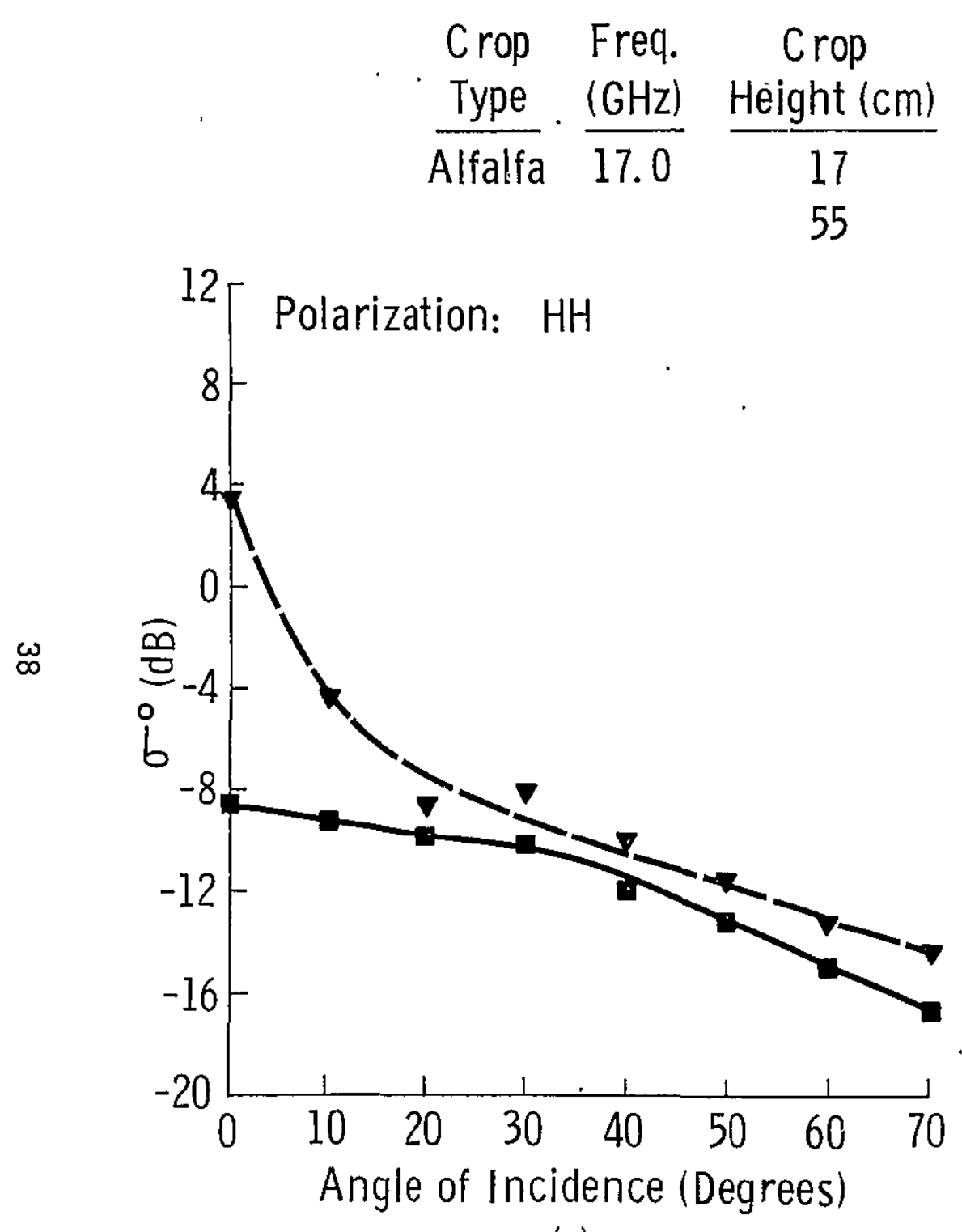

(e)
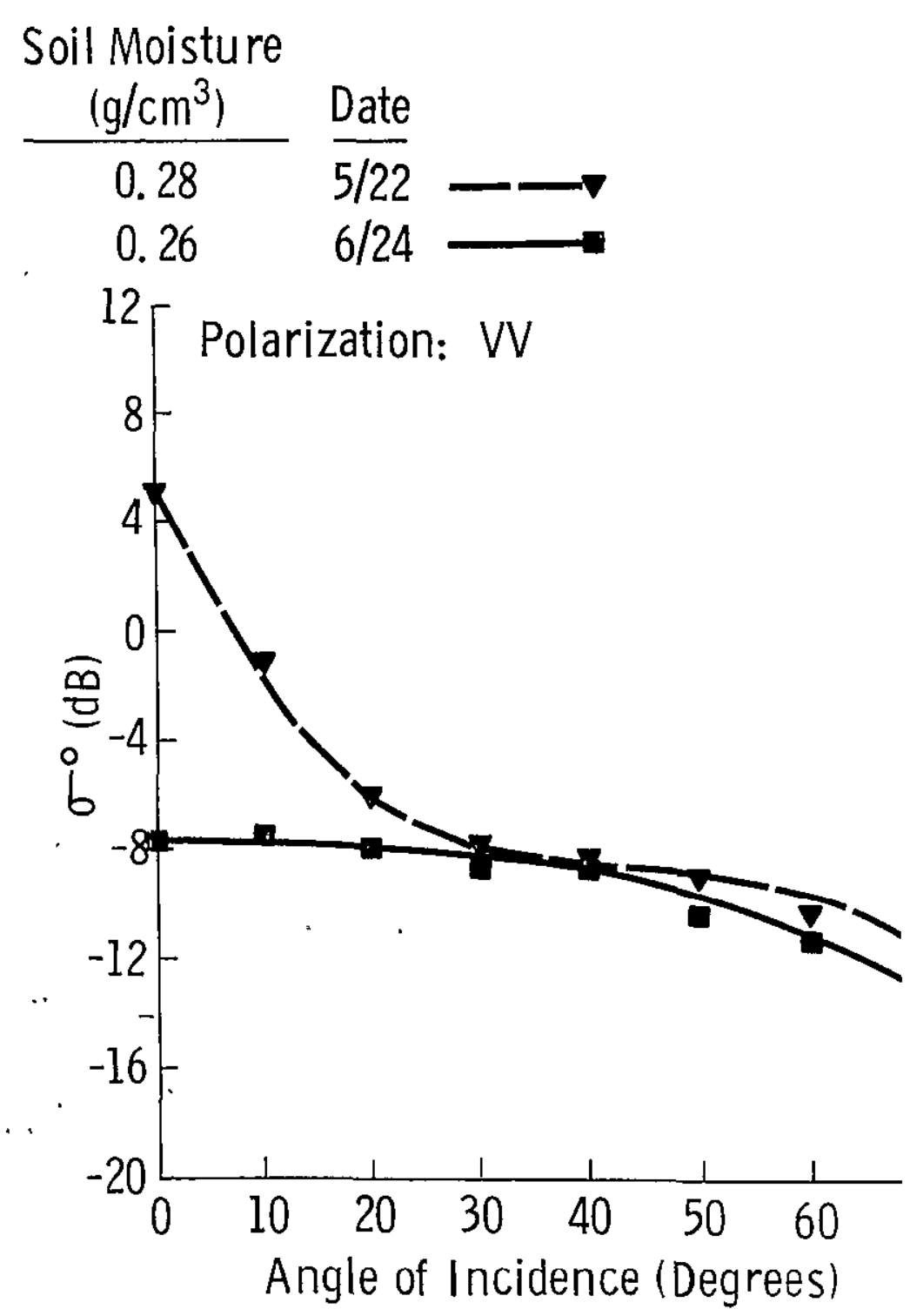

(f) 


\subsection{Spectral Response of $\sigma^{\circ}$}

In this section two data sets have been chosen for discussion. The first was collected on May 22, 1974 when the alfalfa was $17 \mathrm{~cm}$ tall and the soil moisture was $0.28 \mathrm{~g} / \mathrm{cm}^{3}$. The second set was collected when the crop had grown to a height of $43 \mathrm{~cm}$ with a soil moisture content of $0.34 \mathrm{~g} / \mathrm{cm}^{3}$.

Figures 1 la and $1 \mathrm{Ib}$ present data collected at nadir. The abscissa presents the frequency in $\mathrm{GHz}$ while the ordinate presents $\sigma^{\circ}$ in $\mathrm{dB}$. While both data sets show a frend for $\sigma^{\circ}$ to decrease with frequency, Figure $1 \mathrm{lb}$, presenting $\sigma^{\circ}$ for the taller crop, seems to remain rather constant at frequencies above $11.8 \mathrm{GHz}$. This is not the case for $\sigma^{\circ}$ representing the shorter stand of alfalfa which may be attributed to differer in roughness. As frequency is increased for the shor crop, the underlying soil will becol progressively rougher in an electromagnetic sense. This increase in roughness would result in a decrease in the amount of energy backscattered. The taller target, however, will probably look relatively rough even at $8.6 \mathrm{GHz}$. As frequency increases the talle stand of alfalfa will look rougher until it approaches a Lambertian surface, at which point an increase in frequency will have a rather small effect.

For completeness Figures $11 \mathrm{c}-\mathrm{h}$ present spectral data at $30^{\circ}, 50^{\circ}$ and $70^{\circ}$. While these data show a dependency on frequency it is difficult to relate these dependencies to the target characteristics. It should be noted however, that at angles of $30^{\circ}, 50^{\circ}$ and $70^{\circ}, \sigma^{\circ}$ for the $43 \mathrm{~cm}$ canopy shows an increasing trend while $\sigma^{\circ}$ for the $17 \mathrm{~cm}$ canopy shows relatively little tendency to increase.

\subsection{CONCLUDING REMARKS}

Experimental measurements of the backscattering cœefficient $\sigma^{\circ}$ of alfalfa in the $8-18 \mathrm{GHz}$ frequency range indicate that at nadir $\sigma^{\circ}$ responds to variations in plant height and soil moisture content. For tall stands of alfalfa, attenuation by the vegetation masks the effect of soil moisture variations, while for short stands, the majority of the return is contributed by the soil. A semi-empirical semitheoretical backscatter model was developed for a continuous vegetation canopy in terms of measurable target parameters (plant height, plant moisture content and soil moisture content). Attempts to fit the developed expression to the measured data 


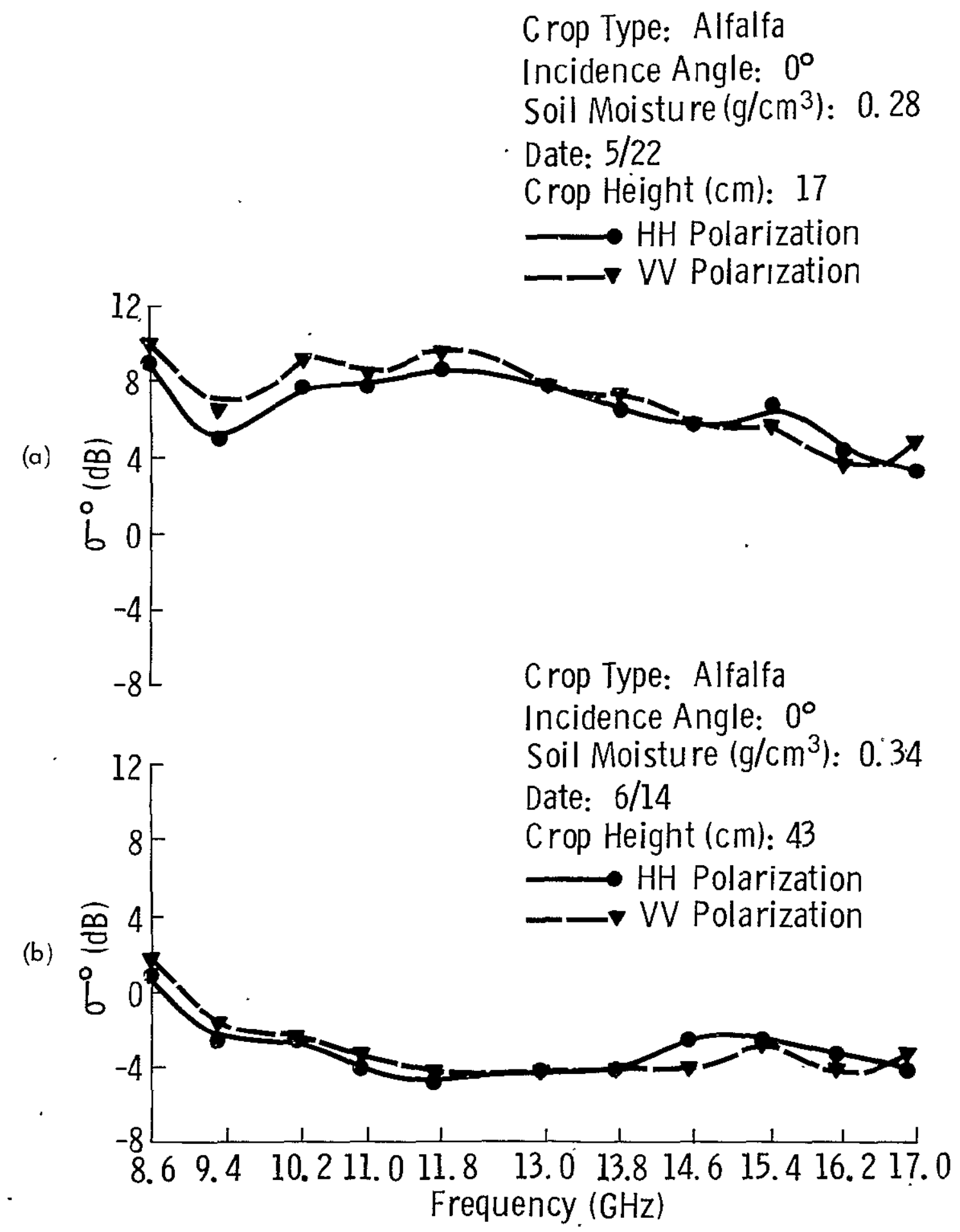

Figure 11. Spectral response of $\sigma_{H}^{\circ}$ and $\sigma_{V}^{\circ}$ for two stands of alfalfa at different growth stages at $0^{\circ}(a$ and $b), 30^{\circ}(c$ and $d), 50^{\circ}(e$ and $f)$, and $70^{\circ}$ (g and $h$ ). 


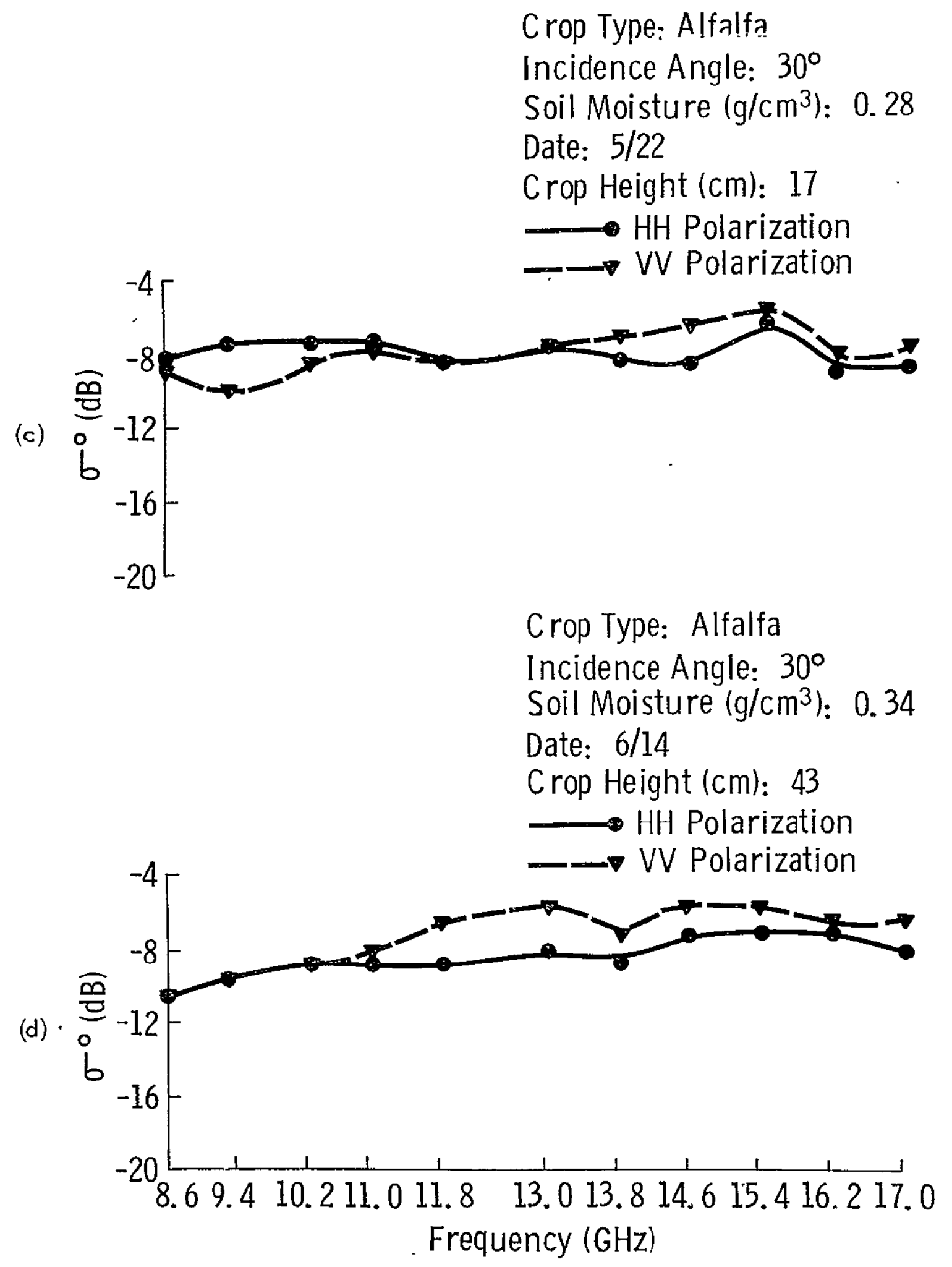


Crop Type: Alfalfa

Incidence Angle: $50^{\circ}$

Soil Moisture $\left(\mathrm{g} / \mathrm{cm}^{3}\right): 0.28$

Date: 5/22

Crop Height (cm): 17

(e)

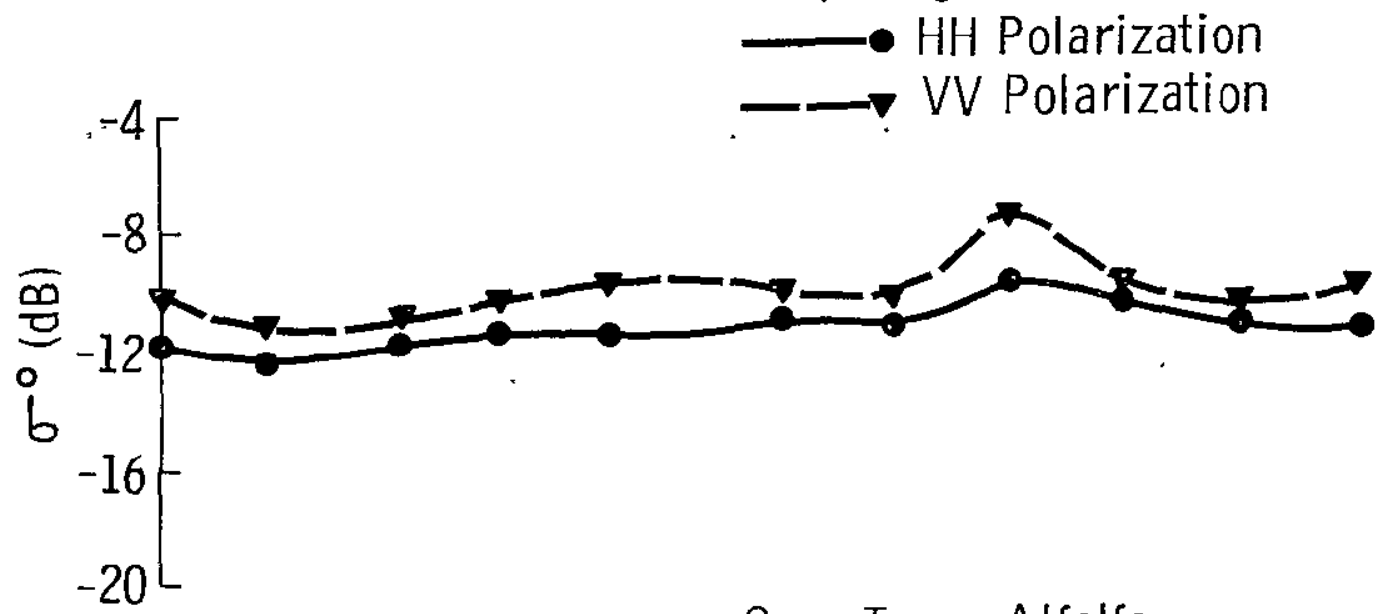

Crop Type: Alfalfa

Incidence Angle: $50^{\circ}$

Soil Moisture $\left(\mathrm{g} / \mathrm{cm}^{3}\right)$ : 0.34

Date: 6/14

Crop Height $(\mathrm{cm}): 43$

$\longrightarrow$ HH Polarization

(f)

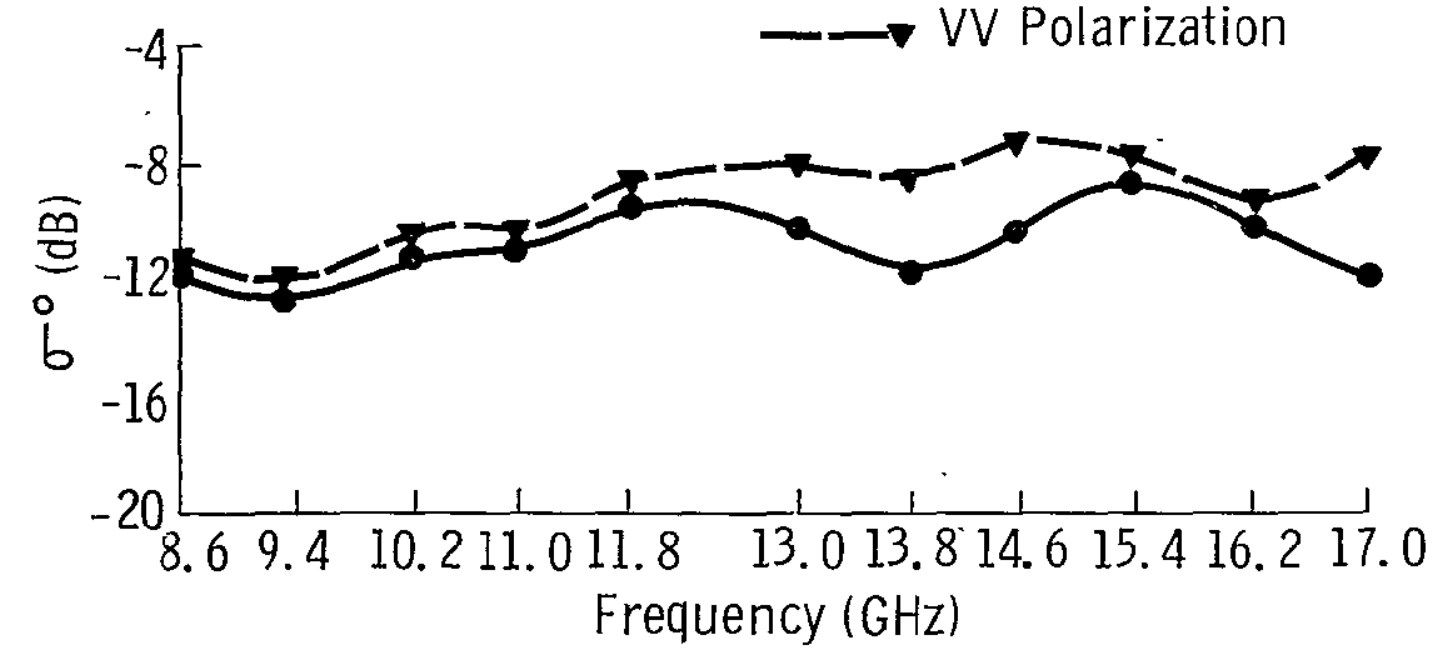



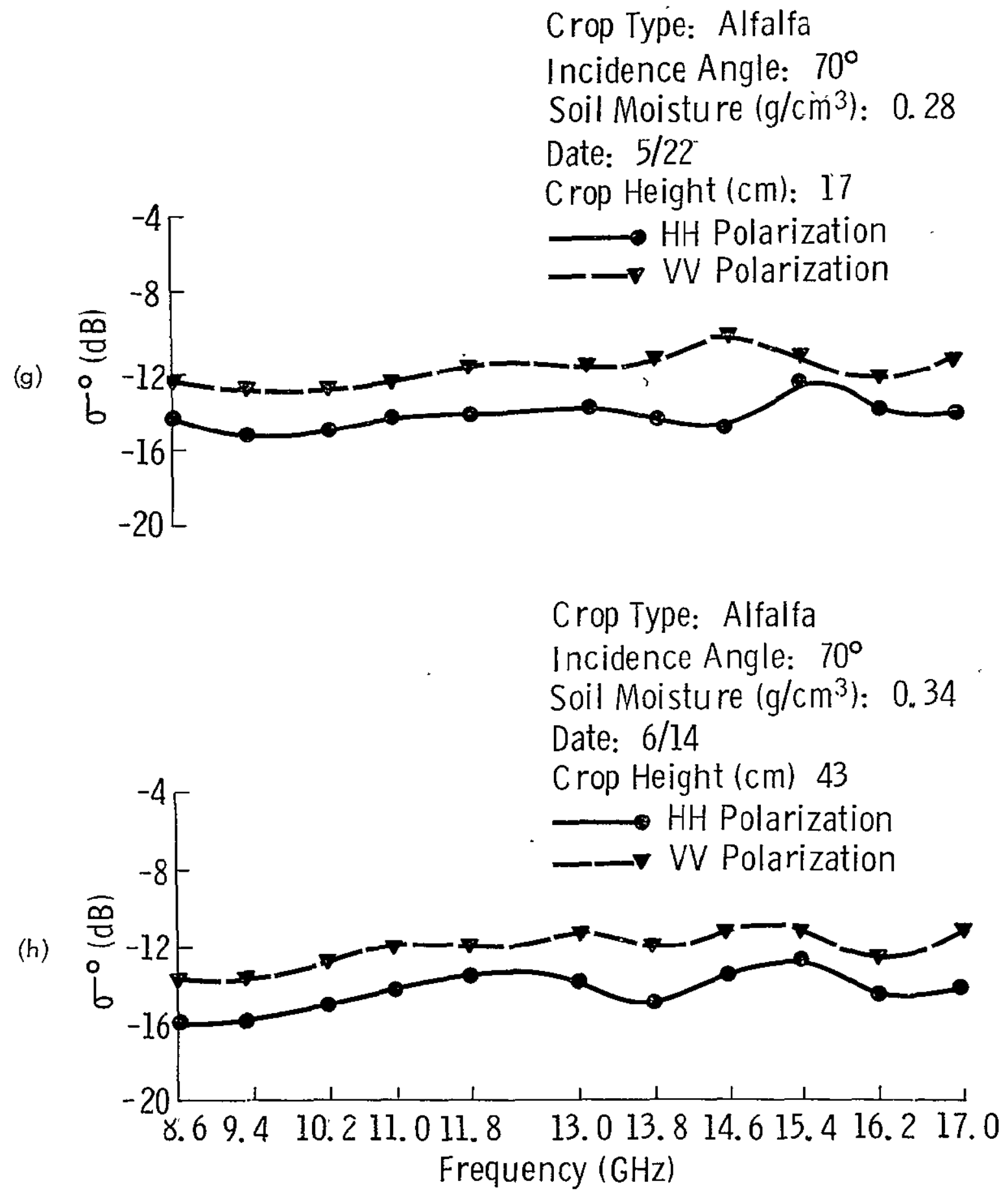
yielded very satisfactory results at nadir. At angles of incidence away from nadir, however, the temporal variations of $\sigma^{\circ}$ did not show a consistent response to any one of the measurable target parameters.

The promising aspect of this study and others $[10,11]$ is that the response of $\sigma^{\circ}$, near nadir, to variations in the height of alfalfa appears to be rather consistent. It is this sort of consistency that is needed for studying the various agricultural targets of interest on an operational bạsis. 


\section{REFERENCES}

[1] Bush, T.F. and F. T. Ulaby, "8-18 GHz Radar Spectrometer," RSL. Technical Report 177-43, University of Kansas Center for Research, Inc., Lawrence, Kansas, September, 1973.

[2] Bush, T. F. and F. T. Ulaby, "Fading Characteristics of Panchromatic Radar Backscatter from Selected Agricultural Targets," IEEE Transactions on Geoscience Electronics, vol. GE-14, October, 1975.

[3] Cihlar, J., "Ground"Data Acquisition Procedure for Microwave (MAPS) Measurements," RSL Technical Memorandum 177-42, University of Kansas Center for Research, Inc., Lawrence, Kansas, July, 1973.

[4] Cihlar, J. and F. T. Ulaby, "Dielectric Properties of Soils as a Function of Moisture Content," RSL Technical Report 177-47, University of Kansas Center for Research, Inc., Lawrence, Kansas, November, 1974.

[5] Carlson, N. L., "Dielectric Constant of Vegetation at $8.5 \mathrm{GHz}$," Ohio State University, Electro Science Lab. Lech. Report 1903-5, 1967.

[6] Ulaby, F..T., J. Cihlar and R. K. Moore, "Active Microwave Measurement of Soil Water Content," Remote Sensing of Environment, vol . 3, pp. 185-203, January, 1974.

[7] Lane, J. A. and J. A. Saxton, "Dielectric Dispersion in Pure Polar Liquids at Very High Radio-Frequencies. 1. Measurements on Water, Methyl and Ethyl Alcohols," Proc. Roy. Soc. London, vol. 214, pp. 531-545, 1951.

[8] Peake, William H., "Interaction of Electromagnetic Waves with Some Natural Surfaces," IRE Trans. on Antennas and Propagation, pp. S324-S329, December, 1959 .

[9] Ulaby, F. T., "Radar Response to Vegetation," IEEE Transactions on Antennas and Propagation, vol. AP-23, no. 1, January, 1975.

[10] de Loor, G. P., "Measurement of Radar Ground Returns," Proc. URSI Specialist Meeting on Emission and Scattering from the Earth, Bern, Switzerland, September, 1974.

[11] Cosgriff, R. L., W. H. Peake and R. C. Taylor, "Terrain Scattering Properties of Sensor System Design," Terrain Handbook II, Engr. Expt. Sta., Ohio State University Bull. 181, May, 1960. 
APPENDIX A: Ground Truth Summary for 1974 Alfalfa

Scattering Experiment

Alfalfa Ground Truth 1974

\begin{tabular}{|c|c|c|c|c|c|}
\hline Date & $N$ & loisture & $\mathrm{F}$ & $\begin{array}{l}\text { Fractional } \\
\text { Plant } \\
\text { Moisture }\end{array}$ & $\begin{array}{l}\text { Plant } \\
\text { Height }(\mathrm{cm})\end{array}$ \\
\hline May 22 & 0.27 & 0.28 & 0.28 & 0.68 & 17 \\
\hline June 14 & 0.36 & 0.34 & 0.33 & 0.85 & 43 \\
\hline June 24 & 0.26 & 0.26 & 0.23 & 0.78 & 55 \\
\hline June 28 & 0.15 & 0.20 & 0.17 & 0.79 & 55 \\
\hline July 5 & 0.32 & 0.30 & 0.30 & 0.76 & 55 \\
\hline July 10 & 0.14 & 0.20 & 0.15 & 0.60 & 11 \\
\hline July 17 & 0.05 & 0.02 & 0.02 & 0.79 & 29 \\
\hline July 23 & 0.03 & 0.04 & 0.03 & 0.80 & 45 \\
\hline August 13 & 0.21 & 0.14 & 0.16 & 0.77 & 73 \\
\hline \multicolumn{6}{|c|}{$N=$ near range sample } \\
\hline \multicolumn{6}{|c|}{$M=$ medium range sample } \\
\hline$F=f a r$ & ample & & & & \\
\hline
\end{tabular}


APPENDIX B: Alfalfa Scattering Coefficients, 1974. 
ANTENENA ANGLE 0

FREQ

POL HH

POL VV
B.6 9.4

7.1

$7.1 \quad 5.3$

10.2

7.7
7.9

9.2
11.0

7.6

8.6
$11.813 . !$

$8 \cdot 6$

9.5

\section{$7.7 \quad 6.5$}

$7 \cdot 7$

$7 \cdot 1$
14.6

5.8

6.4
15.

$6.4 \quad 4.1 \quad 3.1$

$\begin{array}{lll}5.7 & 3.3 & 4.5\end{array}$

ANTENNA ANGLE 10

FREQ

$$
8.6 \quad 9.4
$$

10.211 .0

$11.8 \quad 13.8$

13.8

$14 \cdot 6$

15.

16.217 .0

FOL HH

POL VV

$$
-3 \cdot 1 \quad-5 \cdot 3
$$

$-3.8$

$-4.3$

$-1 .: 1$

$-2.8-3.3$

$-2.8$

ANTENNA ANGLE 20

FREQ

8.69 .4

10.211 .0

$11.813 .:$

13.8

14.6

$15.4 \quad 15.2 \quad 17.5$

FOL HH

$$
-6 \cdot 1 \quad-5 \cdot 8 \quad-6 \cdot 1
$$

$-5.6$

$-4.2 \quad-6.9$

$-6.6$

$-5.3$

$\begin{array}{lll}-5.2 & -8.1 & -8.6\end{array}$

POL VV

$$
-7.9-7.5
$$

$-6 \cdot 1$

$-5.9$

$-3.8$

$-5.6$

$-5 \cdot 1$

ANTENNA ANGLE 30

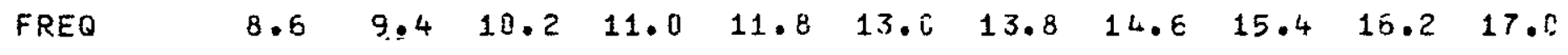

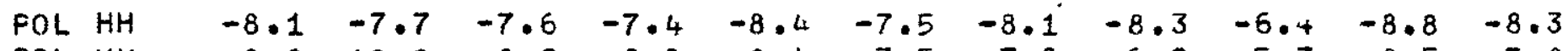

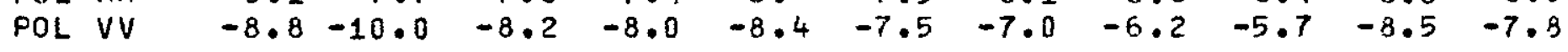

ANTENNA ANGLE 40

$\begin{array}{llllllllllll}\text { FREQ } & 8.6 & 9.4 & 10.2 & 11.0 & 11.8 & 13.6 & 13.8 & 14.6 & 15.4 & 15.2 & 1.7 .0\end{array}$

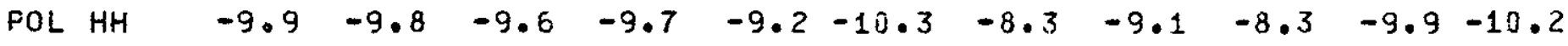

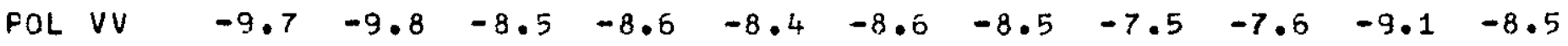

ANTENNA ANGLE 50

$\begin{array}{llllllllllll}\text { FREQ } & 8.6 & 9.4 & 10.2 & 11.0 & 11.8 & 13.6 & 13.8 & 14.6 & 15.4 & 16.2 & 17.0\end{array}$

FOL HH $-11.9-12.1-11.7-11.3-11.3-11.0-11.1 \quad-9.8 \quad-8.8-11.2-11.7$

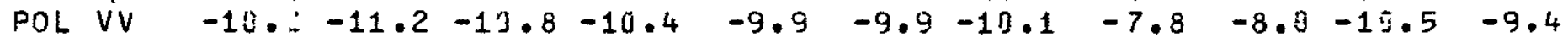

ANTENNA ANGLE 60

$\begin{array}{llllllllllll}\text { FREQ } & 8.6 & 9.4 & 10.2 & 11.0 & 11.8 & 13.0 & 13.8 & 14.6 & 15.4 & 16.2 & 17.8\end{array}$

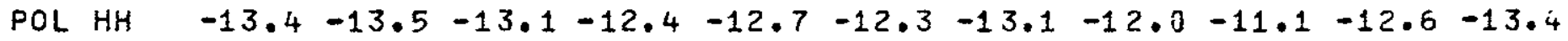

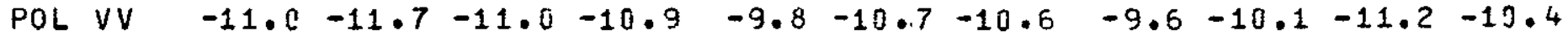

\section{ANTENNA ANGLE 78}

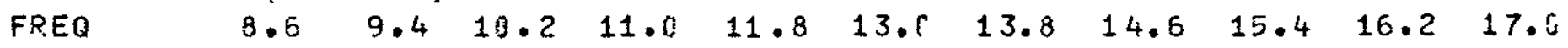

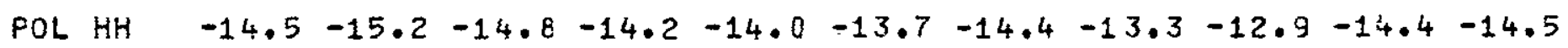
POL VV $-12.6-12.9-12.3-12.2-11.5-11.5-11.4-1.6-11.1-12.6-11.7$ 
Average Sigmao

ANTENNA ANGLE 0
Alfalfa, June 14, 1974

ORIGINAL PAGE IS

OF POOR QUALITY

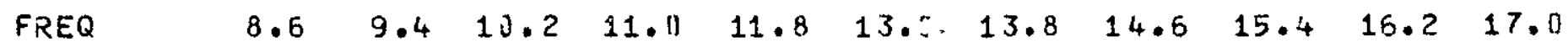

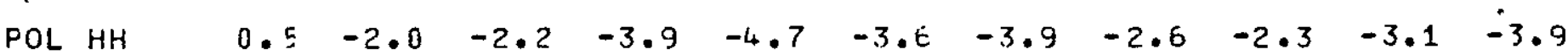

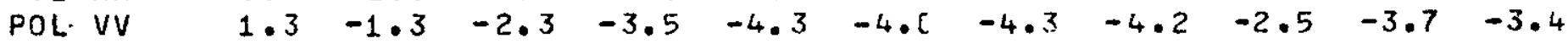

ANTENNA ANGLE 10

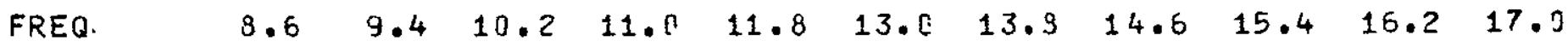

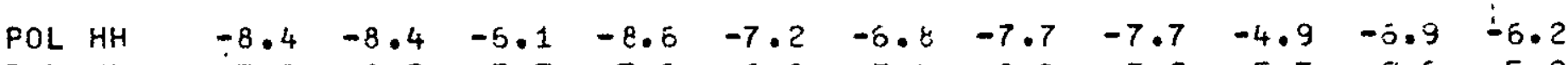

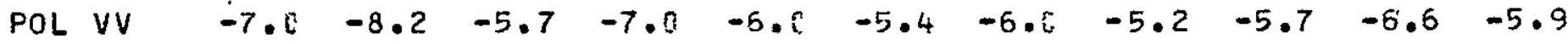

ANTENNA A NGLE 20

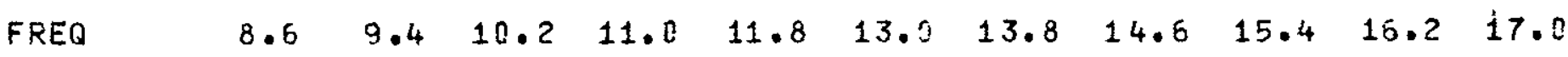

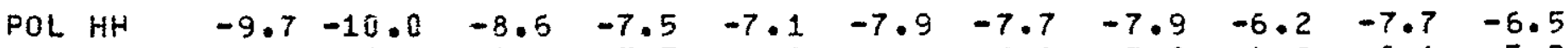

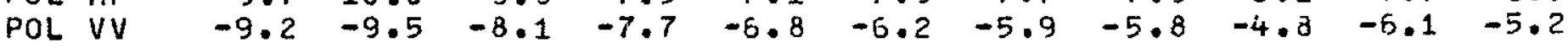

ANTENNA ANGLE 30

$\begin{array}{llllllllllll}\text { FREQ } & -8.6 & 9.4 & 1.2 .2 & 11.0 & 11.8 & 13.0 & 13.8 & 14.6 & 15.4 & 15.2 & 17.0\end{array}$

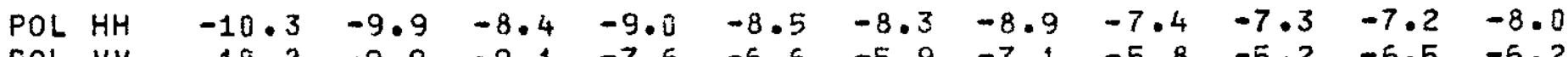

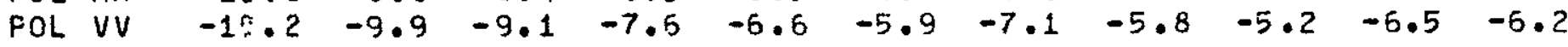

ANTENNA ANGLE 40

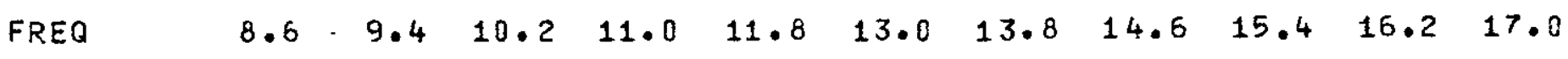

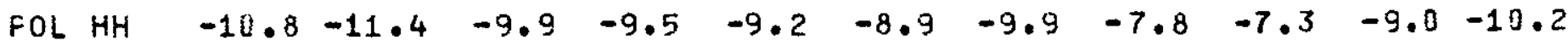

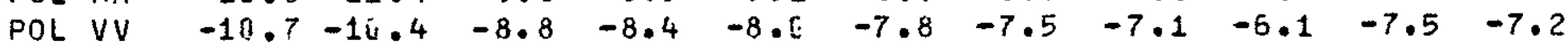

ANTENNA ANGLE 50

\begin{tabular}{|c|c|c|c|c|c|c|c|c|c|c|c|}
\hline FREQ & 8.6 & 9.4 & $10 \cdot 2$ & 11.0 & 11.8 & $13 \cdot 0$ & 13.8 & 14.6 & $15 \cdot 4$ & 16.2 & 17.0 \\
\hline $\begin{array}{ll}20 L & H H \\
2 O L & V V\end{array}$ & $\begin{array}{l}-12 \cdot 1 \\
-11.4\end{array}$ & -11.9 & $\begin{array}{l}-10 \cdot 8 \\
-10 \cdot 4\end{array}$ & $\begin{array}{l}-11 \cdot 1 \\
-10.5\end{array}$ & $\begin{array}{l}-9.9 \\
-8.5\end{array}$ & $\begin{array}{r}-1.3 .7 \\
-8.2\end{array}$ & $\begin{array}{r}-12.0 \\
-8.4\end{array}$ & $\begin{array}{r}-18.7 \\
-7.3\end{array}$ & $\begin{array}{l}-8.5 \\
-7.9\end{array}$ & $\begin{array}{r}-13.7 \\
-9.2\end{array}$ & $\begin{array}{r}-11.8 \\
-8.3\end{array}$ \\
\hline
\end{tabular}

ANTENNA ANGLE 6.0

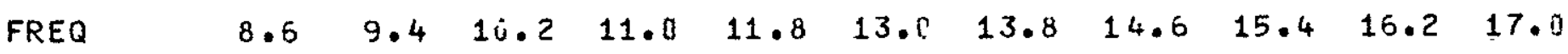

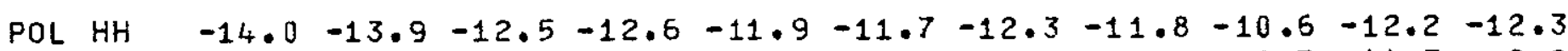

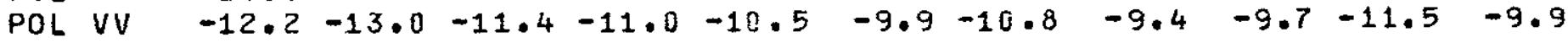

ANTENNA ANGLE 70

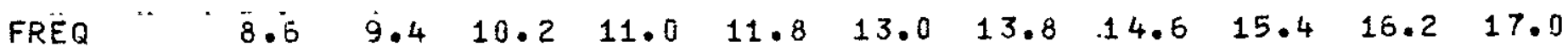
FOL HH $\quad-16.2-16.2-15.1-14.2-13.9-13.3-14.8-13.5-13.2-14.3-14.4$ POL VV $-13.3-13.8-12.4-12.3-11.8-11.4-12.0-10.9-11.3-12.6-11.2$ 
ANTENNA ANGLE 0

$\begin{array}{llllllllllll}\text { FREQ } & 8.6 & 9.4 & 10.2 & 11.0 & 11.8 & 13.0 & 13.8 & 14.6 & 15.4 & 16.2 & 17.0\end{array}$

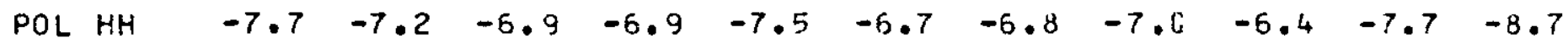

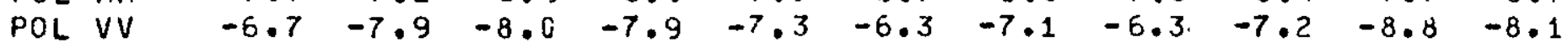

ANTENNA ANGLE 10

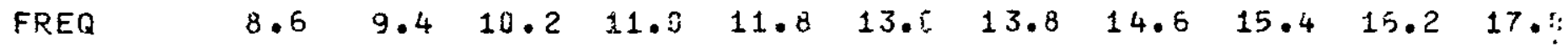

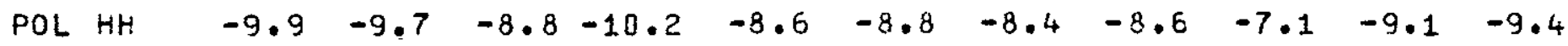

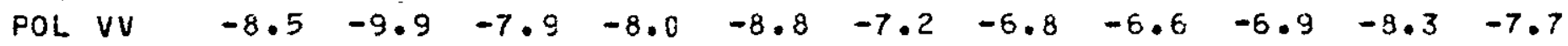

ANTENNA ANGLE 20

$\begin{array}{llllllllllll}\text { FREQ } & 8.6 & 9.4 & 10.2 & 11.0 & 11.8 & 13.6 & 13.8 & 14.6 & 15.4 & 16.2 & 17.0\end{array}$

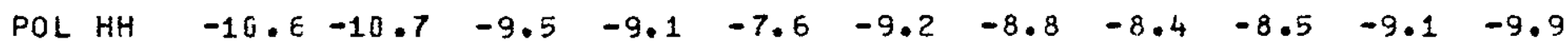

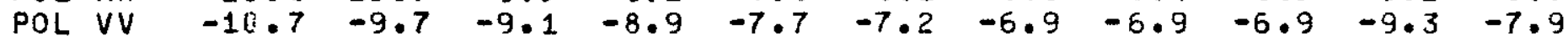

ANTENNA ANGLE 30

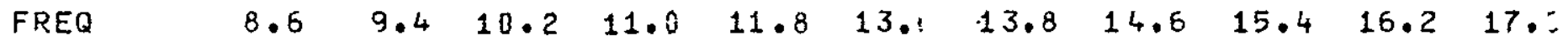

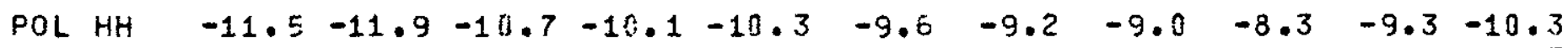

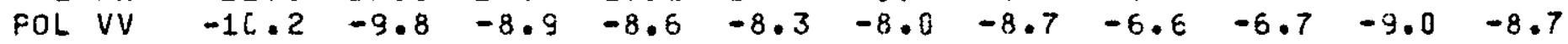
ANTENNA ANGLE 40

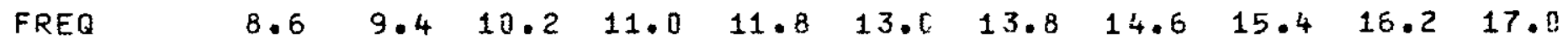

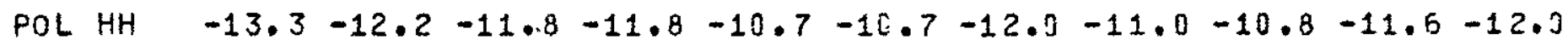

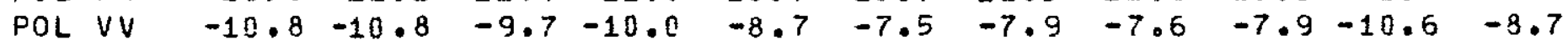

ANTENNA ANGLE 50

$\begin{array}{llllllllllll}\text { FREQ } & 8.6 & 9.4 & 10.2 & 11.0 & 11.8 & 13.0 & 13.8 & 14.6 & 15.4 & 15.2 & 17.0\end{array}$

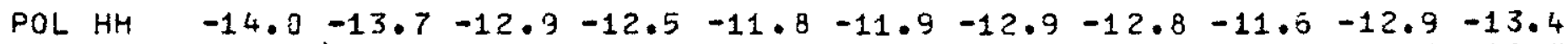

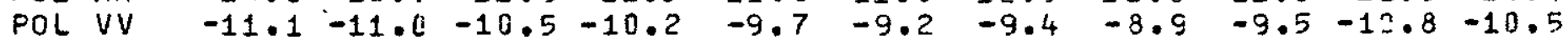

ANTENNA ANGLE 60

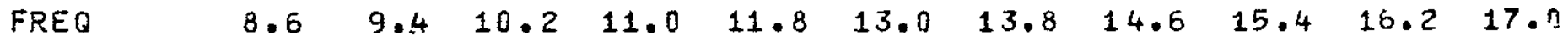

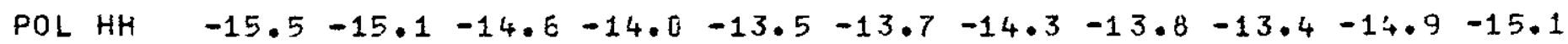

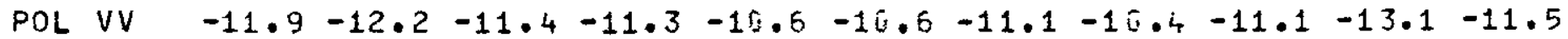

ANTENNA ANGLE 70

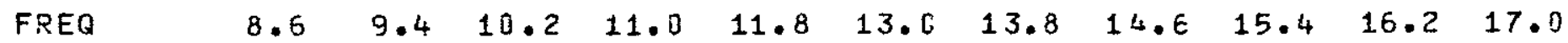

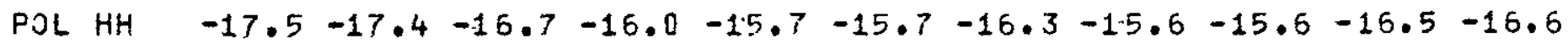

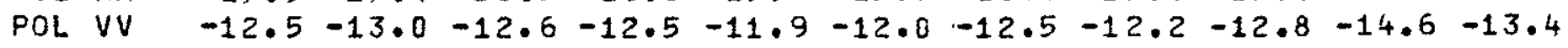


Average Sigmao

ANTENNA ANGLE O

FREG

$8.6 \quad 9.4 \quad 10.2$

11.0

$\begin{array}{ll}-9.7 & -9.0\end{array}$

POL HH
POL VV

$\therefore$ Alfalfa, June 28, 1974

ORIGLNAI PAGE IS
OF POOR QUALITY

ANTENNA ANGLE 10

FREQ

$$
8.6 \quad 9.4 \quad 10.2 \quad 11.6
$$

$11 \cdot 8$

13.0

13.8

14.6

$15.4 \quad 16.2 \quad 17.0$

$\begin{array}{lll}-8.6 & -8.6 & -7.6 \\ -7.6 & -8.1 & -6.8\end{array}$

$-E .2-8.8$

$-6.2-6.7$

$-8.3$

$-4 \cdot 7$

$\begin{array}{lll}-7.7 \cdot & -7.5 & -7.7\end{array}$

$\begin{array}{lll}-7.7 & -7.6 & -7.7\end{array}$

$14.6 \quad 15.4 \quad 15.2 \quad 17.0$

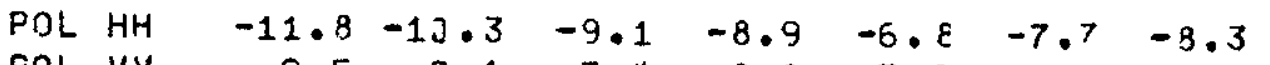

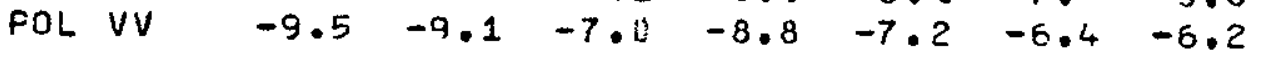

ANTENNA ANGLE 20

FREQ

$8.6 \quad 9.4 \quad 10.2$

$11 \cdot 0$

$11 \cdot 8$

13.0

13.814 .6

15.4

15.217 .0

FOL HH

POL VV.

$-10.8-11.6$

$-9.8$

$-8.9$

$-8 \cdot 7$

$-10 \cdot 8-9.6$

$-7.8$

$-8.6$

$-7 \cdot 6$

$-7 \cdot 5$

$-9.2-8.3$

$\begin{array}{lll}-6.6 & -8.9 & -9.2\end{array}$

ANTENNA ANGLE 30

FREQ

$$
8.69 .4
$$

$10.2 \quad 11.0$

11.8

13.0 $13.8 \quad 14.6$

$15.4 \quad 16.2 \cdot 17 \cdot 0$

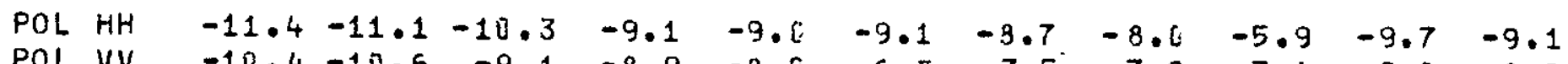

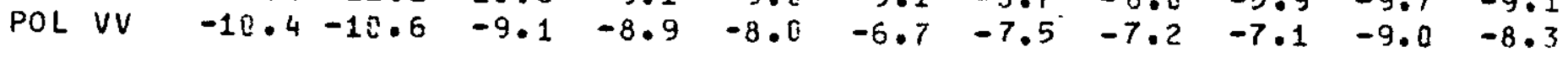

ANTENNA ANGLE 40

$\begin{array}{llllllllllll}\text { FREQ } & 8.6 & 9.4 & 13.2 & 11.0 & 11.8 & 13.6 & 13.8 & 14.6 & 15.4 & 15.2 & 17.7\end{array}$ POL HH $\quad-12.9-12.4-11.5-11.1-10.3-10.4-10.4-10.0-10.3-11.5-12.1$

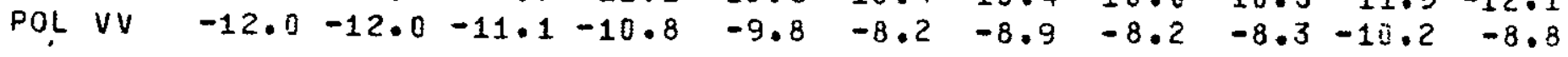

ANTENNA RNGLE 50

$\begin{array}{llllllllllll}\text { FREQ } & 8.5 & 9.4 & 10.2 & 11.0 & 11.8 & 13.6 & 13.8 & 14.6 & 15.4 & 16.2 & 17.0\end{array}$

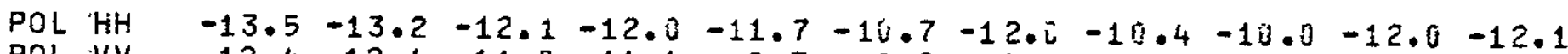

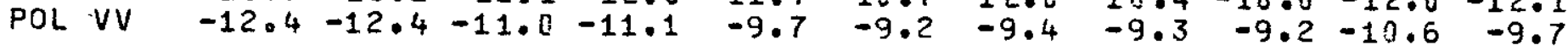

ANTENNA ANGLE 60

$\begin{array}{llllllllllll}\text { FREQ } & 8.6 & 9.4 & 10.2 & 11.0 & 11.8 & 13.0 & 13.8 & 14.6 & 15.4 & 16.2 & 17.3\end{array}$

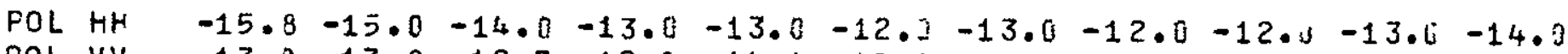
POL VV $-13.8-13.8-12.7-12.6-11.1-10.9-10.6-10.2-11.2-12.0-10.7$

\section{ANTENNA ANGLE 70}

FREQ 
Average Sigmao Alfalfa, July 5, 1974

ANTENNA ANGLE 0

FREQ

8.6

10.2

$11 \cdot 8$

13.0

13.8

14.6

ORIGINAL PAGE
OF POOR QUAE IS

FOL' $\mathrm{HH}$

POL VV

\begin{abstract}
$-5.8 \quad-7.1$
\end{abstract}
$-5.6 \quad-7.2$

$-5.2-4.3$

$-4 \cdot 5$

$-5 \cdot 6$

$-6 \cdot 7$

$-5.2$

15.4

$16.217 . ?$

ANTENNA ANGLE 10

FREQ

$8.6 \quad 9.4$

10.211 .0

11.8

13.0

13.8

14.6

$15.4 \quad 15.2 \quad 17.0$

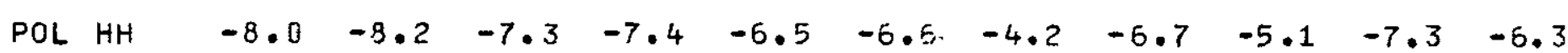

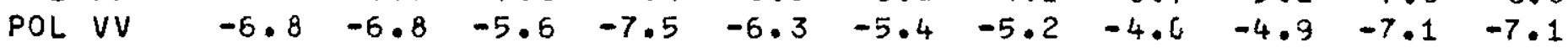

ANTENNA ANGLE 20

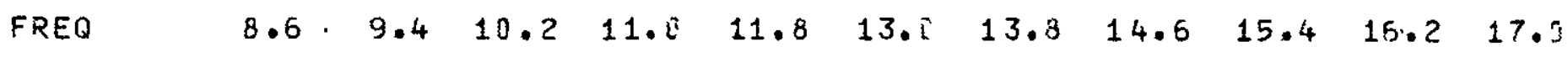

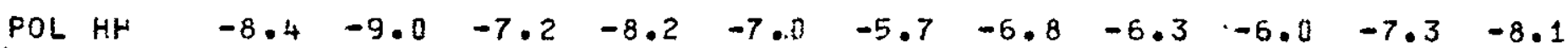

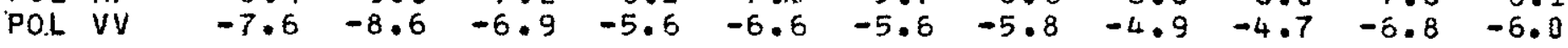

ANTENNA ANGLE 30

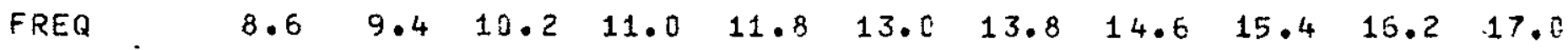

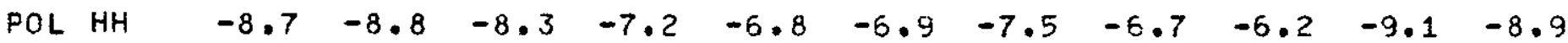

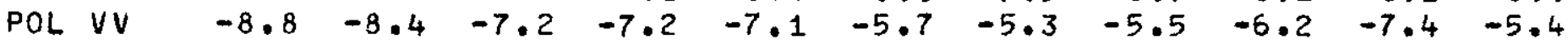

ANTENNA ANGLE 40

$\begin{array}{llllllllllll}\text { FREQ } & 8.6 & 9.4 & 10.2 & 11.0 & 11.8 & 13 . \hat{2} & 13.8 & 14.6 & 15.4 & 16.2 & 17.0\end{array}$

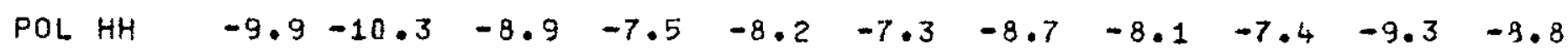

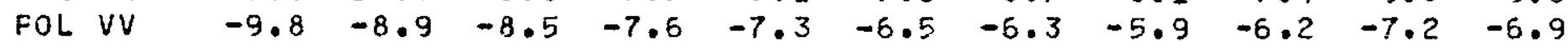

ANTENNA ANGLE 50

$\begin{array}{llllllllllll}\text { FREQ } & 8.6 & 9.4 & 10.2 & 11.8 & 11.8 & 13.0 & 13.8 & 14.6 & 15.4 & 16.2 & 17.0\end{array}$

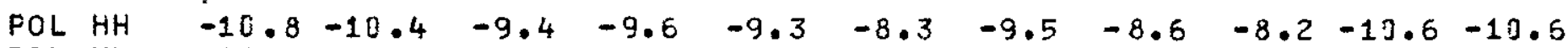

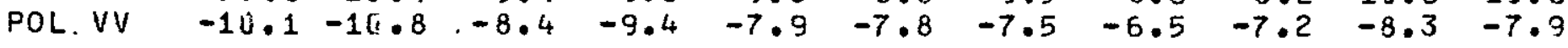

ANTENNA ANGLE 60

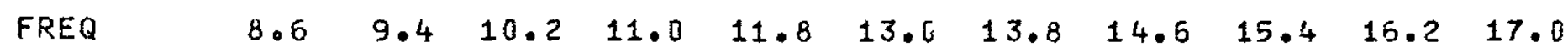

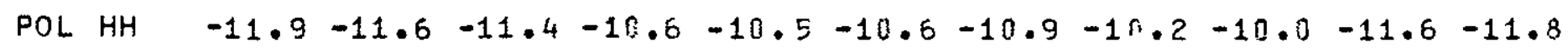

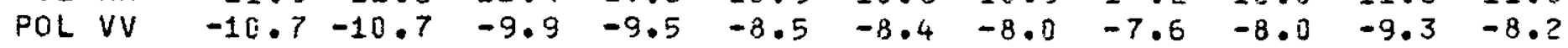

ANTENNA ANGLE 70

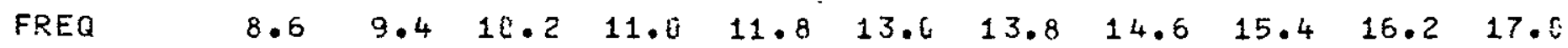
POL HH $\quad-14.2-13.8-13.1-12.9-12.4 .-11.9-13.3-11.9-11.4-13.2-13.3$

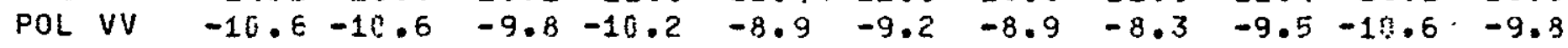


Average Sigmao Alfalfa, July 10, 1974

ANTENNA ANELE 0

FREQ

8.69 .4

10.211 .011 .8

13. C 13.8

14.6

$15 \cdot 4$

15.217 .0

FOL $\mathrm{HH}$

2.20 .7

$2.1 \quad 1.5 \quad 3.4$

$2.7 \quad 1.5$

$3 \cdot 1$

4.6

2. $1 \quad 1.1$

POL VV

3.20 .5

1.5 i. 1

2.9

$0.4-0.5$

1.8

2.5

1.21 .7

ANTENNA ANGLE 10

$\begin{array}{llllllllllll}\text { FREQ } & 8.6 & 9.4 & 10.2 & 11.0 & 11.8 & 13.0 & 13.8 & 14.6 & 15.4 & 15.2 & 17.0 \\ \text { FOL HH } & -8.3 & -6.9 & -7.0 & -5.7 & -7.2 & -9.1 & -7.8 & -6.8 & -6.9 & -6.6 & -7.2 \\ \text { POL VV } & -7.2 & -5.9 & -6.7 & -7.4 & -7.6 & -5.1 & -5.5 & -3.7 & -6.6 & -5.2 & -5.3\end{array}$

ANTENNA ANGLE 20

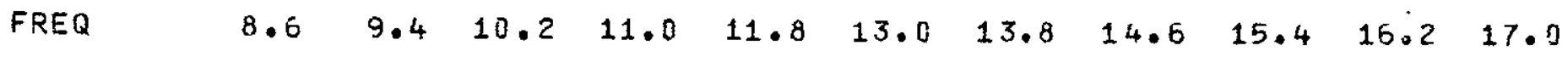

$\begin{array}{llllllllllll}\text { POL HH } & -9.3 & -11.3 & -9.1 & -8.6 & -8.8 & -10.7 & -8.8 & -8.6 & -5.7 & -9.8 & -9.7\end{array}$

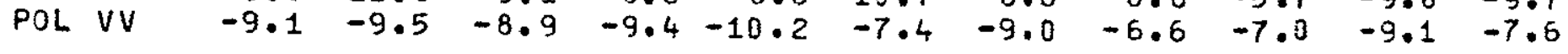

ANTENNA ANGLE 30

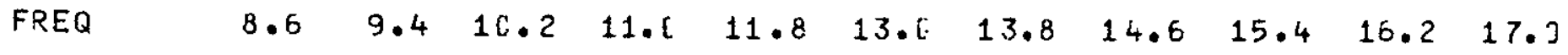

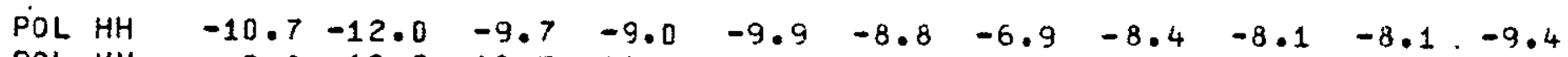

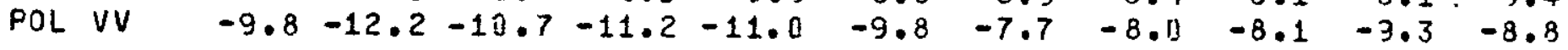

ANTENNA ANGLE 40

$\begin{array}{llllllllllll}\text { FREQ } & 8.6 & 9.4 & 10.2 & 11.0 & 11.8 & 13.6 & 13.8 & 14.6 & 15.4 & 16.2 & 17.0\end{array}$

FOL HH $\quad-13.2-11.7-11.3-11.1-11.5-11.0-10.4-10.7 \quad-9.8-11.3-11.4$

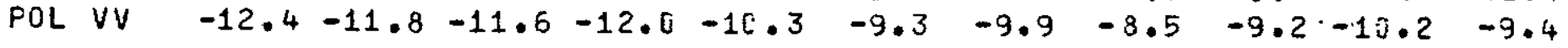

ANTENNA ANGLE 50

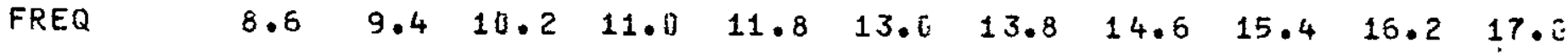

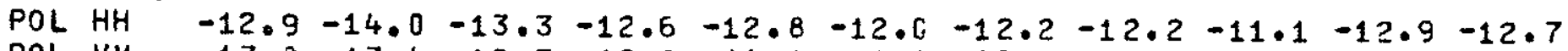

POL VV $-13.0-13.4-12.3-12.2-11.8-11.1-10.8 \quad-9.4-10.5-12.9-10.1$

ANTENNA ANGLE 60

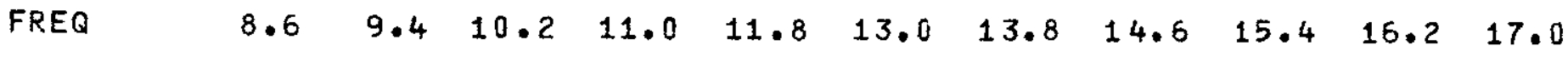
POL HH $\quad-13.0-14.6-14.4 \quad-12.9-13.9-12.2-13.2-12.3-12.0-13.1-13.1$ POL VV $-13.3-13.5-13.2-12.5-12.0-10.8-11.6-10.5-11.3-12.2-10.2$

ANTENNA ANGLE 70

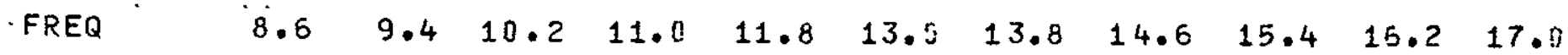

POL HH $\quad-15.3-15.9-15.1-14.4-13.9-13.7-14.9-13.4-13.5-14.0-13.6$ POL VV $-14.1-14.3-13.3-12.8-12.3-11.5-11.8 .-10.9-11.5-12.7-11.3$ 
ANTENNA ANGLE 0

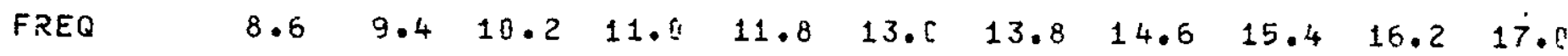

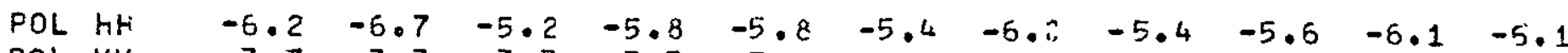

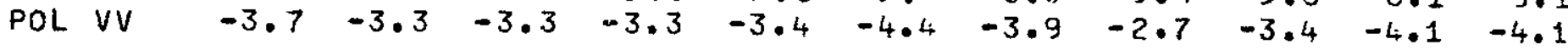

ANTENNA ANGLE 10

$\begin{array}{llllllllllll}\text { FREQ } & 8.6 & 9.4 & 10.2 & 11.0 & 11.8 & 13.6 & 13.8 & 14.6 & 15.4 & 16.2 & 17.0\end{array}$

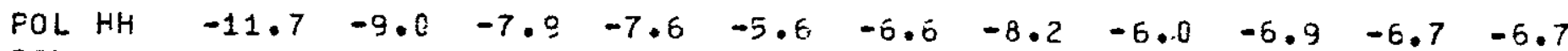

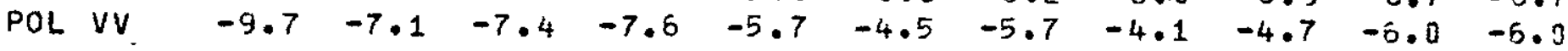

ANTENNA ANGLE. 20

$\begin{array}{llllllllllll}\text { FREQ } & 8.5 & 9.4 & 19.2 & 11.0 & 11.8 & 13.0 & 13.8 & 14.6 & 15.4 & 16.2 & 17.0\end{array}$

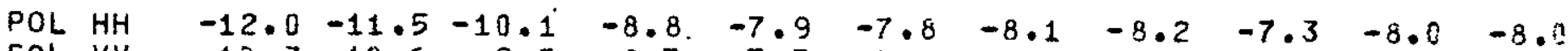

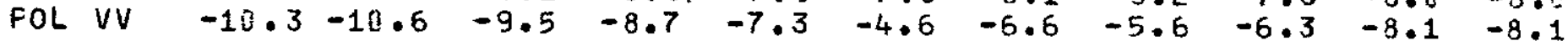

ANTENNA ANGLE 30

$\begin{array}{llllllllllll}\text { FREQ } & 8.6 & 9.4 & 10.2 & 11.0 & 11.8 & 13.0 & 13.8 & 14.6 & 15.4 & 15.2 & 17.3\end{array}$

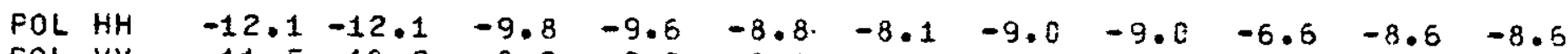

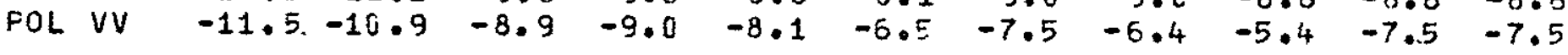

ANTENNA ANGLE 40

$\begin{array}{llllllllllll}\text { FREQ } & 8.6 & 9.4 & 10.2 & 11.0 & 11.8 & 13.0 & 13.8 & 14.6 & 15.4 & 16.2 & 17.0\end{array}$

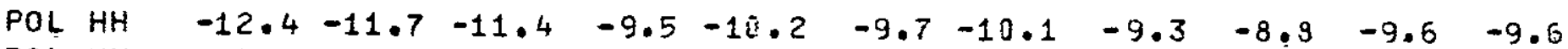

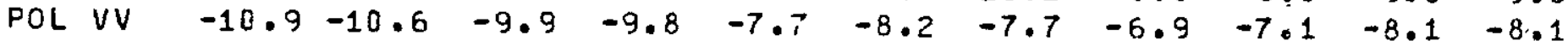

ANTENNA ANGLE 50

FREQ $\quad 8.6 \quad 9.4 \quad 14.2 \quad 11.0 \quad 11.8 \quad 13.0 \quad 13.8 \quad 14.6 \quad 15.4 \quad 16.2 \quad 17.0$

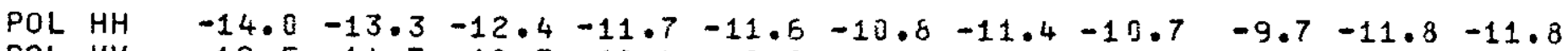
FOL VV $-12.5-11.7-10.3-10.4 \quad-9.2 \quad-8.9 \quad-8.7 \quad-8.3 .-8.8-13.4-13.4$ ANTENNA ANGLE 60

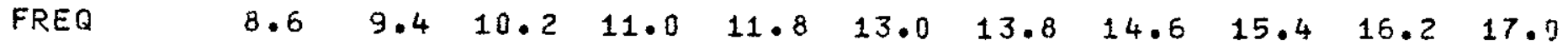

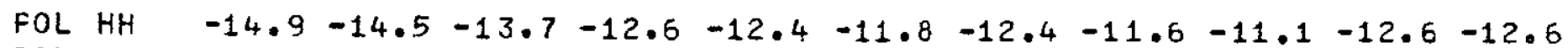

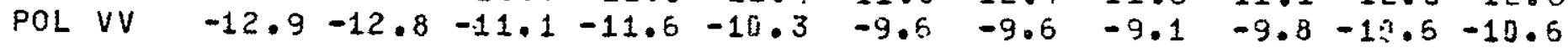

ANTENNA ANGLE 70

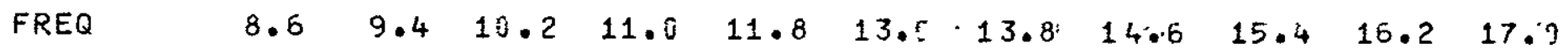

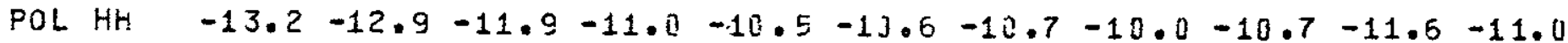

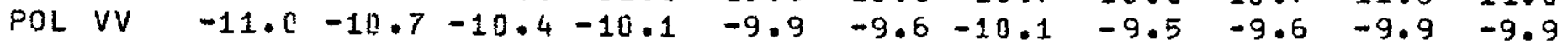




\section{Average Sigmao Alfalfa, July 23,1974}

ANTENNA ANGLE O

$\begin{array}{lrrrrrrrrrrr}\text { FREQ } & 8.6 & 9.4 & 10.2 & 11.1 & 11.8 & 13.1 & 13.8 & 14.6 & 15.4 & 16.2 & 17.0 \\ \text { FOL. HH } & -7.2 & -8.9 & -8.4 & -8.2 & -7.3 & -6.1 & -7.3 & -7.7 & -5.7 & -7.5 & -6.5 \\ \text { POL VV } & -5.2 & -7.1 & -6.3 & -7.2 & -6.1 & -7.1 & -5.7 & -5.5 & -4.6 & -6.9 & -5.1\end{array}$

ANTENNA ANGLE 10

$\begin{array}{llllllllllll}\text { FRE } & 8.6 & 9.4 & 10.2 & 11.0 & 11.8 & 13.6 & 13.8 & 14.6 & 15.4 & 15.2 & 17.2\end{array}$ $\begin{array}{lllllllllllll}\text { POL HH } & -9.7 & -9.7 & -7.7 & -7.4 & -7.2 & -7.1 & -5.8 & -5.9 & -4.6 & -6.4 & -7.0\end{array}$

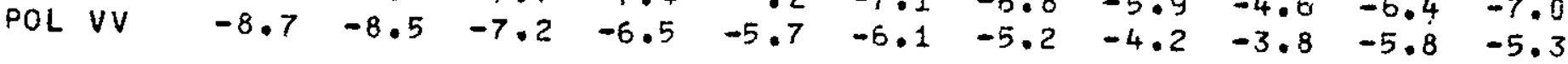

ANTENNA ANGLE 20

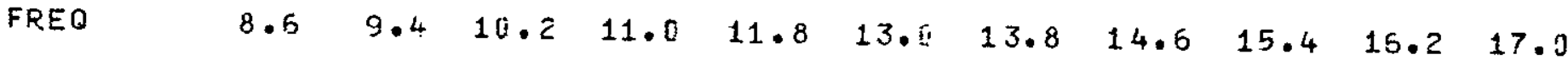
$\begin{array}{llllllllllll}\text { POL HH } & -10.7 & -10.4 & -9.5 & -8.3 & -8.6 & -8.1 & -6.7 & -6.2 & -4.8 & -7.9 & -7.5\end{array}$ ANTENNA ANGLE 30

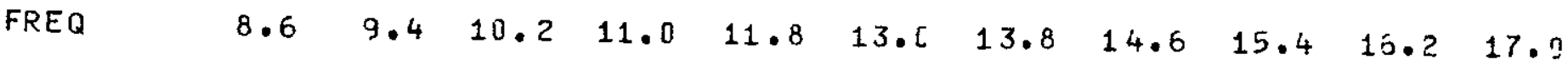
$\begin{array}{llllllllllll}\text { POL HH } & -11.1 & -10.5 & -10.0 & -9.1 & -8.2 & -9.5 & -8.5 & -8.5 & -7.3 & -8.3 & -8.9\end{array}$ ANTENNA ANGLE 40

$\begin{array}{llllllllllll}\text { F.REQ } & 8.6 & 9.4 & 10.2 & 11 . \mathrm{C} & 11.8 & 13.0 & 13.8 & 14.6 & 15.4 & 16.2 & 17.0\end{array}$

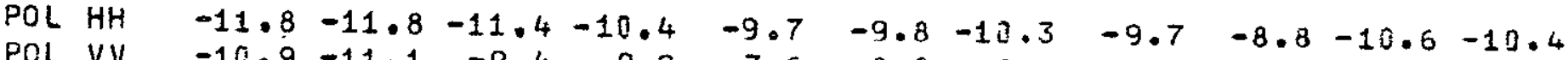

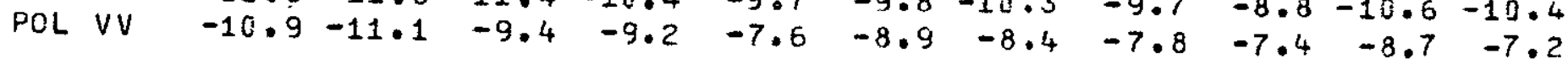
ANTENNA ANGLE 50

$\begin{array}{llllllllllll}\text { FREQ } & 8.6 & 9.4 & 10.2 & 11.0 & 11.8 & 13.6 & 13.8 & 14.6 & 15.4 & 16.2 & 17.5\end{array}$ POL HH $\quad-13.5-12.8-12.2-11.9-11.9-12 . \mathrm{C}-12.1-11.4-10.0-11.7-11.3$

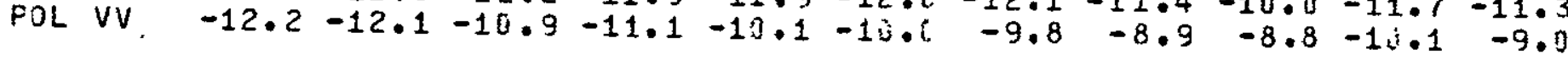

ANTENNA ANGLE 60

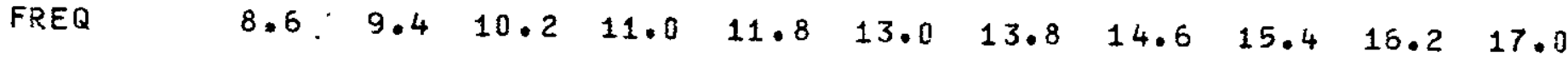
POL HH $-15.3-14.4-13.6-13.5-13.8-13.3-13.6-12.8-12.5-13.5-13.4$ POL VV $-12.4-12.2-11.5-11.9-11.1-11.3-10.3 \quad-9.8 \quad-9.8-11.5-10.5$ ANTENNA ANGLE 70

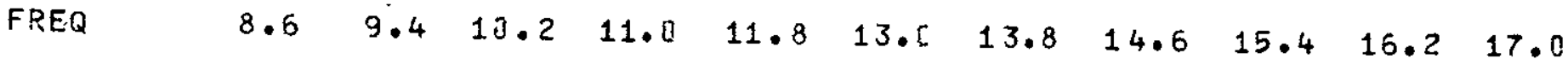

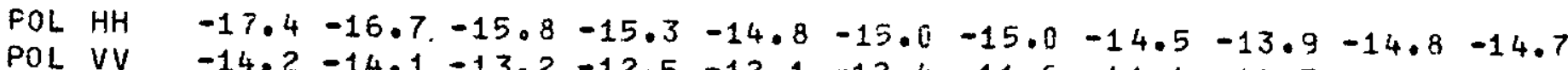
POL VV $-14.2-14.1-13.2-12.5-12.1-12.4-11.5-11.4-11.7-13.2-11.5$ 


\section{Average Sigmao Alfalfa, August 13, 1974}

ANTENNA ANGLE 0

$\begin{array}{llllllllllll}\text { FREQ } & 8.6 & 9.4 & 10.2 & 11.0 & 11.8 & 13.5 & 13.8 & 14.6 & 15.4 & 15.2 & 17.0\end{array}$

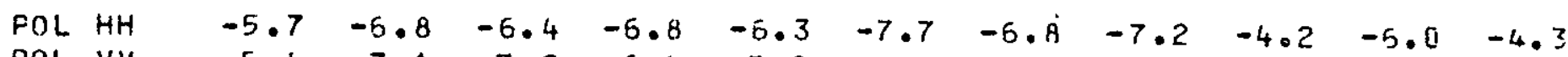

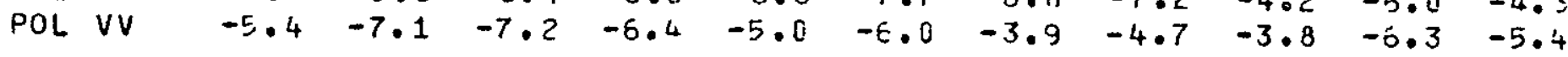

ANTENNA ANGLE 10

$\begin{array}{llllllllllll}\text { FREQ } & 8.6 & 9.4 & 16.2 & 11.0 & 11.8 & 13.5 & 13.8 & 14.6 & 15.4 & 15.2 & 17.3\end{array}$

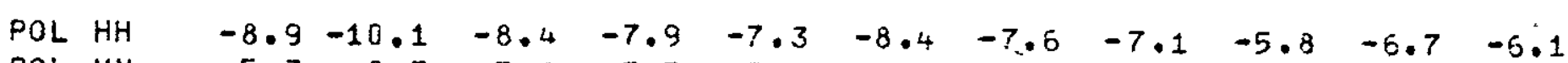

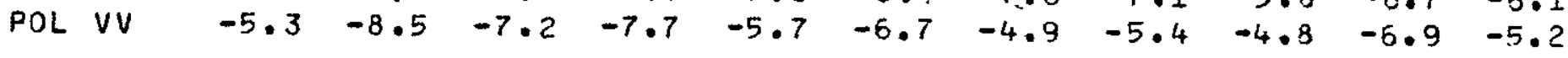

ANTENNA ANGLE 20

$\begin{array}{llllllllllll}\text { FREQ } & 8.6 & 9.4 & 10.2 & 11.0 & 11.8 & 13.5 & 13.8 & 14.6 & 15.4 & 16.2 & 17.0\end{array}$

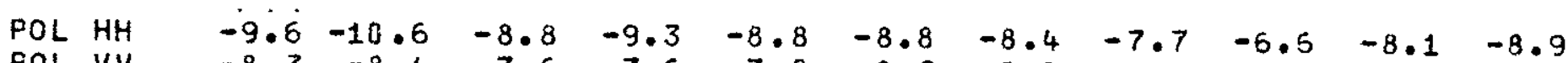

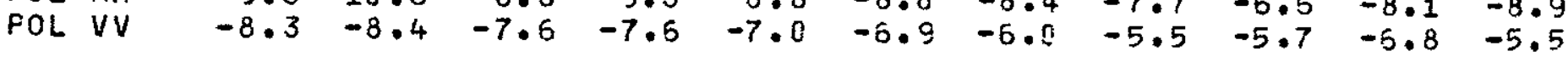

ANTENNA ANGLE 30

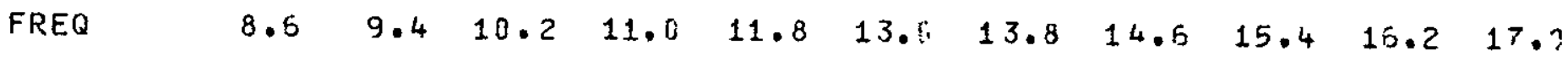
$\begin{array}{llllllllllll}\text { POL HH } & -10.7 & -10.2 & -10.0 & -9.5 & -9.1 & -9.7 & -9.4 & -8.2 & -7.2 & -8.0 & -8.2\end{array}$ $\begin{array}{llllllllllll}\text { POL VV } & -8.1 & -8.7 & -8.6 & -7.8 & -8.2 & -7.9 & -7.1 & -6.9 & -5.7 & -7.2 & -6.6\end{array}$ ANTENNA ANGLE 40

$\begin{array}{llllllllllll}\text { FREQ } & 8.6 & 9.4 & 10.2 & 11.0 & 11.8 & 13.0 & 13.8 & 14.6 & 15.4 & 16.2 & 17.0\end{array}$

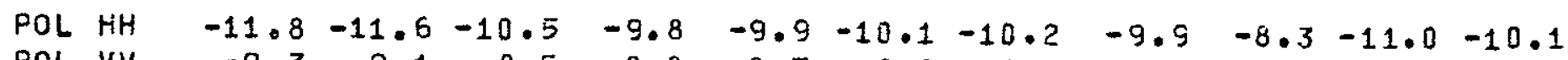

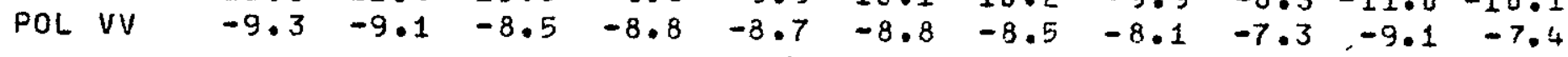
ANTENNA ANELE 50

$\begin{array}{llllllllllll}\text { FREQ } & 8.5 & 9.4 & 10.2 & 11.0 & 11.8 & 13.0 & 13.8 & 14.6 & 15.4 & 16.2 & 17.0\end{array}$ POL HH $-12.6-12.7-11.9-11.5-11.0-12.2-11.6-11.1-14.3-12.0-12 . ?$ POL VV -12.6 $-12.6-11.9-10.9-10.6-10.7-10.2-8.8-9-3-10.4-8.7$ ANTENNA ANGLE 60

$\begin{array}{llllllllllllll}\text { FREQ } & 8.6 & 9.4^{\circ} & 10.2 & 11.8 \cdot & 11.8 & 13.6 & 13.8 & 14.6 & 15.4 & 16.2 & 17.3\end{array}$

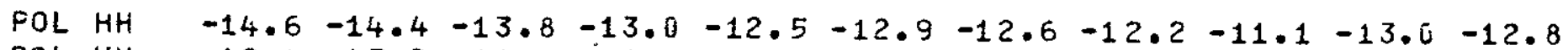

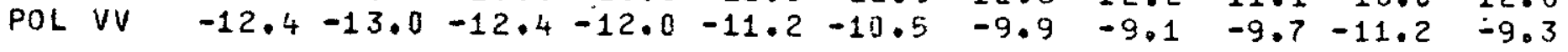
ANTENNA ANGLE 70

$\begin{array}{llllllllllll}\text { FREQ } & 8.6 & 9.4 & 10.2 & 11.0 & 11.8 & 13.6 & 13.8 & 14.6 & 15.4 & 16.2 & 17.0\end{array}$ POL HH $-16.2-15.2-15.2-14.3-14.5-14.2-14.5-13.7-13.2-14.3-13.8$ POL VV $-12.8-13.3-12.6-12.0-11.6-11.6-10.7-10.5-10.6-12.0-10.1$ 


\section{CRINC LABORATORIES}

Chemical Engineering Low Temperature Laboratory

Remote Sensing Laboratory

Flight Research Laboratory

Chemical Engineering Heat Transfer Laboratory

Nuclear Engineering Laboratory

Environmental Health Engineering Laboratory

Information Processing Laboratory

Wafer Resources Institute

Technical Transfer Laboratory

Air Pollution Laboratory

Safellite Applications Laboratory 


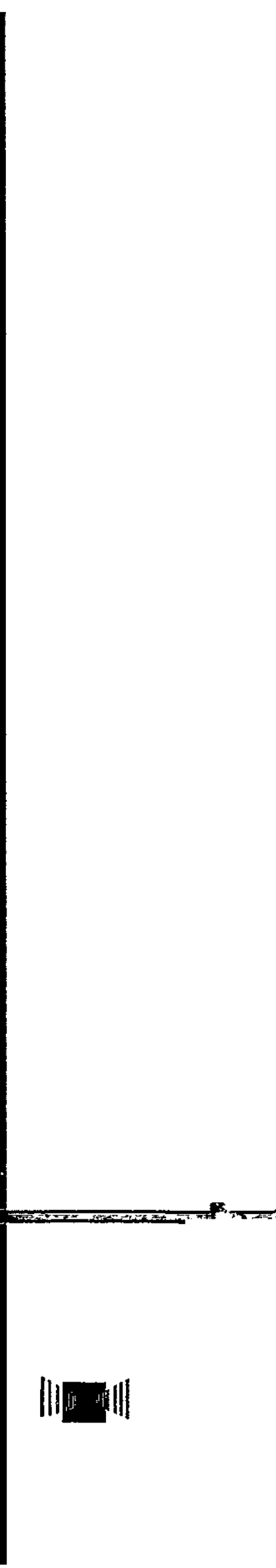

